NBER WORKING PAPER SERIES

DIVERGING TRENDS IN NATIONAL AND LOCAL CONCENTRATION

Esteban Rossi-Hansberg

Pierre-Daniel Sarte

Nicholas Trachter

Working Paper 25066

http://www.nber.org/papers/w25066

\author{
NATIONAL BUREAU OF ECONOMIC RESEARCH \\ 1050 Massachusetts Avenue \\ Cambridge, MA 02138 \\ September 2018
}

The views expressed herein are those of the authors and do not necessarily represent the views of the Federal Reserve Bank of Richmond, the Federal Reserve System, or the National Bureau of Economic Research. We thank Eric LaRose and Sara Ho for outstanding research assistance.

At least one co-author has disclosed a financial relationship of potential relevance for this research. Further information is available online at http://www.nber.org/papers/w25066.ack

NBER working papers are circulated for discussion and comment purposes. They have not been peer-reviewed or been subject to the review by the NBER Board of Directors that accompanies official NBER publications.

(C) 2018 by Esteban Rossi-Hansberg, Pierre-Daniel Sarte, and Nicholas Trachter. All rights reserved. Short sections of text, not to exceed two paragraphs, may be quoted without explicit permission provided that full credit, including $\odot$ notice, is given to the source. 
Diverging Trends in National and Local Concentration

Esteban Rossi-Hansberg, Pierre-Daniel Sarte, and Nicholas Trachter

NBER Working Paper No. 25066

September 2018

JEL No. E23,L11,R12

\begin{abstract}
$\underline{\text { ABSTRACT }}$
The views expressed herein are those of the authors and do not necessarily represent the views of the Federal Reserve Bank of Richmond or the Federal Reserve System. We thank Eric LaRose and Sara Ho for outstanding research assistance.Using U.S. NETS data, we present evidence that the positive trend observed in national product-market concentration between 1990 and 2014 becomes a negative trend when we focus on measures of local concentration. We document diverging trends for several geographic definitions of local markets. SIC 8 industries with diverging trends are pervasive across sectors. In these industries, top firms have contributed to the amplification of both trends. When a top firm opens a plant, local concentration declines and remains lower for at least 7 years. Our findings, therefore, reconcile the increasing national role of large firms with falling local concentration, and a likely more competitive local environment.
\end{abstract}

\author{
Esteban Rossi-Hansberg \\ Nicholas Trachter \\ Princeton University \\ Department of Economics \\ 289 Julis Romo Rabinowitz Building \\ Federal Reserve Bank of Richmond \\ 701 E Byrd Street \\ Richmond, VA 23219 \\ Princeton, NJ 08544-1021 \\ Nicholas.Trachter@rich.frb.org \\ and CEPR \\ and also NBER \\ erossi@princeton.edu \\ Pierre-Daniel Sarte \\ Research Department. \\ Federal Reserve Bank of Richmond \\ PO Box 27622 \\ Richmond, VA 23261 \\ pierre.sarte@rich.frb.org
}




\title{
Diverging Trends in National and Local Concentration*
}

\author{
Esteban Rossi-Hansberg \\ Princeton University
}

\author{
Pierre-Daniel Sarte \\ Federal Reserve Bank of Richmond
}

Nicholas Trachter

Federal Reserve Bank of Richmond

September 12, 2018

\begin{abstract}
Using U.S. NETS data, we present evidence that the positive trend observed in national product-market concentration between 1990 and 2014 becomes a negative trend when we focus on measures of local concentration. We document diverging trends for several geographic definitions of local markets. SIC 8 industries with diverging trends are pervasive across sectors. In these industries, top firms have contributed to the amplification of both trends. When a top firm opens a plant, local concentration declines and remains lower for at least 7 years. Our findings, therefore, reconcile the increasing national role of large firms with falling local concentration, and a likely more competitive local environment.
\end{abstract}

\section{Introduction}

Most product markets are local. The reason is simply that the transportation of goods and people is costly so firms set up production plants, distribution centers, and stores close to customers. In turn, individuals locate in areas where they can obtain the goods they desire. A coffee shop or restaurant in Manhattan does not compete with similar establishments in Seattle, and probably not even in Brooklyn. The wedge in prices created by the inconvenience and monetary cost of buying a product far away from the desired consumption point shields companies in different locations from direct competition. Of course the size of these costs, and therefore the geographic extent of the market, varies by product. Markets are also product-specific. Producers of a particular product are shielded from competition by producers of distinct but related goods and services to the degree that their consumption requires households to move away from their ideal variety.

Much has been written recently about the increase in national market concentration observed over the last two decades, and the role that large national firms have played in driving this trend. The evidence for the rise in

\footnotetext{
*Rossi-Hansberg: erossi@princeton.edu. Sarte: pdgs4frbr@gmail.com. Trachter: trachter@gmail.com The views expressed herein are those of the authors and do not necessarily represent the views of the Federal Reserve Bank of Richmond or the Federal Reserve System. We thank Eric LaRose and Sara Ho for outstanding research assistance.
} 
concentration is uncontroversial; the share of the largest firms and the Herfindahl-Hirschman Index, among other measures of concentration, have increased consistently in most sectors since 1990 11 A narrative has emerged whereby this increase in national concentration is perceived as the cause of lower product-market competition. This fall in competition is then viewed as the culprit of other apparent trends, such as rising markups and market power (De Loecker and Eeckhout, 2017), the increasing profits of large firms (Barkai, 2017), declining labor market dynamism and firm entry (Decker, Haltiwanger, Jarmin and Miranda, 2017), and a declining labor share (Autor, Dorn, Katz, Patterson, and Van Reenen, 2017). All of these trends, and in particular those related to concentration, markups, and profits, point to the notion that market power has been increasing. While the empirical robustness and validity of some of these trends has been contested in recent work, the rise in national market concentration remains as their main empirical foundation. ${ }^{2}$

In this short paper, we document four main facts regarding national and local product-market concentration in the U.S. economy between 1990 and 2014 $3^{3}$ We make use of the National Establishment Time Series (NETS) dataset which covers the universe of U.S. firms and their plants.4 The dataset includes sales and employment numbers for all plants at different levels of geographical and industrial disaggregation down to the SIC 8 product code.

Our first fact is that the observed positive trend in market concentration at the national level has been accompanied by a corresponding negative trend in average local market concentration. We measure concentration using the Herfindahl-Hirschman index (HHI), but our findings hold for a variety of statistics. We observe an increase in concentration at the national level overall across the vast majority of sectors and industries, but a fall in concentration when it is measured at the CBSA, County, or Zip code levels 5 The narrower the geographic definition, the faster the decline in local concentration. This is meaningful because the relevant definition of concentration from which to infer changes in competition is, in most sectors, local and not national.

The second fact shows that local concentration is falling across SIC 8 industries that together account for $77 \%$ of employment and $70 \%$ of sales. Furthermore, conditioning on industries where national concentration is rising, industries where local concentration has declined account for the majority of employment overall (70\% of employment and $65 \%$ of sales) across all major sectors. The presence of these diverging trends is always large but

\footnotetext{
${ }^{1} \mathrm{~A} 2016$ report by the Council of Economic Advisers, for instance, finds that the national revenue share of the top 50 firms has increased across most NAICS sectors between 1997 and 2012.The report can be found at https://obamawhitehouse.archives.gov/sites/default/files/page/files/20160414_cea_competition_issue_brief.pdf. Gutiérrez and Philippon (2017) show that this increase in U.S.-wide market concentration is not uniform across all sectors and has been most pronounced in non-manufacturing sectors. Barkai (2017), and Autor, Dorn, Katz, Patterson, and Van Reenen (2017), find that the national sales share of top firms has also been rising since 1997 and, in fact, helps explain the decline in the labor share over the same period.

${ }^{2}$ While rising market concentration at the national level is relatively undisputed, the evidence regarding markups is more mixed. De Loecker and Eeckhout (2017) show evidence of rising markups since the 1980s among publicly traded firms. Hall (2018) finds similarly increasing markups at the sectoral level using KLEMS productivity data. However, Traina (2018) points out that the evidence on markups depends crucially on the measurement of variable costs. When variable costs include marketing and management costs, as well as other indirect costs of production, markups have been relatively flat since the mid-1980s. Similarly, Karabarbounis and Neiman (2018) find generally flat markups over time when also accounting for selling, general, and administrative expenses. Anderson, Rebelo, and Wong (2018) focus on the retail sector and find stable markups since 1979 using scanner data on the price of transactions and measuring marginal costs as replacement costs at the store level. Edmond, Midrigan and Xu (2018) show that when weighted by costs rather than sales, as implied by the microfoundations they lay out, aggreate markups have increased only modestly.

${ }^{3}$ See Neumark, Zhang and Wall (2006), or Barnatchez, Crane and Decker (2017) for a thorough discussion of the advantages and disadvantages of this data source relative to U.S. Census data.

${ }^{4}$ Throughout the paper we interchangeably use the terms plant and establishment. We also treat firm and enterprise as synonymous.

${ }^{5}$ In the main text, we focus mostly on ZIP codes as our geographic definition of a local market. The appendix presents results with other geographic units.
} 
more pronounced in services, retail trade, and FIRE relative to wholesale trade and manufacturing. This ordering is natural given that transport costs are less relevant in the latter two sectors. Together, these first two facts underscore an unmistakable decline in local concentration on average that is pervasive across all sectors.

How does one reconcile a positive trend in national concentration with a negative trend in local concentration? Our third fact shows that among SIC 8 industries that exhibit this pattern, top firms have accelerated these trends. That is, excluding the top firm in each industry (in terms of national sales in their SIC 8 industry in 2014), the national increase in concentration becomes naturally less pronounced. Perhaps more surprisingly, the decline in local concentration also becomes less pronounced. Put another way, large firms have materially contributed to the observed decline in local concentration $\sqrt[6]{6}$ Among industries with diverging trends, large firms have become bigger but the associated geographic expansion of these firms, through the opening of more plants in new local markets, has lowered local concentration thus suggesting increased local competition. In the considerably smaller set of industries where we observe increases in both national and local concentration, top firms have also been responsible for both forms of concentration.

Our fourth fact establishes that among industries with falling local concentration, the opening of a plant by a top firm is associated with a decline in local concentration at the time of the opening, and that this lower level of concentration persists for at least the next 7 years. This observation provides further evidence that in those industries, large enterprises do not enter and dominate the local market but instead lower its concentration, either by competing with the previous local monopolist or by simply adding one more establishment that grabs a proportional market share from other local establishments. In any case, the notion that entry by large firms eliminates local producers to the point of increasing concentration is certainly not supported in the vast majority of industries where most of U.S. employment resides.

Consider the much-publicized case of Walmart. Most of Walmart's establishments are in the discount department stores industry, an industry with declining local concentration. Consistent with fact four, when Walmart opens a store, the HHI falls by 0.15 in the associated ZIP code. In contrast, computing the HHI without taking into account the opening Walmart establishment, concentration remains constant. One can also consider the effect of Walmart on the number of firms in a market. When Walmart enters, the total number of establishments in the ZIP code increases, though by less than one-to-one (about 3/4). In other words, Walmart generates some exit but the net result of opening a Walmart store is a greater number of competitors in the market for at least 7 years after entry 7 This case is paradigmatic, but there are many others across all major sectors. For example, the expansion of Cemex, the top firm by sales in 2014 in the ready-mixed concrete industry, led to a similar decline in local concentration and an expansion in the local number of establishments in the industry $8^{8}$

Our findings challenge the view that product-market concentration is increasing in the U.S. They do so not by

\footnotetext{
${ }^{6}$ This finding also holds when we exclude the top three firms in each industry instead of just the top firm.

${ }^{7} \mathrm{Jia}(2008)$ studies competition by Walmart and other discount retail stores. She proposes a structural model of this competition and argues that the profits of previously available retailers decrease when 'Walmart comes to town'. This is consistent with our view that Walmart lowers concentration by taking market share away from local competitors. Moreover, the exit of firms we observe is also consistent with those of Jia (2008) when measured at the county level. Holmes (2011) studies the expansion strategy of Walmart and, in particular, its geographic expansion strategy. Our findings are exactly consistent with this view of geographic expansion and provide related facts concerning its impact on local concentration. In contrast to these studies, our empirical findings extend to most U.S. industries in addition to the discount retail sector.

${ }^{8}$ This industry was singled out in Syverson (2008) as an example of an industry with a local market. We present the results of this case in the appendix.
} 
challenging the evidence that national concentration has increased - we actually provide additional evidence to that effect across many industries - but by observing that this national trend does not imply a positive local trend in concentration. In fact, we show that it implies the opposite in most industries, a declining trend in concentration. Ultimately, concentration matters because it can lead to less competition. Hence, measures of concentration have to be aligned with product markets as well as their geographic and industrial scope. In particular, for the majority industries, concentration is likely more relevant to firm pricing and other strategic behavior at a more local level. Our findings are also consistent with the mixed evidence found in recent literature regarding secular changes in markups across individual industries. If local competition matters, we should not see increases in markups or profits in the markets where local competition is increasing. The measurement of markups in local markets associated with particular industries depends on important assumptions and requires very detailed data. The NETS data does not allow us to calculate these local statistics, but there exists evidence of flat markups over time in specific industries with declining concentration (Anderson, Rebelo, and Wong, 2018), and in the aggregate (Traina, 2018).

The facts we document are directly relevant to the design of antitrust policy and other policies that can prevent successful firms from growing at the national level. We document heterogenous trends across industries and, in some industries, concentration is clearly rising both at the national and local level. However, our results should provide pause for policy-makers that worry about increases in market power. On the whole, and in most industries, large firms are lowering local concentration and, therefore, most likely increasing product market competition. Carl Shapiro, a former Deputy Assistant Attorney General at the Antitrust Division of the Department of Justice, and member of the President's Council of Economic Advisers under Barack Obama, makes a similar argument. Discussing evidence on the positive trend in national market concentration, he observes: "So, while these data do reflect the fact that large, national firms have captured an increasing share of overall revenue during the past 20 years in many of these 893 'industries,' they do not, in and of themselves, indicate that the relevant local markets have become more concentrated." In this paper, we provide the empirical evidence supporting the notion that, in the face of rising national concentration, local markets have indeed become on average significantly less concentrated 9

The rest of the paper is organized as follows. Section 2 describes our data, the way we use it, as well as our benchmark measure of national and local concentration. Section 3 presents our main four facts and describes their implications. Section 4 concludes. The appendix presents a large variety of additional calculations using other concentration statistics, and provides additional detail regarding the data and the results in the main text.

\section{Data and Concentration Statistics}

Our analysis uses data from the National Establishment Time Series (NETS), which is provided by Walls \& Associates, and comprises annual observations on specific lines of business at unique locations over the period 1990-2014. In particular, NETS data allow us to observe sales and employment of between 7 and 15 million lines of business each year in our sample. Each line of business is assigned a data universal numbering system (DUNS) identifier that makes it possible to track its sales and employment over time at the SIC 8 level of Standard Industrial Classification (SIC) and at specific latitudes and longitudes. Industries can be mapped into broader SIC 2 classifications

\footnotetext{
${ }^{9}$ De Loecker and Eeckhout (2018) also argue that in order to measure concentration in a way that is meaningful as an indicator of market power, this measurement has to be carried out for specific goods and local markets using the universe of firms. This is exactly what we do in this paper using the NETS data.
} 
or divisions, and locations can be mapped into ZIP codes, counties, or Core-Based Statistical Areas (CBSAs). In addition, each line of business is also assigned a headquarters (HQ) number that gives the particular enterprise to which it reports. Thus, the NETS data encompass the universe of establishments operating in the U.S., and the enterprise to which each belongs, between 1990 and 2014.

To better illustrate the nature of the NETS data, consider the case of Walmart as an example of an enterprise. It is headquartered in Bentonville, AR, and in 2014, it is associated with approximately 4700 establishments across all 50 states. Each of these 4700 establishment is assigned its own 8-digit primary SIC code, with 3718 establishments operating mainly as discount department stores (SIC 53119901), 603 establishments operating mainly as warehouse club stores (SIC 53999906), 241 establishments operating primarily as grocery stores (SIC 54110000), and the remaining establishments scattered mostly across various retail classifications.

Because each establishment in the NETS data is assigned a unique DUNS identifier, it is possible to track when an establishment enters our sample (for those that enter after 1990) and, if applicable, when it exits. In addition, the DUNS identifier follows each establishment over time even if it is sold from one enterprise to another, or becomes included in a merger of enterprises, so that sales and employment of particular establishments may be tracked irrespective of corporate-level changes.

Approximately a quarter of enterprises in the NETS data have only one employee. This feature of the data is typically not accounted for by alternative government sources of local employment as estimated by the County Business Patterns (CBP) or the Quarterly Census of Employment and Wages (QCEW) ${ }^{10}$ Since these establishments nevertheless report positive sales, we include them in our benchmark analysis. In the supplement to this paper, we show that our results are robust to excluding enterprises with only one employee.

At the 2-digit SIC code, the data is classified in terms of 11 divisions, including Manufacturing, Services, Retail Trade, Wholesale Trade, and Finance, Insurance and Real Estate (FIRE), that together account for approximately 85 percent of sales and 80 percent of employment respectively in 2014. Because our analysis centers on the relationship between market concentration and the geographic expansion of enterprises, we exclude from our benchmark exercises industries that are intrinsically tied to specific locations because of weather or endowments of natural resources. These industries include Mining, Agriculture, Forestry, and Fishing, Construction, and Transportation and Public Utilities. We also exclude from our benchmark analysis any government establishment, including establishments belonging to enterprises whose headquarters are associated with a public administration SIC code, and establishments associated with education, non-profit endeavors, health care, and central banking 11

\subsection{Measuring Concentration}

Establishments in our dataset are indexed by industry, $i$, location, $\ell$, and year, $t$. Industries are defined by an SIC 8 code. Locations are defined by a latitude-longitude pair. We denote collections of industries into broader classifications (SIC 2 or divisions) by $d$. We denote collections of locations into broader geographies (ZIP codes,

\footnotetext{
${ }^{10}$ Many enterprises with one employee are non-employer enterprises, or in other words, have no paid employees. While employment at those enterprises is then at times the result of imputations, Barnatchez, Crane, and Decker (2017) show that taking out those imputations leaves measures of local employment that are generally highly correlated with those in the CBP across industries.

${ }^{11}$ We eliminate health-care from our analysis since changes in the organization of the sector driven by changes in its institutional framework (in particular Obamacare) have generated a number of changes that are specific to this context. The appendix shows that including the sector does not change our country-wide average implications.
} 
Counties, CBSAs, or the whole U.S.) by $g$. When defining locations at the CBSA level, counties that are not within CBSAs are not represented, which amounts to between 5 and 10 percent of establishments in any given year.

Let $S_{e, i, \ell, t}$ denote the nominal sales of enterprise $e$ in industry $i$ at location $\ell$ in year $t$, and $S_{e, i, g, t}=\sum_{\ell \in g} S_{e, i, \ell, t}$ its sales in the broader geography $g$ (i.e. the sum of all its establishments' sales across all latitude-longitude pairs in geography $g$ ). We then denote by $s_{e, i, g, t}$ this enterprise's share of all sales in industry $i$ located in geography $g$ at date $t$. We adopt as our benchmark measure of market concentration the Herfindahl-Hirschman Index,

$$
\mathcal{C}_{i, g, t}=\sum_{e} s_{e, i, g, t}^{2}
$$

where $\mathcal{C}_{i, g, t} \in[1 / N, 1]$ is the sales concentration, and $N$ the number of enterprises in $(i, g, t)$. In the appendix, we also consider alternative measures of concentration, such as the sales share of the top firm, top 3 firms, and the adjusted Herfindahl, and show that all of our findings are robust to these other measures.

\section{National and Local Market Concentration: The Facts}

We organize the discussion of our findings into four main facts. The first two facts document the diverging trends in national and local concentration and their importance across sectors and geographic definitions of a 'local' market. The third and fourth facts document the role that large firms have played in these trends. As a form of corollary to the last fact, we also present evidence specific to Walmart, a firm that has featured prominently in the debate on the evolution of market concentration.

\subsection{Fact 1: Diverging Trends on Average}

Fact 1 is summarized in Figures (1). Figure (1) shows a weighted average of the change in concentration, $\Delta \mathcal{C}_{t}$, across all industry-geography pairs $(i, g)$ for different definitions of geography, namely ZIP code, County, CBSA, and the whole U.S.,

$$
\Delta \mathcal{C}_{t}=\sum_{i, g} w_{i, g, t} \Delta \mathcal{C}_{i, g, t},
$$

where the weights $w_{i, g, t}$ are given by the employment shares of industry-geography $(i, g)$ in aggregate employment in year $t$, and $\Delta \mathcal{C}_{i, g, t}$ denotes the change in market concentration between year $t$ and the first year for which we observe sales in the location-industry pair $(i, g) 12$

As indicated in the 2016 CEA report, Barkai (2017), Gutiérrez and Philippon (2017), and others, market concentration at the national level has been steadily increasing since 1990. However, the exact opposite is true for less aggregated measures of concentration. Figure (1 a) shows that the more geographically disaggregated the measure of concentration, the more pronounced its downward trend over the last two and a half decades.

Figure (10) shows a weighted average of the change in concentration across all industry-geography pairs $(i, g)$ within a particular division, $d$, namely Manufacturing, Services, Retail Trade, Wholesale Trade, and FIRE, for

\footnotetext{
${ }^{12}$ Given differences in the number of firms and other industry characteristics, the HHI cannot be compared directly across sector. This is why we aggregate changes in the HHI. Using sales shares instead of employment shares as weights yields similar results, as shown in the appendix.
} 
geographies defined by ZIP code and the whole U.S.,

$$
\Delta \mathcal{C}_{t}^{d}=\sum_{i \in d, g} w_{i, g, t} \Delta \mathcal{C}_{i, g, t}
$$

Figure (13) shows that while increasing market concentration at the national level holds broadly across all divisions, it is equally the case that concentration has steadily fallen at the ZIP code level in these divisions. Observe, in particular, that market concentration in the Retail Trade division has been increasing nationally more than in any other division. However, Retail Trade is also among the divisions that show the steepest decline in concentration at the ZIP code level. This fact is especially striking given that physical retail establishments in our dataset are likely to have very local markets.

a) Average Change in HHI from First Year

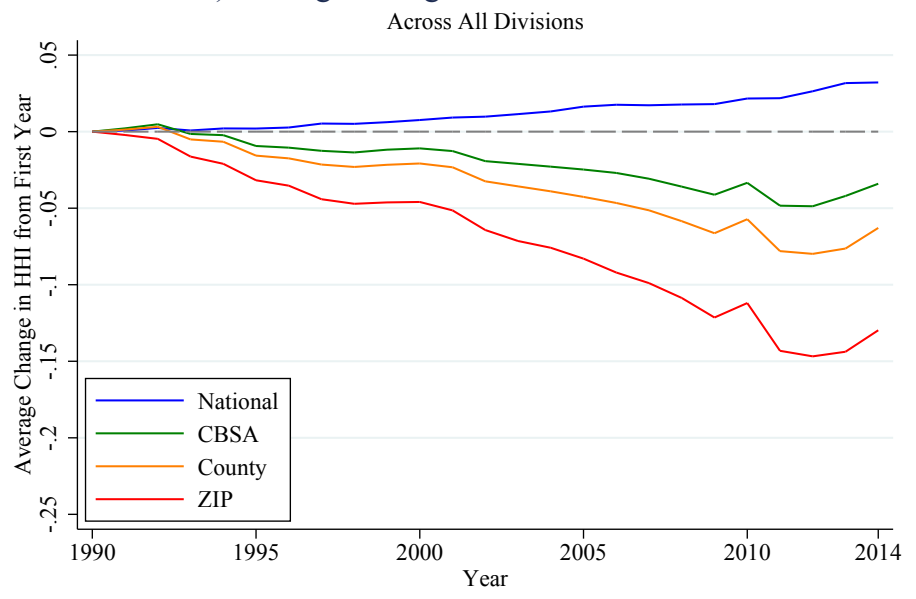

b) Average Change in HHI from First Year National and ZIP Levels, for Each Division

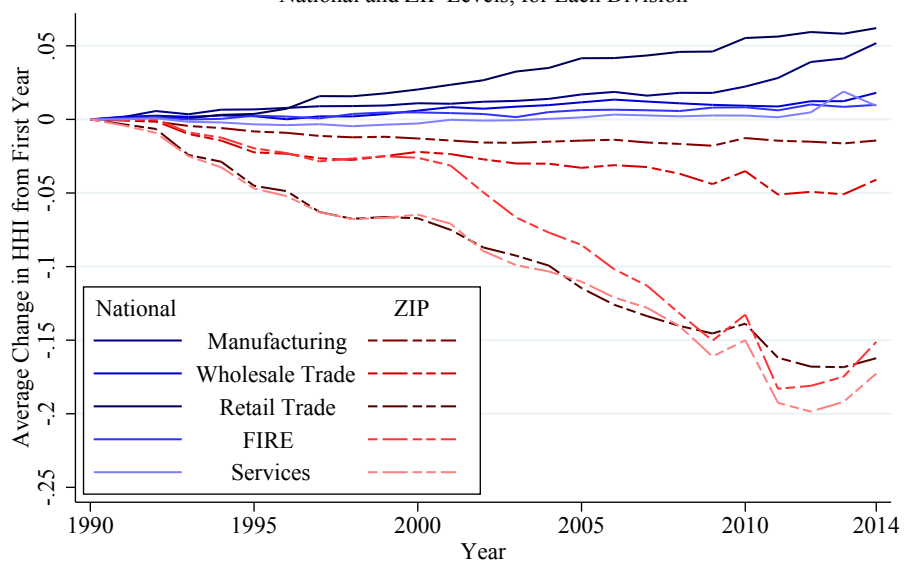

Figure 1: Diverging national and local concentration trends

\subsection{Fact 2: Pervasive Diverging Trends}

Fact 2 is presented in Figure (2). Within each SIC 2 classification, the figure gives a breakdown of employment in industries with different market concentration trends. In particular, for a given SIC 2 classification, the height of each bar gives the percentage of employment in all industries within that classification that have rising market concentration at the national level between 1990 and 2014. For each SIC 8 industry $i$ within an SIC 2 classification, we compute in each year $\Delta C_{i, t}=\sum_{g} w_{i, g, t} \Delta C_{i, g, t}$, where $g$ denotes the whole U.S., and regress $\Delta C_{i, t}$ on $t$. The height of the bar then represents the percent of labor, within that SIC 2 and across all years, employed in all SIC 8 industries with positive national concentration time trends. Thus, the major part of U.S. employment resides in industries with rising national concentration across all SIC 2 classifications. Within a bar associated with a given SIC 2 classification in Figure (2), the colors red, blue, and black represent, respectively, the percent of employment that resides in industries with declining, rising, and flat market concentration at the ZIP code level 13

Figure 2 shows the pervasiveness of SIC 8 industries with diverging trends 14 That is, a substantive share

\footnotetext{
${ }^{13}$ Specifically, in the calculation of $\Delta C_{i, t}=\sum_{g} w_{i, g, t} \Delta \mathcal{C}_{i, g, t}, g$ now represents a ZIP code.

${ }^{14}$ We reserve the term of 'diverging trends' for a case of positive national trend and a negative local trend. The case of a negative
} 
of employment resides in industries with rising market concentration at the national level and declining market concentration at the ZIP code level. It also shows the heterogeneity in this share across SIC 2 divisions. For example, in division 52, which includes General Merchandise Stores, virtually all employment resides in SIC 8 industries with diverging trends (96.38\%). In contrast, in division 21, which includes Tobacco Products, none of the SIC 8 industries exhibit a positive national trend and a negative local trend. Diverging trends are more pronounced in Retail, FIRE and Services, than in Wholesale Trade and Manufacturing, though still very much present in the latter two divisions.

The proportion of aggregate U.S. employment located in all SIC 8 industries with increasing national market concentration and decreasing ZIP code level market concentration is 43 percent. Thus, given that some industries have also had declining concentration at both the national and ZIP code level, 77 percent (or over 3/4) of U.S. employment resides in industries with declining local market concentration 15

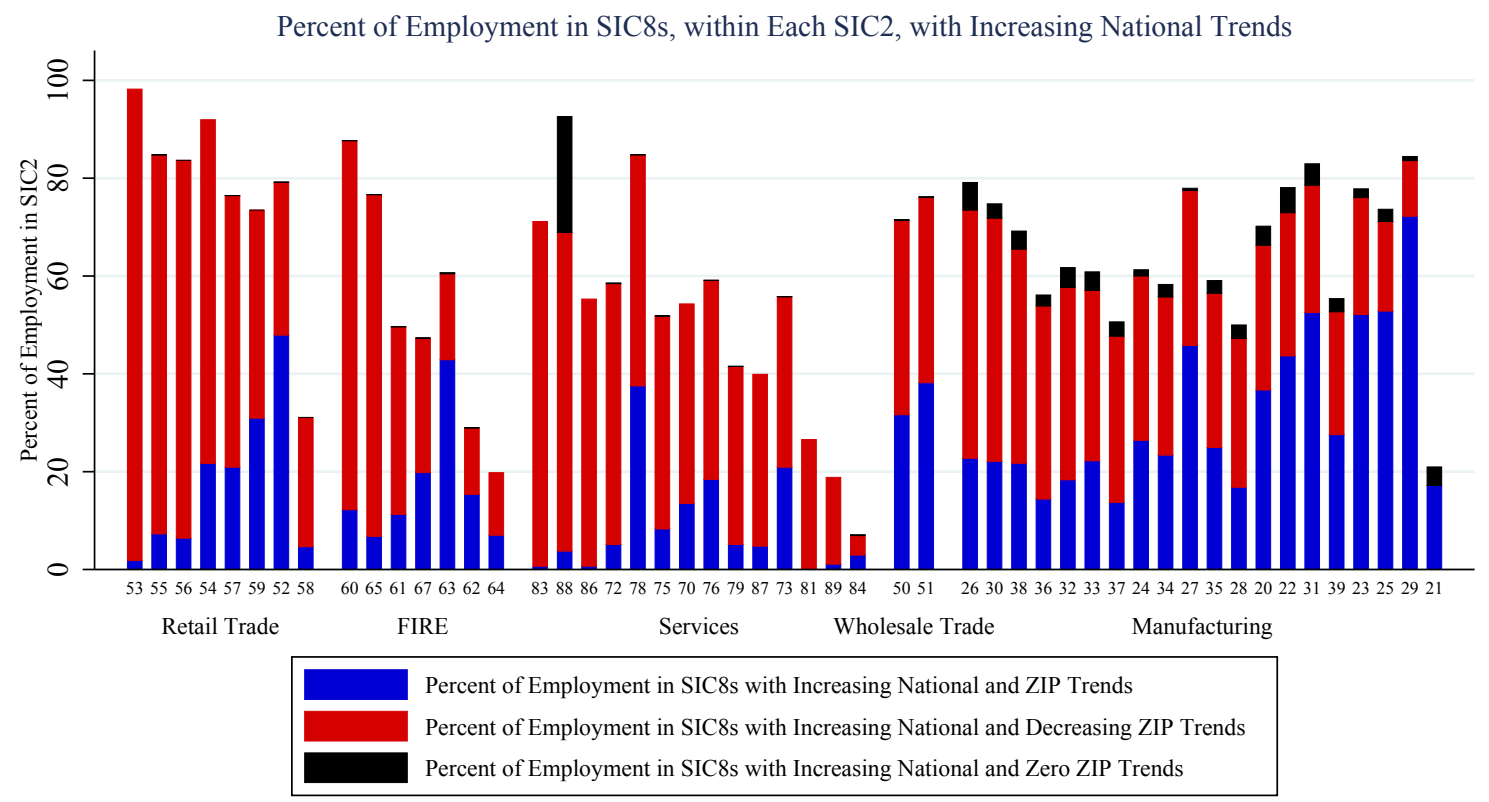

Figure 2: Pervasive diverging trends across 2-digit sectors

\subsection{Fact 3: The Role of Top Firms}

Fact 3 explores the contribution that top firms -in terms of sales share- have made to the diverging trends in each SIC 8 industry. Figures (3a) and (3b) focus on just those industries whose market concentration has increased at the national level since 1990, represented by the height of the bars in Figure (2). Those industries account for roughly half of all industries in our sample, $61 \%$ of aggregate U.S. employment, and $67 \%$ of aggregate sales.

Within that set of SIC 8 industries, Figure (3a) focuses on those that exhibit negative local concentration trends. These industries account for $70 \%$ of total employment in industries with positive national trend (65\% of sales). The figure presents in solid orange and solid red, respectively, the national HHI and the local ZIP code level HHI among

national trend and a positive local trend is also possible, though much less common in virtually all industries.

${ }^{15}$ The share of national sales in sectors with decreasing local market concentration is $70 \%$. 
these industries. Given our industry selection, the national concentration (orange) line is increasing by construction and the local concentration (red) line is decreasing by construction. The dashed orange and dashed red lines in that figure depict the same objects but excluding the top enterprise in each SIC 8 industry as measured by sales in 2014 16 We consider only industry-geography pairs $(i, g)$ for which $i$ 's top enterprise has at least one establishment present in $g$ in at least one year. Furthermore, because we are interested in isolating the effect of the top enterprise on market concentration, among those remaining industry-geography pairs, we then only include observations $(i, g, t)$ where at least one establishment remains after dropping the top enterprise in $i$ and its associated establishments ${ }^{17}$

Figure (3a) shows that among SIC 8 industries with diverging trends, excluding the top firm results in a national concentration trend that is less pronounced. The fact that large firms have contributed to the national increase in concentration is as expected. More surprising is the observation that the top firms have also contributed to the decline in local concentration. Figure (3a) shows that when we exclude the top firm, the negative trend in ZIP-code-level concentration is less pronounced. Hence, the top firm (and more generally the largest firms) in an industry are responsible (though not entirely) for the diverging trends.

Figure (3b) is constructed exactly as Figure (3a) but uses the SIC 8 industries with increasing national trends which are not depicted in Figure (3a). In other words, it uses the SIC 8 industries with positive national and local trends. The figure shows that for this set of industries, excluding the top firm lowers both the national and the local trend in concentration. Over the last ten years or so, it also shows that excluding the top firm reduces the trend in national concentration significantly more than that in local concentration.

a) Average Change in HHI from First Year Across SIC8s with Positive National and Negative ZIP Trends

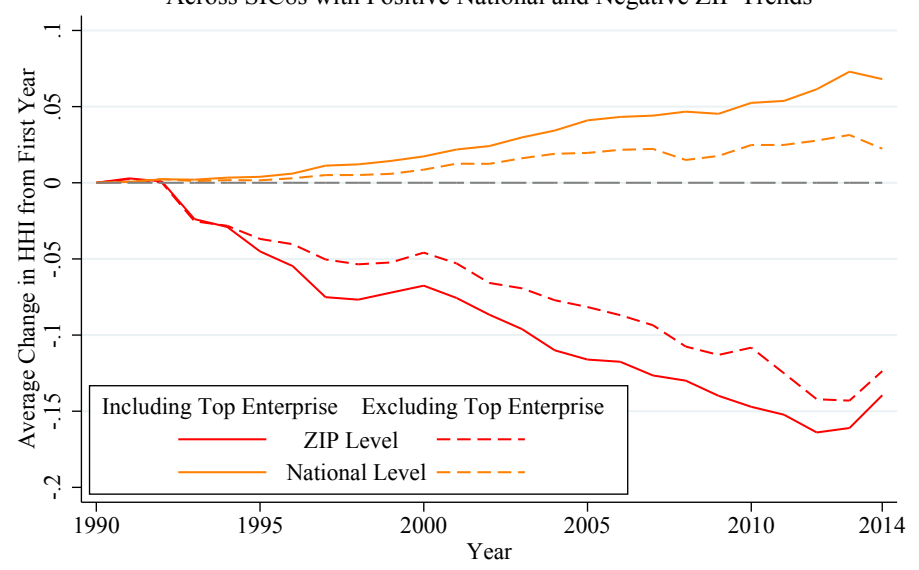

b) Average Change in HHI from First Year Across SIC8s with Positive National and Positive ZIP Trends

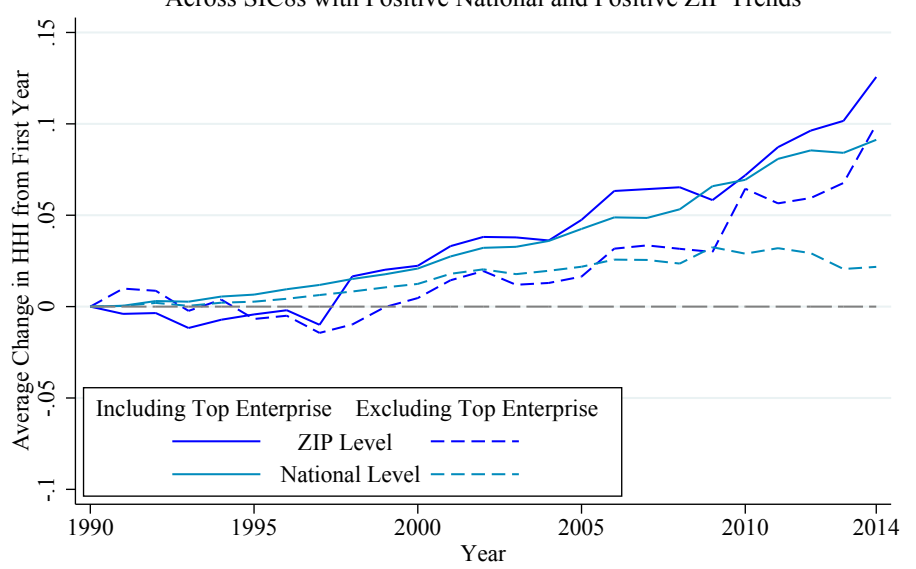

Figure 3: The role of top firms in national and local concentration trends

How can the growth of large firms contribute to the divergence in these trends? To a large extent, top enterprises expand by adding new establishments in new locations. The new establishments tend to decrease local concentration as they compete with existing establishments in the area, even as the top firm acquires a larger national market share, increasing national concentration. Next, we explore the impact of local entry by a top firm.

\footnotetext{
${ }^{16}$ We show in the appendix that we obtain similar results when we exclude the top 3 firms rather than only the top firm.

${ }^{17}$ We also exclude industry-geography pairs whose first year of observed sales results from only one establishment belonging to the top enterprise, since the change in market concentration cannot be computed in that case.
} 


\subsection{Fact 4: When a Top Firm Comes to Town}

To further illustrate the impact of an industry's top enterprise on market concentration at the local level, Figure (4) presents an event study describing the effect of local entry by an establishment associated with a top firm (defined by 2014 sales in an SIC 8 industry as in Fact 3) in a ZIP code. Specifically, Figure (4) examines the effect of a top firm opening a new establishment in a ZIP code on local market concentration. The calculations here mimic those in Figure (3). In Figure (4), the $x$-axis plots a 10-year window surrounding a top firm establishment opening in a given ZIP code, with 0 denoting the opening year. To better highlight the net effect of entry on concentration, we normalize the change in concentration to zero in the year prior to the establishment opening.

Figure (4a) depicts the event study for all SIC 8 industries with increasing market concentration at the national level and decreasing local market concentration, that is, SIC 8 industries with diverging trends. Figure (4b) illustrates findings for the remaining SIC 8 industries with increasing national concentration: those where both national and local trends are positive over our sample period. The solid lines in both figures present the evolution of the HHI index when the entering establishment is included; the dashed lines illustrate the same object when excluding the opening establishment owned by the top enterprise within each industry.

Among industries with diverging trends, the opening of an establishment in a ZIP code is associated with a fall in market concentration. Moreover, this fall persists at about the same size for at least 7 years after the event. In contrast, among industries with increasing local market concentration, the opening of an establishment leads to a temporary decrease in market concentration but one that reverses quickly. After 4 to 5 years, concentration is higher than it would have been absent the opening. Hence, in the former case, the establishment owned by the top enterprise does not become dominant, while in the latter case it eventually dwarfs the establishments of other firms. The data suggest that on the whole, the case where the top firm does not become dominant at the local level is markedly more relevant 18

The dashed lines in both panels of Figure (4) suggest that when all shares are re-calculated excluding sales of the opening establishment belonging to the top enterprise in each industry, market concentration does not exhibit a significant trend over the entire 10-year window. Thus, the dashed-lines lend credibility to a central assumption underlying the event study, namely that entry by a top enterprise in a local market is the main event affecting concentration in each market.

\subsubsection{The Case of Walmart}

The event study presented in Fact 4 averages the effect of entry by a top enterprise across many markets. It is informative, therefore, to further delve into the data within a particular sector. In the last couple of decades, one of the most widely studied cases of an expanding firm has been the case of Walmart 19 Hence, here we repeat the calculations underlying Fact 4 but for the particular case of Walmart and the SIC 8 industries with which it is

\footnotetext{
${ }^{18}$ Neumark, Zhang and Wall (2006) and Barnatchez, Crane and Decker (2017) argue that NETS dataset might at times be slow in reporting the entry and exit of small firms. Given their findings, one might question the extent to which our results are driven by the exit of small firms not being reported accurately. However, the fact that the fall in the HHI persists for up to 7 years diminishes this potential concern. Another potential concern is that ZIP codes are too narrow a geographic definition of a market. In the appendix, we show that the fall in the local HHI as a result of local entry by a top enterprise in industries with diverging trends holds and persists when we using counties rather than ZIP codes.

${ }^{19}$ See, for example: Basker (2007), Jia (2008), Ailawadi, Zhang, Krishna, Krueger (2010), Zhu, Singh, Manuszak (2009), Holmes (2011).
} 

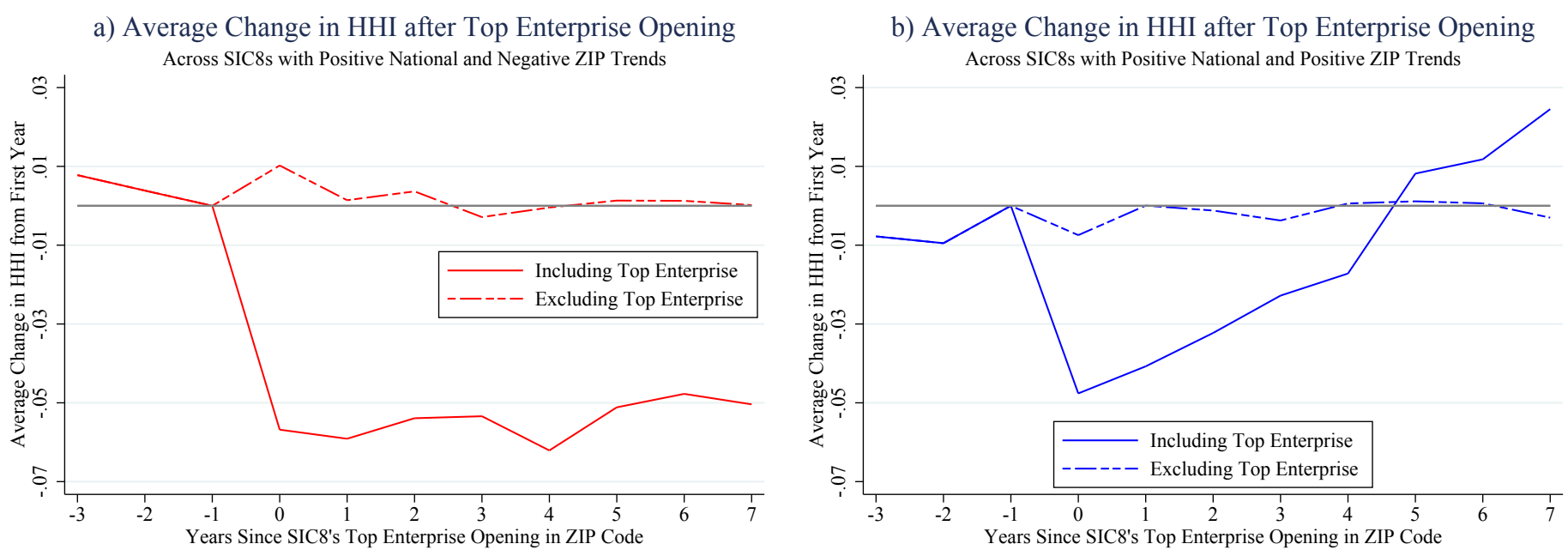

Figure 4: Effect on concentration when a top firm enters a local market

associated. The solid line depicted in Figure (5a) represents a weighted average of concentration within Walmart's primary industry (discount department stores) across all ZIP codes. The dashed line represents the same object but excluding the opening establishment owned by Walmart (i.e. all shares are re-calculated excluding Walmart's sales from the new establishment).

Our findings for Walmart are qualitatively similar to those in Fact 4 for industries with diverging trends (as is the case for Walmart's industries). Absent a Walmart opening, there is no trend in concentration, but there is a significant fall in the HHI of a ZIP code in which Walmart opens a new establishment. This lower level of concentration remains about constant for at least 7 years.

One advantage of considering a particular firm and its industries is that we can also show, and easily interpret, the effect of entry on the number of establishments in the local market. To do so, Figure (5b) illustrates the effect of a Walmart establishment opening in a given ZIP code on the number of establishments in that ZIP code. The solid line in the figure indicates that, when averaged across all ZIP codes (weighted by geography-SIC 8 employment, as in all other figures), the opening of a Walmart establishment is associated with an increase in the number of local establishments. This increase is somewhat less than one-for-one (roughly 0.75) which suggests that the entry of Walmart is associated with some establishment exits across ZIP codes. Consistent with this observation, the dashed line indicates that when the newly established Walmart is excluded from the calculation, the number of establishments falls somewhat across ZIP codes 20

\section{Conclusions}

We have shown, by way of four main facts, that the increase in market concentration observed at the national level over the last 25 years is being shaped by enterprises expanding into new local markets. This expansion into local markets is accompanied by a fall in local concentration as firms open establishments in new locations. These

\footnotetext{
${ }^{20}$ Consistent with the findings in Jia (2008) and Basker (2007), carrying out these calculations at the county level reveals a more pronounced effect of Walmart's entry on firm exit. Nevertheless, the decline in the HHI is still large on impact and still negative after 7 years.
} 


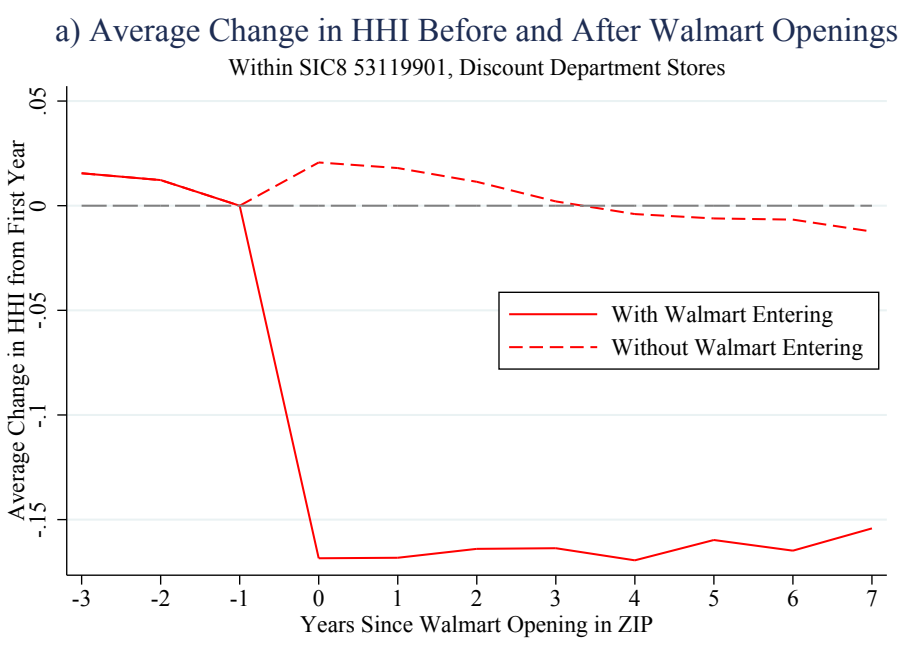

b) Avg. Number of Estab. Before and After Walmart Openings

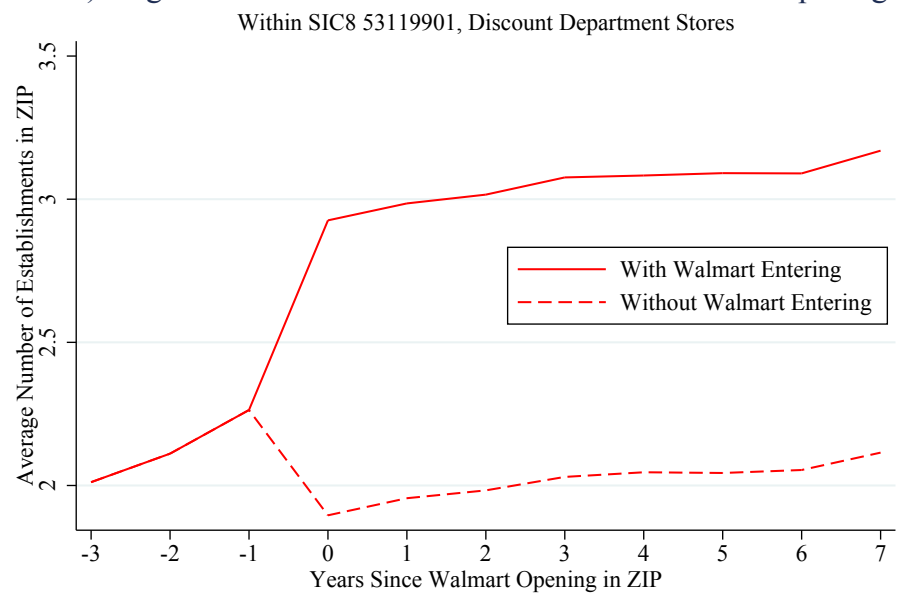

Figure 5: Effect on concentration and the number of firms when Walmart enters a local market

observations are suggestive of more, rather than less, competitive markets.

The findings in this paper potentially help reconcile the observation of increasing concentration at the national level and the more mixed evidence on increasing markups and profits. Virtually no theory of product market competition associates decreasing concentration with either increasing markups or increasing profits. Our facts also indicate that the rising trend in national concentration is not, in and of itself, necessarily a concern for antitrust policy. By decreasing local concentration, the growth of top firms has likely increased local competition and, therefore, helped improve the quality and reduce the prices of much of what we buy. 


\section{References}

[1] Ailawadi, Kusum L., Aradhna Krishna, Michael W. Kruger, and Jie Zhang. 2010. "When Wal-Mart Enters: How Incumbent Retailers React and How This Affects Their Sales Outcomes." Journal of Marketing Research. 47 (4): 577-93.

[2] Anderson, Eric, Sergio Rebelo, and Arlene Wong. 2018. "Markups Across Space and Time." NBER Working Paper 24434.

[3] Autor, David, David Dorn, Lawrence F. Katz, Christina Patterson, and John Van Reenen. 2017. "The Fall of the Labor Share and the Rise of Superstar Firms." NBER Working Paper 23396.

[4] Barkai, Simcha. 2017. "Declining Labor and Capital Shares."

http://facultyresearch.london.edu/docs/BarkaiDecliningLaborCapital.pdf.

[5] Barnatchez, Keith, Leland D. Crane, and Ryan A. Decker. 2017. "An Assessment of the National Establishment Time Series (NETS) Database." Finance and Economics Discussion Series 2017-110.

[6] Basker, Emek. 2007. "The Causes and Consequences of Wal-Mart's Growth." Journal of Economic Perspectives 21 (3): 177-98.

[7] Choi, Taelim, John C. Robertson, and Anil Rupasingha. 2013. "High-Growth Firms in Georgia." Federal Reserve Bank of Atlanta Working Paper 2013-20.

[8] Decker, Ryan A., John Haltiwanger, Ron S. Jarmin, and Javier Miranda. 2017. "Declining Dynamism: Allocative Efficiency, and the Productivity Slowdown." American Economic Review: Papers 8 Proceedings. 107 (5): 322-6.

[9] De Loecker, Jan, and Jan Eeckhout. 2017. "The Rise of Market Power and the Macroeconomic Implications." NBER Working Paper 23687.

[10] De Loecker, Jan, and Jan Eeckhout. 2018. "Global Market Power." NBER Working Paper 24768.

[11] Edmond, Chris, Virgiliu Midrigan, and Daniel Yi Xu. 2018. "How Costly are Markups?" NBER Working Paper 24800.

[12] Fulton, Brent D. 2017. "Health Care Market Concentration Trends in the United States: Evidence and Policy Responses." Health Affairs 36 (9): 1530-1538.

[13] Gutiérrez, Germán, and Thomas Philippon. 2017. "Declining Competition and Investment in the U.S." NBER Working Paper 23583.

[14] Hall, Robert E. 2018. "New Evidence on the Markup of Prices Over Marginal Costs and the Role of MegaFirms in the US Economy." NBER Working Paper 24574.

[15] Holmes, Thomas J. 2011. "The Diffusion of Wal-Mart and Economics of Density." Econometrica 79 (1): 253-302. 
[16] Jia, Panle. 2008. "What Happens When Wal-Mart Comes to Town: An Empirical Analysis of the Discount Retailing Industry." Econometrica 76 (6): 1263-1316.

[17] Karabarbounis, Loukas, and Brent Neiman. 2018. "Accounting for Factorless Income." NBER Working Paper 24404.

[18] Neumark, David, Junfu Zhang, and Brandon Wall. 2006. "Employment Dynamics and Business Relocation: New Evidence from the National Establishment Time Series." NBER Working Paper 11647.

[19] Syverson, Chad. 2004. "Market Structure and Productivity: A Concrete Example." Journal of Political Economy, 112 (6): 1181-1222.

[20] Syverson, Chad. 2008. "Markets: Ready-Mixed Concrete." Journal of Economic Perspectives 22 (1): 217-33.

[21] Traina, James. 2018. "Is Aggregate Market Power Increasing? Production Trends Using Financial Statements." Stigler Center New Working Paper Series No. 26.

[22] Walls \& Associates. 2014. "National Establishment Time-Series (NETS) Database."

[23] Zhu, Ting, Vishal Singh, and Mark D. Manuszak. 2009. "Market Structure and Competition in the Retail Discount Industry." Journal of Marketing Research. 46 (4): 453-66. 


\section{Appendix}

\section{A Data Description}

\section{A.1 NETS}

The National Establishment Time Series (NETS) is made available through Walls \& Associates, which relies on data compiled by Dun \& Bradstreet (D\&B). D\&B provides each business establishment, corresponding to a distinct business activity by an enterprise at a specific location, a unique 9-digit Data Universal Numbering System (DUNS) number, which remains with that establishment even in the case of broader corporate-level changes, name changes, and relocations ${ }^{21}$ Each year, D\&B compiles data for its Duns Marketing Information file on business characteristics of every establishment, including its sales, employment, location, primary industry, and the DUNS number of the establishment to which it reports (i.e. its parent company) ${ }^{22}$ As described by Neumark, Zhang, and Wall (2006), as well as Barnatchez, Crane, and Decker (2017), D\&B makes an exhaustive effort to ensure that the file accurately covers the entire universe of business establishments, relying on many sources of information including direct phone calls, Yellow Pages, newspapers, and multiple government agencies. Furthermore, D\&B and the establishments from which they gather information both have incentives to ensure information is accurate.

While D\&B compiles annual cross-sections of establishment characteristics, Walls \& Associates aggregates these files into a longitudinal database that makes it possible to track the birth and death of establishments. Neumark et al. (2007) note that this process requires imputation of sales and employment to many establishment-year pairings.

We use the NETS database to gather data on employment, sales, and the primary industry (8-digit SIC code) for each establishment for each year from 1990 through 2014, as well as the DUNS number of the establishment's headquarters in each year (HQ or enterprise number). In each year, an enterprise is then defined as a collection of all the establishments with a given HQ number. We additionally collect the establishment's county, ZIP code, and legal status, as well as the most recent HQ number of the establishment ${ }^{23}$ The data is provided in wide form, with one observation per establishment and separate variables for establishment characteristics in each year, but we reshape the data into long form with one observation per establishment-year. We then drop any observations that have missing employment, sales, industry, or HQ numbers, and consider an establishment to "exist" in a given year if it has an observation associated with it (i.e. it has non-missing employment, sales, industry, and HQ numbers). We can then see the first year in which each establishment exists (its entry year) and the last year (its exit year) ${ }^{24}$

Among these remaining establishment-year pairs, we identify the industry corresponding to the headquarters for each enterprise, and drop any establishments belonging to an enterprise whose headquarters has an SIC 8 industry code corresponding to the Public Administration division. We then drop any establishments which have an SIC 8 code either equal to 73899999 (Business Activities at Non-Commercial Sites), falling under Public Administration (even if their enterprise headquarters do not), the Educational Services 2-digit SIC sector (SIC 2 82), the Health Services 2-digit SIC sector (SIC 2 80), or the SIC 3-digit code 601, Central Reserve Depository. Additionally, we

\footnotetext{
${ }^{21}$ If an establishment goes out of business, its DUNS number will not be re-used.

${ }^{22}$ This file contains data on many other establishment characteristics that we do not consider in this paper.

${ }^{23}$ The NETS database additionally has a variable for the business name, allowing us to identify the firms associated with specific HQ numbers.

${ }^{24}$ Establishments that exist in 1990 are assigned 1990 as their entry year, as we have no data on them prior to this year. Likewise, establishments which exist in 2014 have that as their exit year.
} 
drop any establishments whose HQ number corresponds to the United States Postal Services (USPS), whose legal status identifies them as a non-profit organization, or which are in counties located outside of the 50 U.S. states and the District of Columbia. Among remaining establishments, we keep only those whose primary industry falls into one of the following five divisions: Manufacturing; Wholesale Trade; Retail Trade; Finance, Insurance, and Real Estate (FIRE); and Services.

In the remaining dataset, we have roughly 38 million unique establishments spread across approximately 290 million establishment-year pairs. Figure (6a) shows the number of establishments in our sample in each year, while Figure (6b) shows total employment. Employment increases steadily in the first 10 years of the sample but has largely flattened out since 2000. The number of establishments, on the other hand, continues to increase considerably through 2009.

Figure 6: Employment and Establishment Counts in NETS Database, 1990-2014
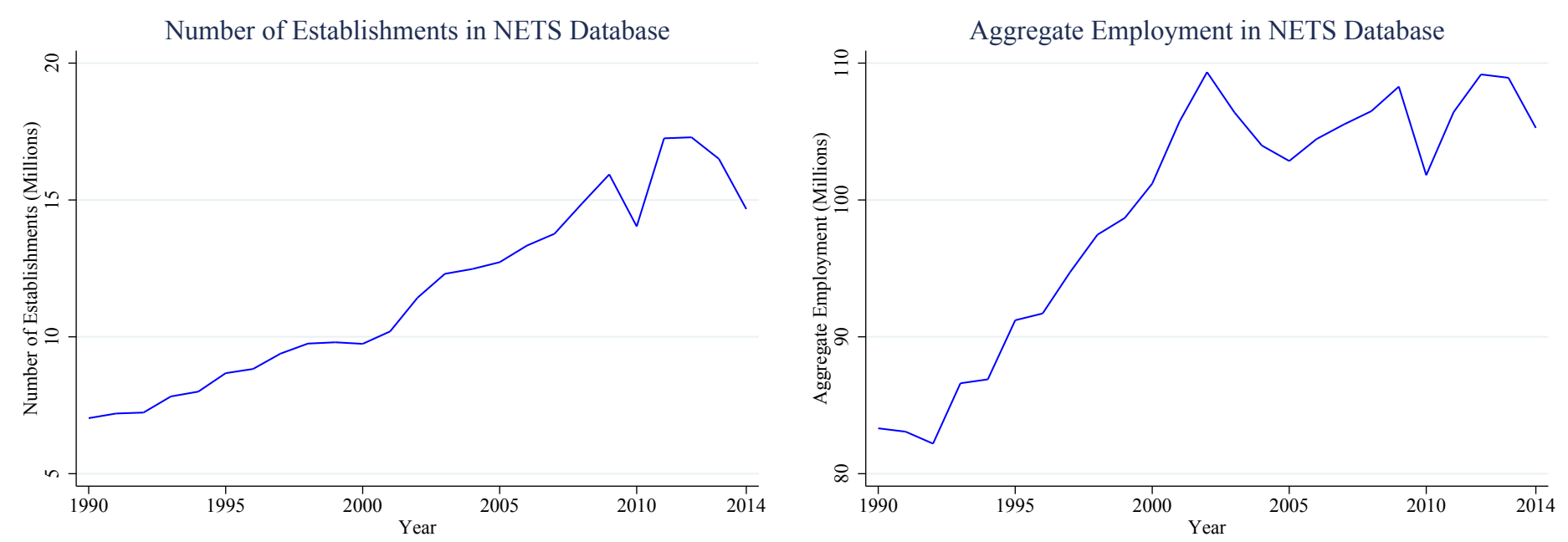

\section{A.1.1 Data Quality}

A number of researchers have attempted to compare the scope and accuracy of the NETS database to official sources such as the County Business Patterns (CBP), the Quarterly Census of Employment and Wages (QCEW), the Longitudinal Business Database (LBD), and Census Nonemployer Statistics (CES). Neumark et al. (2006); Neumark, Wall, and Zhang (2011); and Barnatchez et al. (2017) find that NETS reports substantially higher aggregate employment than these sources. This discrepancy seems to arise primarily from the inclusion of nonemployer establishments, which consist only of business owners and have no paid employees, in the NETS data; such establishments are generally not counted in government employment data. Since nonemployer establishments tend to have very small employment numbers, NETS vastly overstates the number of establishments in the 1-4 employee bin compared to Census counts of establishments with employment in this range, as noted by Neumark et al. (2006) and Barnatchez et al. (2017). Using an extract of the NETS data covering Georgia, Choi, Robertson, and Rupasingha (2013) find that, compared to the QCEW, NETS has nearly 75\% more establishments in the state in 2000 and roughly three times as many in 2009.

In the main text, we include these nonemployer establishments because they do report positive sales. Following 
the advice of Barnatchez et al. (2017), however, we show later in this appendix that the results hold when modifying the data to attempt to remove such establishments. While Neumark et al. (2006) argue that subtracting one from establishments' employment counts to remove business owners makes the NETS universe comparable to that of official sources and eliminates most nonemployer establishments, Barnatchez et al. (2017) instead propose subtracting one from employment counts at the headquarters of each enterprise, because enterprise owners will generally only be counted at their headquarters. Along those lines, we present an alternative specification in which, for each year, we exclude sales and employment from all enterprises that report only one employee.

However, there is some evidence that dropping single-employee enterprises may not remove the entire set of nonemployers. While over one-quarter of establishment-year pairs in our dataset have only one employee, nearly as many report two employees. Furthermore, because the CBP and LBD report establishment counts in employment bins, we can only compare the number of establishments with between 1 and 4 employees in NETS and these other sources. In fact, Barnatchez et al. (2017) find that NETS still overcounts the number of establishments in this range even after dropping single-employee enterprises. Consequently, we explore a second specification in which we exclude sales and employment from all enterprise-year pairs reporting four or fewer employees 25 Surely there are many employer establishments falling into this size range, so this specification should be interpreted as a very conservative attempt to remove the influence of nonemployer establishments in the database. Figure (7) supports this notion by showing that single-employee enterprises contain an immaterial percentage of aggregate sales and employment but dropping enterprises with fewer than 5 employees removes shares well over four times as large. Additionally, it is worth noting that while Neumark et al. (2006) and Barnatchez et al. (2017) note a high rate of imputation in establishments' reported employment and sales numbers, such imputation is mostly prevalent among smaller establishments, and so dropping small enterprises should eliminate the main share of imputed values.

Figure 7: Percent of Employment and Sales in Small Enterprises, 1990-2014
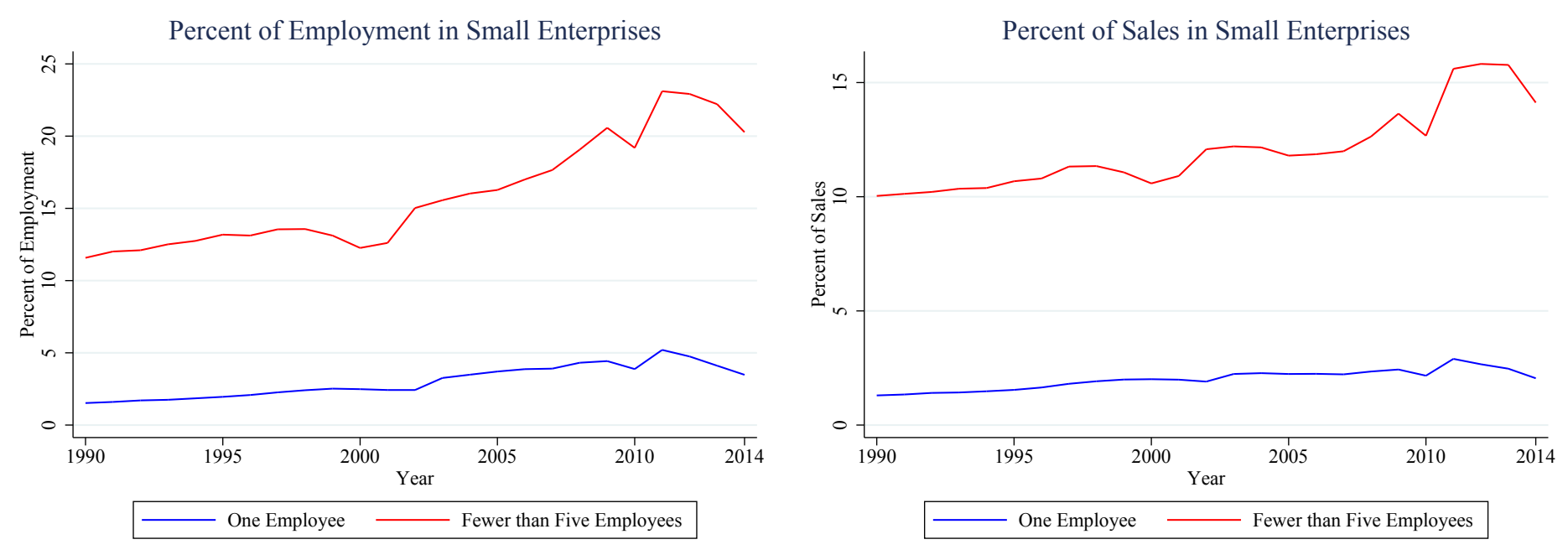

There are two other potential issues regarding the NETS database to be addressed. First, Neumark et al. (2006) observe that NETS can be slow to report the birth and death of establishments, often operating on a two-to-three year lag in such cases. Second, the NETS data reported for each year are collected primarily in the prior year, and

\footnotetext{
${ }^{25}$ Since the vast majority of enterprises only have one establishment, results removing establishments based on establishment size rather than enterprise size should be roughly equivalent.
} 
unlike official government sources NETS data are collected throughout the year, with establishments potentially reporting data at different months in different years ${ }^{26}$ Because our dataset encompasses a 25-year period, such lags and inconsistencies in data collection timing should not affect the long-term trends we observe in the main text.

\section{A.2 SIC 8 Codes}

Our benchmark definition of an industry is an 8-digit Standard Industrial Classification (SIC) code. The first four digits of each SIC 8 code (SIC 4 codes) are created and determined by U.S. government agencies and assigned to business establishments. D\&B supplements these codes with an additional four digits, providing a much finer level of detail regarding establishments' primary activities; there are over 18,000 unique 8-digit SIC codes compared to only about 1,000 unique SIC codes at the 4-digit level and 84 at the 2-digit level. Each SIC code is also assigned to one of 11 divisions, five of which we consider in this paper 27

To better illustrate this "hierarchy" of SIC codes, consider the case of Walmart. As mentioned in the main text, the large majority of Walmart's establishments in 2014 have SIC 8 53119901, Discount Department Stores, as their primary industry. This SIC 8 is a subset of SIC 4 5311, Department Stores, which also contains three other industries including SIC 8 53119902, Non-discount Department Stores. This SIC 4 code is further contained within the General Merchandise sector, SIC 2 53, which encompasses other industries corresponding to, for instance, Warehouse Club Stores and Miscellaneous General Merchandise. Finally, the Retail Trade division contains these industries and others as diverse as Grocery Stores, Optical Goods Stores, Eating Places, and Hardware Stores.

Individual SIC 8 codes vary widely in their sizes as measured by employment, sales, and the number of establishments. For instance, among the 15,102 SIC 8 codes considered in the main text, over one-quarter of these have reported 2014 employment of fewer than 100 employees across all establishments with that primary industry ${ }^{28}$ On the other hand, there are 182 industries with greater than 100,000 reported employees, with the Discount Department Stores industry having over 1.8 million. Overall, industries in Retail Trade, FIRE, and Services have much higher employment on average than industries in Manufacturing and Wholesale Trade.

To get a better sense of this heterogeneity across industries, Table (1) shows total employment and the number of SIC 8 industries within each of our 50 SIC 2 sectors in 2014, as well as the division into which each SIC 2 code falls. Even at the sector level, there are huge differences in these variables. Over 10 million employees work in the Business Services sector, while many sectors in the Manufacturing division have only a few hundred thousand employees. Sectors in Retail Trade, FIRE, and Services tend to have higher employment than sectors in Manufacturing and Wholesale Trade, while the latter two divisions encompass over three-quarters of all SIC 8 codes.

\footnotetext{
${ }^{26}$ Some researchers roll back NETS data one year, but Barnatchez et al. (2017) find more favorable comparisons with government sources leaving years unchanged.

${ }^{27}$ In addition to the primary 8-digit SIC code of each establishment, the NETS database reports the establishment's primary North American Industry Classification System (NAICS) code. While government agencies developed the SIC system in the early 1900s, the Office of Management and Budget developed the NAICS system in 1992 to better reflect changes in the structure of the economy. Although the NAICS system contains a higher share of codes in more service-oriented industries, the most detailed NAICS code level only contains roughly 1, 100 industries, a level of aggregation much more comparable to the 4-digit than the 8-digit SIC code. Consequently, we use SIC 8 codes as they offer by far the most granular available definition of an industry.

${ }^{28}$ Approximately $90 \%$ of these industries are in the Manufacturing division.
} 
Table 1: Employment and Number of SIC 8 Codes in Each SIC 2 Sector in 2014

\begin{tabular}{|c|c|c|c|c|c|}
\hline SIC 2 Code & SIC 2 Description & Division & Employment in 2014 (Thousands) & Number of SIC 8 codes in 2014 & $\begin{array}{l}\text { Mean SIC } 8 \text { employment in } 2014 \\
\text { (Thousands) }\end{array}$ \\
\hline 20 & Food and Kindred Products & Manufacturing & 1637 & 805 & 2 \\
\hline 21 & Tobacco Products & Manufacturing & 25 & 11 & 2 \\
\hline 22 & Textile Mill Products & Manufacturing & 343 & 587 & 1 \\
\hline 23 & $\begin{array}{l}\text { Apparel, Finished Products from } \\
\text { Fabrics and Similar Materials }\end{array}$ & Manufacturing & 386 & 385 & 1 \\
\hline 24 & $\begin{array}{c}\text { Lumber and Wood Products, } \\
\text { Except Furniture }\end{array}$ & Manufacturing & 699 & 371 & 2 \\
\hline 25 & Furniture and Fixtures & Manufacturing & 429 & 262 & 2 \\
\hline 26 & Paper and Allied Products & Manufacturing & 680 & 328 & 2 \\
\hline 27 & $\begin{array}{l}\text { Printing, Publishing and Allied } \\
\text { Industries }\end{array}$ & Manufacturing & 1472 & 299 & 5 \\
\hline 28 & Chemicals and Allied Products & Manufacturing & 1345 & 643 & 2 \\
\hline 29 & $\begin{array}{l}\text { Petroleum Refining and Related } \\
\text { Industries }\end{array}$ & Manufacturing & 189 & 75 & 3 \\
\hline 30 & $\begin{array}{c}\text { Rubber and Miscellaneous Plastic } \\
\text { Products }\end{array}$ & Manufacturing & 895 & 334 & 3 \\
\hline 31 & Leather and Leather Products & Manufacturing & 101 & 162 & 1 \\
\hline 32 & $\begin{array}{c}\text { Stone, Clay, Glass, and Concrete } \\
\text { Products }\end{array}$ & Manufacturing & 576 & 516 & 1 \\
\hline 33 & Primary Metal Industries & Manufacturing & 610 & 345 & 2 \\
\hline 34 & Fabricated Metal Products & Manufacturing & 1488 & 736 & 2 \\
\hline 35 & $\begin{array}{c}\text { Industrial and Commercial } \\
\text { Machinery and Computer } \\
\text { Equipment }\end{array}$ & Manufacturing & 2144 & 1123 & 2 \\
\hline 36 & $\begin{array}{l}\text { Electronic and Other Electrical } \\
\text { Equipment and Components }\end{array}$ & Manufacturing & 1967 & 694 & 3 \\
\hline 37 & Transportation Equipment & Manufacturing & 1802 & 373 & 5 \\
\hline 38 & $\begin{array}{c}\text { Measuring, Photographic, } \\
\text { Medical, and Optical Goods, and } \\
\text { Clocks }\end{array}$ & Manufacturing & 1401 & 784 & 2 \\
\hline 39 & $\begin{array}{c}\text { Miscellaneous Manufacturing } \\
\text { Industries }\end{array}$ & Manufacturing & 570 & 627 & 1 \\
\hline 50 & Wholesale Trade - Durable Goods & Wholesale Trade & 4527 & 1104 & 4 \\
\hline 51 & $\begin{array}{c}\text { Wholesale Trade - Nondurable } \\
\text { Goods }\end{array}$ & Wholesale Trade & 2966 & 653 & 5 \\
\hline 52 & $\begin{array}{c}\text { Building Materials, Hardware, } \\
\text { Garden Supplies and Mobile } \\
\text { Homes }\end{array}$ & Retail Trade & 1400 & 77 & 18 \\
\hline 53 & General Merchandise Stores & Retail Trade & 3346 & 11 & 304 \\
\hline 54 & Food Stores & Retail Trade & 3935 & 61 & 65 \\
\hline 55 & $\begin{array}{c}\text { Automotive Dealers and Gasoline } \\
\text { Service Stations }\end{array}$ & Retail Trade & 2783 & 68 & 41 \\
\hline 56 & Apparel and Accessory Stores & Retail Trade & 1462 & 78 & 19 \\
\hline 57 & $\begin{array}{c}\text { Home Furniture, Furnishings and } \\
\text { Equipment Stores }\end{array}$ & Retail Trade & 1279 & 125 & 10 \\
\hline 58 & Eating and Drinking Places & Retail Trade & 10446 & 81 & 129 \\
\hline 59 & Miscellaneous Retail & Retail Trade & 4446 & 358 & 12 \\
\hline 61 & Nondepository Credit Institutions & FIRE & 749 & 65 & 12 \\
\hline 62 & $\begin{array}{l}\text { Security and Commodity Brokers, } \\
\text { Dealers, Exchanges and Services }\end{array}$ & FIRE & 901 & 56 & 16 \\
\hline 63 & Insurance Carriers & FIRE & 1191 & 77 & 15 \\
\hline 64 & $\begin{array}{c}\text { Insurance Agents, Brokers and } \\
\text { Service }\end{array}$ & FIRE & 1373 & 27 & 51 \\
\hline 65 & Real Estate & FIRE & 4217 & 63 & 67 \\
\hline 67 & $\begin{array}{c}\text { Holding and Other Investment } \\
\text { Offices }\end{array}$ & FIRE & 1679 & 48 & 35 \\
\hline 70 & $\begin{array}{l}\text { Hotels, Rooming Houses, Camps, } \\
\text { and Other Lodging Places }\end{array}$ & Services & 2736 & 49 & 56 \\
\hline 72 & Personal Services & Services & 2501 & 168 & 15 \\
\hline 73 & Business Services & Services & 10524 & 487 & 22 \\
\hline 75 & $\begin{array}{c}\text { Automotive Repair, Services and } \\
\text { Parking }\end{array}$ & Services & 1822 & 106 & 17 \\
\hline 76 & Miscellaneous Repair Services & Services & 928 & 227 & 4 \\
\hline 78 & Motion Pictures & Services & 535 & 67 & 8 \\
\hline 79 & $\begin{array}{c}\text { Amusement and Recreation } \\
\text { Services }\end{array}$ & Services & 2357 & 306 & 8 \\
\hline 81 & Legal Services & Services & 1869 & 25 & 75 \\
\hline 83 & Social Services & Services & 2755 & 109 & 25 \\
\hline 84 & $\begin{array}{c}\text { Museums, Art Galleries and } \\
\text { Botanical and Zoological Gardens }\end{array}$ & Services & 125 & 15 & 8 \\
\hline 86 & Membership Organizations & Services & 3025 & 125 & 24 \\
\hline 87 & $\begin{array}{c}\text { Engineering, Accounting, } \\
\text { Research, and Management } \\
\text { Services }\end{array}$ & Services & 7927 & 198 & 40 \\
\hline 89 & Services, Not Elsewhere Classified & Services & 734 & 46 & 16 \\
\hline
\end{tabular}




\section{A.2.1 Percent of Sector-Level Employment in Industries with Diverging Trends}

Table (2) provides more detail for Figure (2) in the main text and further highlights this degree of heterogeneity by displaying the exact percentages of employment in each sector and division across industries with diverging trends. In the column headings, $\alpha_{n}$ and $\alpha_{z}$ refer to the coefficients obtained from regressing the weighted average change in the HHI in each industry on the year with a constant at the national and ZIP code levels, respectively. The first three columns to the right of the sector and division descriptions show the percentage of employment in industries that have a positive national trend and positive, negative, and flat ZIP code trends, respectively. The last column displays the percentage of employment in industries with positive national trends located in industries that also have negative local trends. In all five divisions, over half of employment in industries with positive national trends is also located in industries that have declining concentration over time at the ZIP code level.

\section{B Robustness}

In the remainder of this appendix, we show that the benchmark results in the main text are robust to both different measures of market concentration, and to various modifications of the NETS database.

\section{B.1 Different Measures of Concentration}

While the figures in the main text all rely on the Herfindahl-Hirschman Index (HHI), here we replicate them for alternative measures of concentration. In particular, we look at the adjusted HHI, which modifies the HHI for the number of enterprises in a market, as well as the share of the top enterprise, as measured by sales, for each geography-industry-year grouping. For reasons discussed in more detail below, we believe the HHI used in the main text remains the best measure of concentration; however, the results in this section show that all the findings in the main text still hold using these alternative measures.

\section{B.1.1 Adjusted HHI}

Let $C_{i, g, t}$ denote the HHI for industry $i$ in geography $g$ in year $t$, and let $N_{i, g, t}$ denote the number of enterprises in this industry-geography-year grouping. Then $C_{i, g, t} \in\left[1 / N_{i, g, t}, 1\right]$. Because $C_{i, g, t}$ is bounded below by the inverse of the number of enterprises, comparisons of the HHI between groupings with different numbers of enterprises can be somewhat difficult. A grouping with only a handful of enterprises will tend to have a much higher HHI than a grouping with dozens of enterprises (or alternatively, the HHI in an industry-geography pair will tend to decrease over time if the number of enterprises in that pair increases).

In contrast, the adjusted Herfindahl-Hirschman Index for any pair with more than 1 enterprise can take on any value between 0 and 1, inclusive. In particular, the adjusted HHI of industry $i$ in geography $g$ in year $t, C_{i, g, t}^{*}$, can be defined as

$$
C_{i, g, t}^{*}=\left\{\begin{array}{ll}
\frac{C_{i, g, t}-\frac{1}{N_{i, g, t}}}{1-\frac{1}{N_{i, g, t}}} & N_{i, g, t}>1 \\
1 & N_{i, g, t}=1
\end{array} .\right.
$$

For groupings with a very large numbers of enterprises (for example, most groupings with a geography defined at 
Table 2: Percent of Sector Employment in Industries with Diverging Trends

\begin{tabular}{|c|c|c|c|c|c|c|}
\hline Division & SIC2 & Description & Pct. $\operatorname{Emp} \alpha_{n}>0, \alpha_{z}>0$ & Pct. $\operatorname{Emp} \alpha_{n}>0, \alpha_{z}<0$ & Pct. $\operatorname{Emp} \alpha_{n}>0, \alpha_{z}=0$ & Pct. Emp $\alpha_{z}<0 \mid \alpha_{n}>0$ \\
\hline $\mathrm{D}$ & & Manufacturing & 27.44 & 33.82 & 2.78 & 52.82 \\
\hline $\mathrm{D}$ & 20 & Food and Kindred Prod. & 36.94 & 29.6 & 3.66 & 42.16 \\
\hline $\mathrm{D}$ & 21 & Tobacoo Prod. & 17.18 & 0 & 3.79 & 0 \\
\hline $\mathrm{D}$ & 22 & Textile Mill Prod. & 43.54 & 29.4 & 5.14 & 37.65 \\
\hline $\mathrm{D}$ & 23 & $\begin{array}{l}\text { Apparel, Finished Prod. } \\
\text { from Fabrics }\end{array}$ & 52.12 & 23.91 & 1.8 & 30.72 \\
\hline $\mathrm{D}$ & 24 & $\begin{array}{c}\text { Lumber and Wood Prod., } \\
\text { Exc. Furn. }\end{array}$ & 26.47 & 33.53 & 1.28 & 54.71 \\
\hline $\mathrm{D}$ & 25 & Furniture and Fixtures & 52.83 & 18.31 & 2.51 & 24.86 \\
\hline $\mathrm{D}$ & 26 & Paper and Allied Prod. & 22.74 & 50.72 & 5.67 & 64.1 \\
\hline $\mathrm{D}$ & 27 & Printing and Publishing & 45.8 & 31.69 & .46 & 40.65 \\
\hline $\mathrm{D}$ & 28 & Chemicals and Allied Prod. & 16.81 & 30.4 & 2.78 & 60.81 \\
\hline $\mathrm{D}$ & 29 & Petroleum Refining & 72.23 & 11.37 & .85 & 13.46 \\
\hline $\mathrm{D}$ & 30 & $\begin{array}{c}\text { Rubber and Misc. Plastic } \\
\text { Prod. }\end{array}$ & 22.11 & 49.7 & 2.95 & 66.48 \\
\hline $\mathrm{D}$ & 31 & Leather and Leather Prod. & 52.53 & 26.01 & 4.4 & 31.36 \\
\hline $\mathrm{D}$ & 32 & $\begin{array}{l}\text { Stone Clay, Glass, and } \\
\text { Concrete Prod. }\end{array}$ & 18.33 & 39.32 & 4.07 & 63.7 \\
\hline $\mathrm{D}$ & 33 & Primary Metal Ind. & 22.1 & 34.83 & 3.92 & 57.24 \\
\hline $\mathrm{D}$ & 34 & Fabricated Metal Prod. & 23.39 & 32.32 & 2.57 & 55.46 \\
\hline $\mathrm{D}$ & 35 & $\begin{array}{l}\text { Ind. and Comm. Machinery } \\
\text { and Comp. Equip. }\end{array}$ & 24.94 & 31.52 & 2.61 & 53.36 \\
\hline $\mathrm{D}$ & 36 & $\begin{array}{c}\text { Electronic and Electric } \\
\text { Equip. }\end{array}$ & 14.41 & 39.46 & 2.26 & 70.31 \\
\hline $\mathrm{D}$ & 37 & Transport. Equip. & 13.73 & 33.97 & 2.94 & 67.09 \\
\hline $\mathrm{D}$ & 38 & $\begin{array}{c}\text { Instruments and Related } \\
\text { Products }\end{array}$ & 21.72 & 43.76 & 3.72 & 63.24 \\
\hline $\mathrm{D}$ & 39 & Misc. Manufact. Ind. & 27.57 & 25.11 & 2.71 & 45.33 \\
\hline $\mathrm{F}$ & & Wholesale Trade & 34.17 & 39.01 & .18 & 53.17 \\
\hline $\mathrm{F}$ & 50 & Wholesale- Durable Goods & 31.65 & 39.71 & .19 & 55.5 \\
\hline $\mathrm{F}$ & 51 & $\begin{array}{l}\text { Wholesale- Nondurable } \\
\text { Goods }\end{array}$ & 38.18 & 37.89 & .16 & 49.7 \\
\hline G & & Retail Trade & 14.57 & 52.71 & .01 & 78.33 \\
\hline G & 52 & $\begin{array}{c}\text { Bldg. Materials and Garden. } \\
\text { Supp. }\end{array}$ & 47.91 & 31.25 & .06 & 39.45 \\
\hline $\mathrm{G}$ & 53 & Gen. Merch. Stores & 1.83 & 96.38 & 0 & 98.14 \\
\hline $\mathrm{G}$ & 54 & Food Stores & 21.69 & 70.27 & 0 & 76.41 \\
\hline G & 55 & $\begin{array}{c}\text { Auto. Dealers and Service } \\
\text { Stations }\end{array}$ & 7.27 & 77.5 & .01 & 91.41 \\
\hline G & 56 & Apparel and Access. Stores & 6.42 & 77.24 & 0 & 92.33 \\
\hline G & 57 & Furn. and Homefurn. Stores & 20.92 & 55.51 & .02 & 72.6 \\
\hline G & 58 & Eating and Drinking Places & 4.66 & 26.43 & .01 & 85 \\
\hline G & 59 & Misc. Retail & 30.94 & 42.54 & 0 & 57.89 \\
\hline $\mathrm{H}$ & & $\begin{array}{c}\text { Finance, Insurance, and Real } \\
\text { Estate }\end{array}$ & 14.26 & 46.17 & .04 & 76.35 \\
\hline $\mathrm{H}$ & 60 & Depository Inst. & 12.23 & 75.44 & .01 & 86.04 \\
\hline $\mathrm{H}$ & 61 & Nondepository Inst. & 11.27 & 38.33 & .06 & 77.19 \\
\hline $\mathrm{H}$ & 62 & $\begin{array}{c}\text { Security and Commod. } \\
\text { Brokers }\end{array}$ & 15.37 & 13.58 & .03 & 46.86 \\
\hline $\mathrm{H}$ & 63 & Insurance Carr. & 42.88 & 17.58 & .23 & 28.97 \\
\hline $\mathrm{H}$ & 64 & $\begin{array}{l}\text { Ins. Agents, Brokers, and } \\
\text { Service }\end{array}$ & 7.01 & 12.78 & 0 & 64.6 \\
\hline $\mathrm{H}$ & 65 & Real Estate & 6.77 & 69.86 & .01 & 91.16 \\
\hline $\mathrm{H}$ & 67 & $\begin{array}{l}\text { Holding and Oth. Invest. } \\
\text { Offices }\end{array}$ & 19.81 & 27.48 & .04 & 58.06 \\
\hline $\mathrm{I}$ & & Services & 10.14 & 41.02 & .02 & 80.15 \\
\hline I & 70 & Hotels and Lodging Places & 13.51 & 40.79 & 0 & 75.12 \\
\hline I & 72 & Personal Serv. & 5.11 & 53.34 & .15 & 91.03 \\
\hline I & 73 & Business Serv. & 20.89 & 34.85 & .01 & 62.5 \\
\hline I & 75 & $\begin{array}{c}\text { Auto Repair, Serv., and } \\
\text { Park. }\end{array}$ & 8.29 & 43.55 & .01 & 84 \\
\hline I & 76 & Misc. Repair Serv. & 18.42 & 40.68 & .04 & 68.78 \\
\hline $\mathrm{I}$ & 78 & Motion Pict. & 37.54 & 47.23 & .05 & 55.68 \\
\hline $\mathrm{I}$ & 79 & Amusement and Rec. Serv. & 5.12 & 36.38 & .06 & 87.52 \\
\hline $\mathrm{I}$ & 81 & Legal Services & .11 & 26.45 & 0 & 99.59 \\
\hline $\mathrm{I}$ & 83 & Social Services & .66 & 70.49 & 0 & 99.07 \\
\hline I & 84 & Museums, Art Gall., Zoos & 2.95 & 3.99 & .18 & 56.1 \\
\hline I & 86 & Membership Org. & .67 & 54.62 & 0 & 98.78 \\
\hline I & 87 & $\begin{array}{c}\text { Engineering and Mgmt. } \\
\text { Services }\end{array}$ & 4.77 & 35.14 & 0 & 88.04 \\
\hline I & 88 & Private Households & 3.76 & 65.14 & 23.72 & 70.33 \\
\hline I & 89 & Misc. Serv. & 1.09 & 17.75 & 0 & 94.22 \\
\hline
\end{tabular}


Figure 8: Adjusted HHI: Diverging national and local concentration trends

a) Average Change in Adjusted HHI from First Year

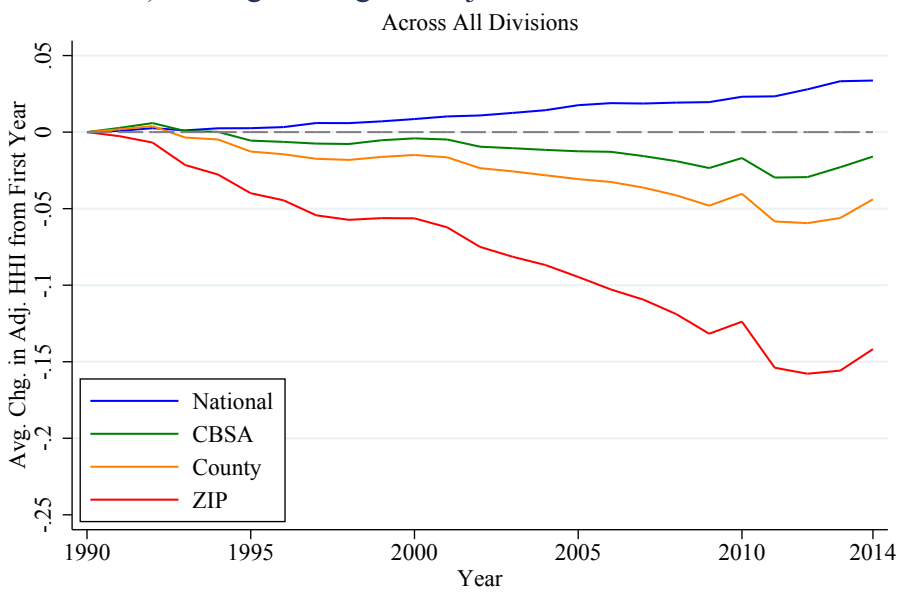

b) Average Change in Adjusted HHI from First Year National and ZIP Levels, for Each Division

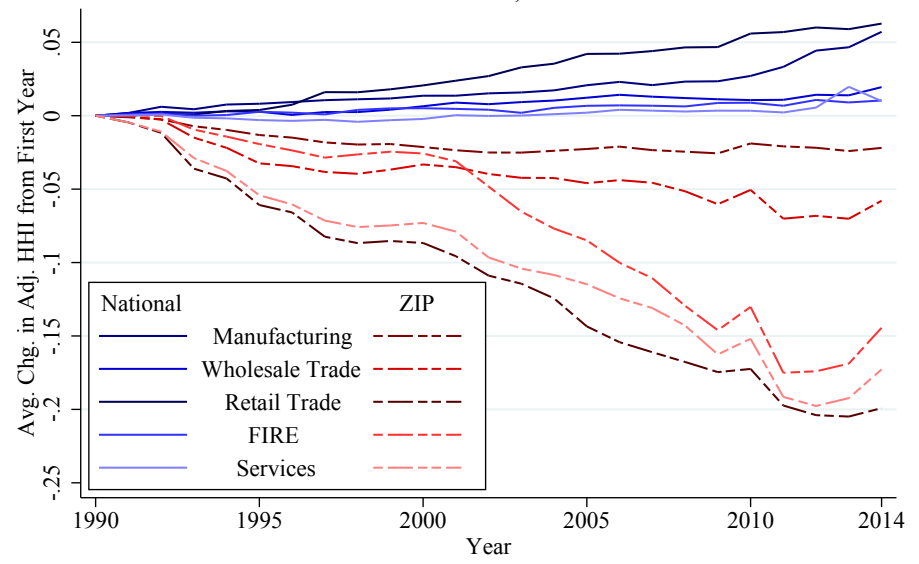

the national level), the adjusted and unadjusted HHIs will be very close. However, groupings defined at the ZIP code level typically have a small number of enterprises, leading to potentially large differences between the adjusted and unadjusted measures. In such cases, the unadjusted HHI is preferable because, in some sense, the number of an enterprises in a market itself partly determines concentration. That is, a market with, say, 3 enterprises is arguably more concentrated than a market with 10, even if all enterprises have equal sales in both markets.

The 5 figures below replicate the figures in the main text using the adjusted HHI. Overall, these results are remarkably similar to the corresponding figures in the main text. The lines corresponding to concentration measured at the national level in Figures (8) and (10) are not discernibly different from the corresponding lines calculated using the unadjusted HHI in Figures (1) and (3), respectively, in the main text. This observation is unsurprising given that most SIC 8 codes have a large number of enterprises at the national level. On the other hand, when concentration is measured at the ZIP code level, these figures show that concentration actually falls slightly more when using the adjusted HHI. Given that over $70 \%$ of ZIP code-SIC 8 pairs have only one enterprise in their first year in the NETS dataset (i.e. have an adjusted and unadjusted HHI of 1), this trend reflects the fact that as more firms enter ZIP code-industry pairs, the adjusted HHI will tend to fall more than its unadjusted counterpart, because its lower bound is 0 regardless of the number of firms. In Figure (12), the average fall in the adjusted HHI when Walmart enters a ZIP code within its primary industry is over 0.1 more than the fall in the HHI shown in Figure (5) of the main text.

\section{B.1.2 Share of Top Enterprise}

Another common measure of market concentration is the concentration ratio, which looks at the total market share accounted for by a certain number of top firms in a market. Here, we measure concentration in a geographyindustry-year grouping as that pair's share of total sales in the top enterprise measured by sales. This share will obviously equal 1 for any geography-industry-year groupings with only one enterprise.

We prefer the HHI as a measure of concentration because the HHI captures in a more precise way the entire distribution of market shares. The share of the top enterprise fails to capture any variation in the structure of 
Figure 9: Adjusted HHI: Pervasive diverging trends across 2-digit sectors

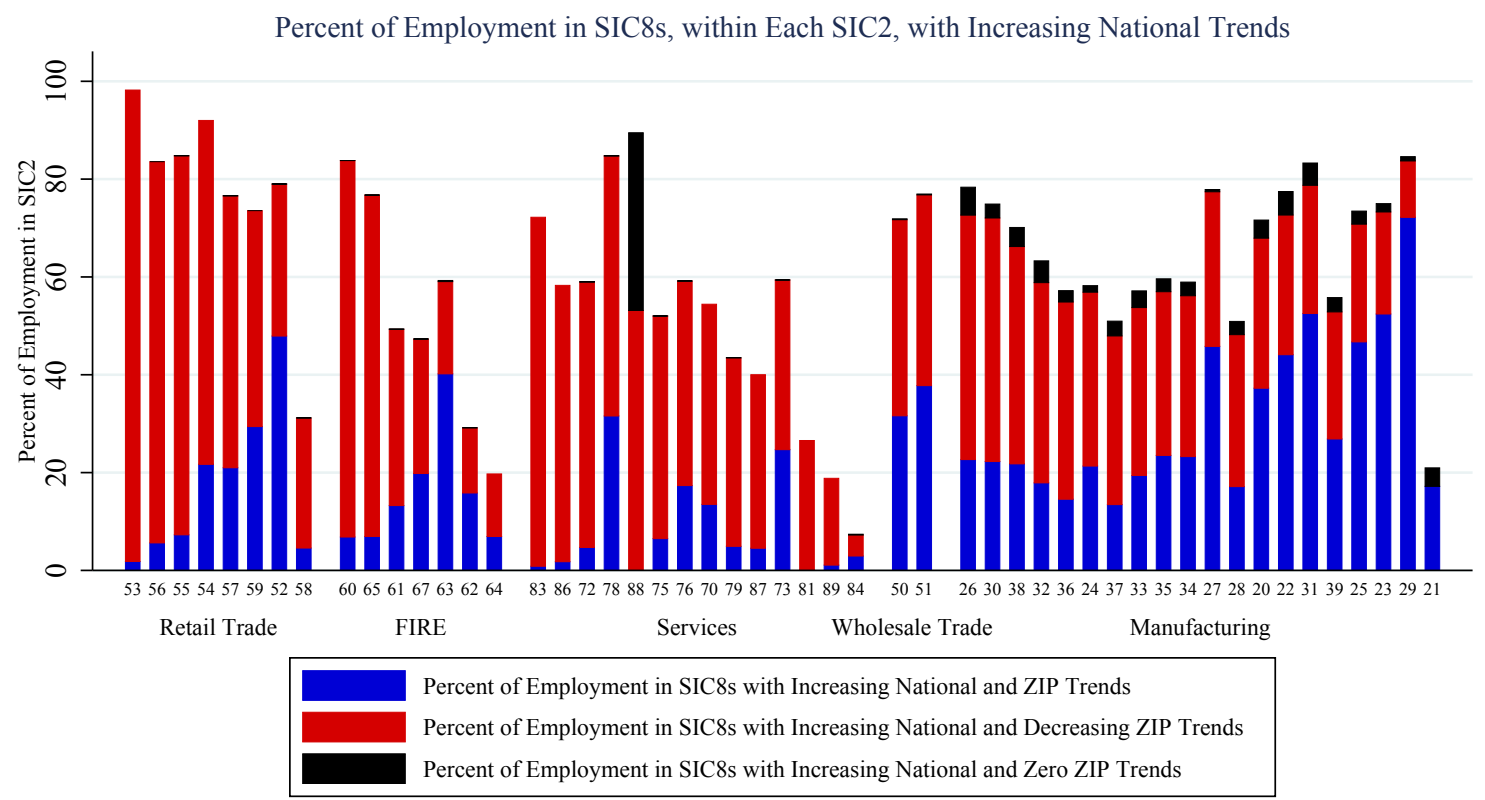

Figure 10: Adjusted HHI: The role of top firms in national and local concentration trends
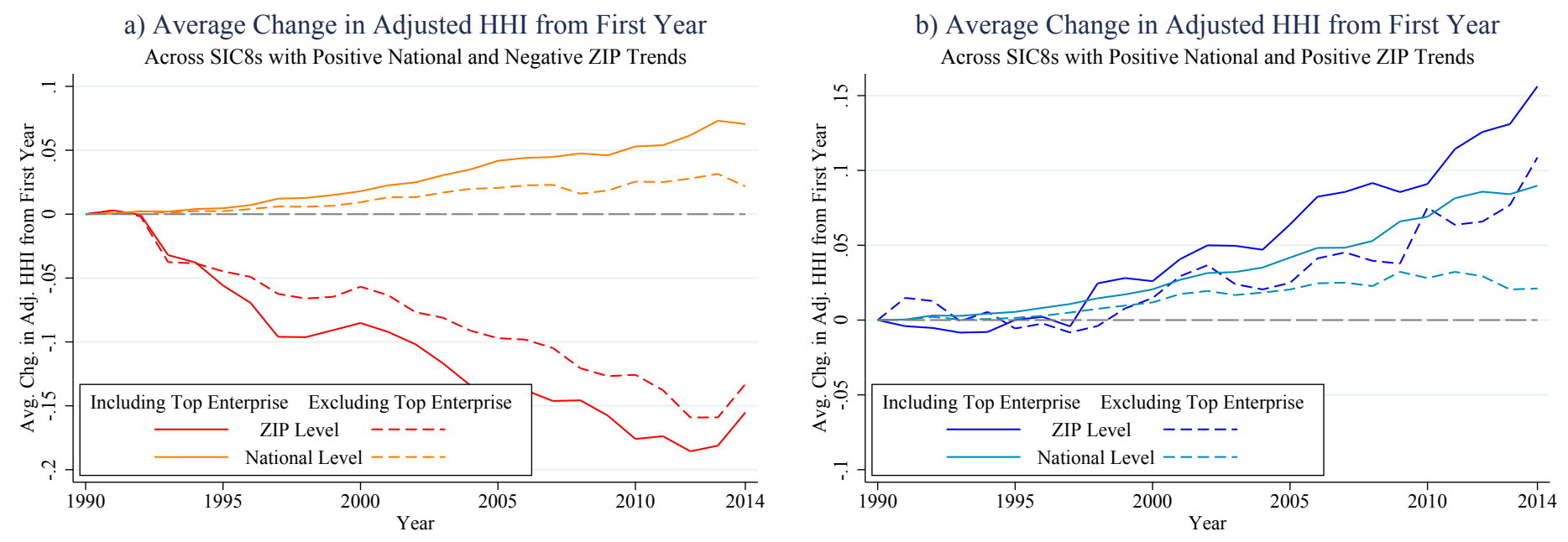

market shares among enterprises beyond the top enterprise. For instance, this measure would conclude that among two markets in which the top enterprises control $60 \%$ of total sales, a market in which there is only one other enterprise comprising the remaining $40 \%$ of sales is just as concentrated as one in which ten enterprises each have $4 \%$ of sales. In contrast, the HHI would indicate considerably more concentration in the first market.

Nevertheless, as shown in the 5 figures below, using the share of the top enterprise leaves our key results in the main text unchanged. In Figures (13) and (15), we can see that the decline in concentration at the ZIP code level is slightly less pronounced using this measure, while concentration generally increases slightly more as measured at the national level. The overall movements and trends of concentration are the same here as in the main text. As shown in Figure (14), it is also still the case that a substantial portion of employment (approximately 42\%) 
Figure 11: Adjusted HHI: Effect on concentration when a top firm enters a local market
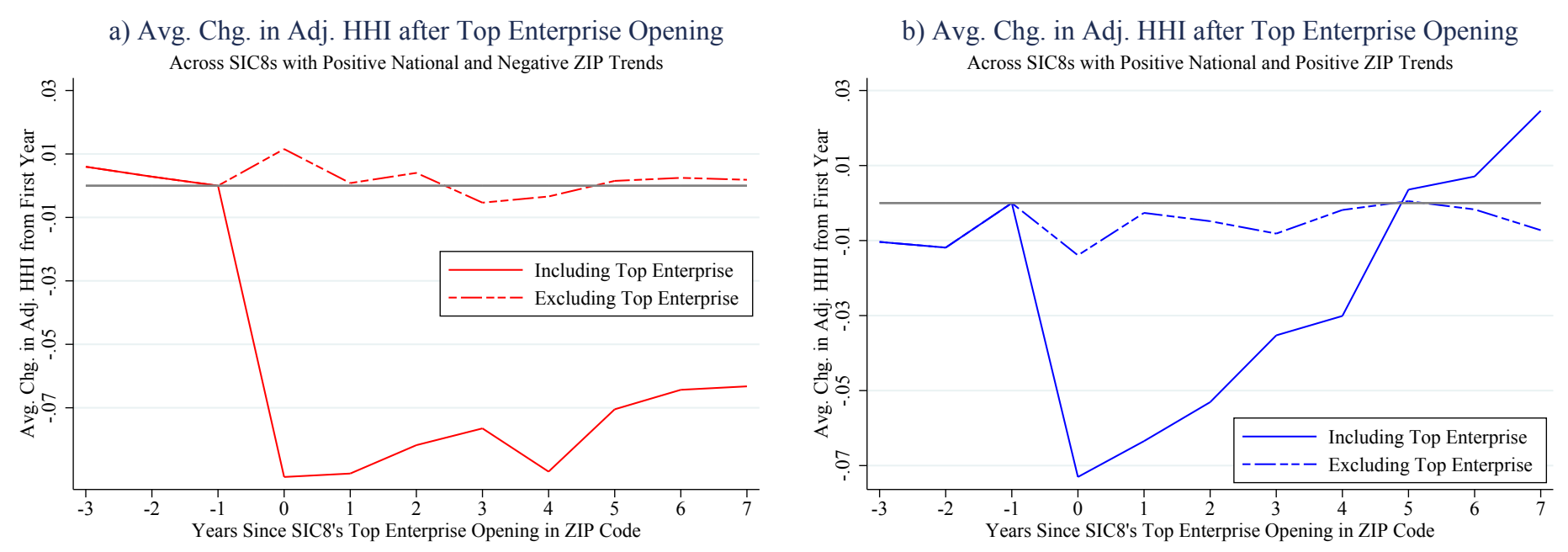

Figure 12: Adjusted HHI: Effect on concentration when Walmart enters a local market

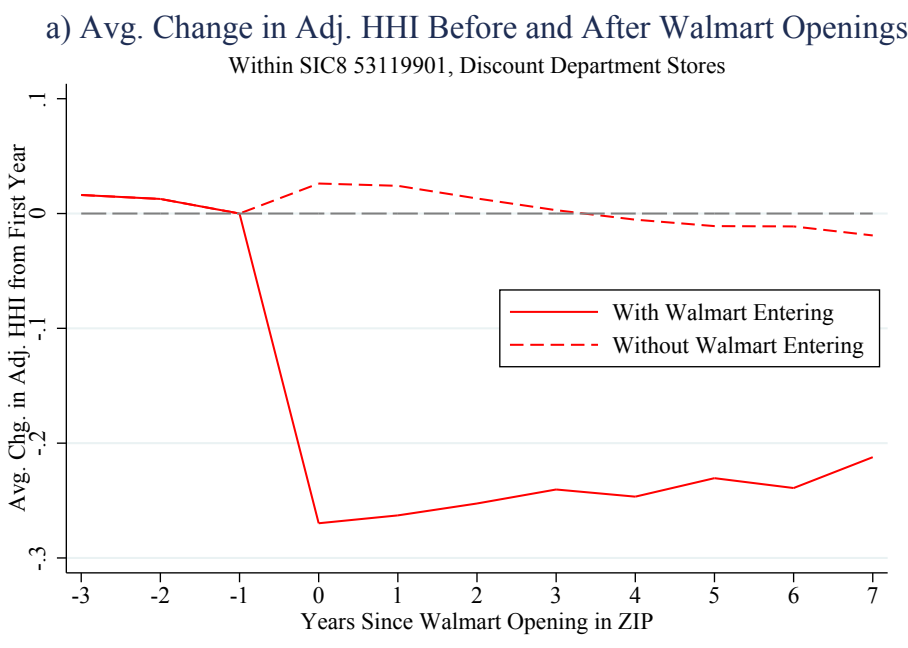

resides in industries with increasing concentration at the national level and decreasing concentration at the local level. Compared to Figure (2) in the main text, some SIC 2 sectors, such as SIC 287 (Engineering \& Management Services), have a slightly lower share of employment in industries with such diverging trends. Furthermore, Figure (16a) shows that in industries with diverging trends, the share of the top enterprise in each industry-ZIP code pair also falls upon entry of that industry's top enterprise.

\section{B.2 Removing Nonemployer Enterprises}

As discussed above, this section contains two modifications to the NETS database in order to reduce the occurrence of nonemployer establishments in the data. The first modification, removing enterprise-year pairs with only one employee, likely leaves a large number of nonemployment establishments remaining, while dropping enterprise-year pairs with four or fewer employees probably overstates the prevalence of such establishments. 
Figure 13: Share of Top Enterprise: Diverging national and local concentration trends

a) Average Change in Top 1 Share from First Year Across All Divisions

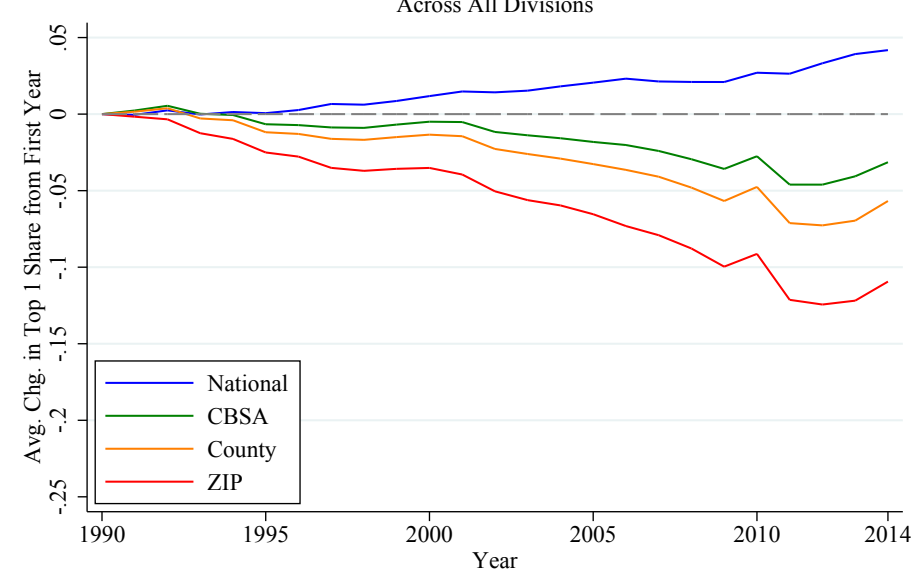

b) Average Change in Top 1 Share from First Year National and ZIP Levels, for Each Division

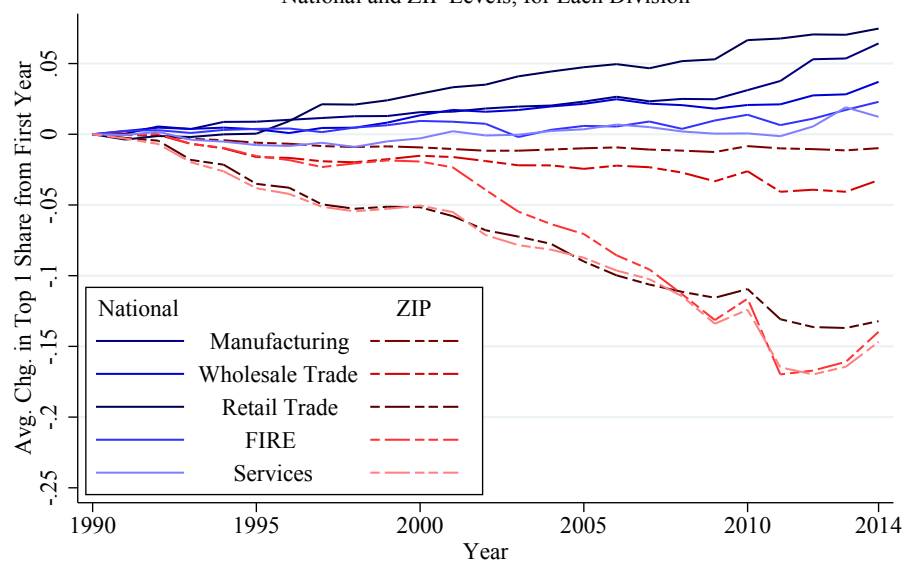

Figure 14: Share of Top Enterprise: Pervasive diverging trends across 2-digit sectors

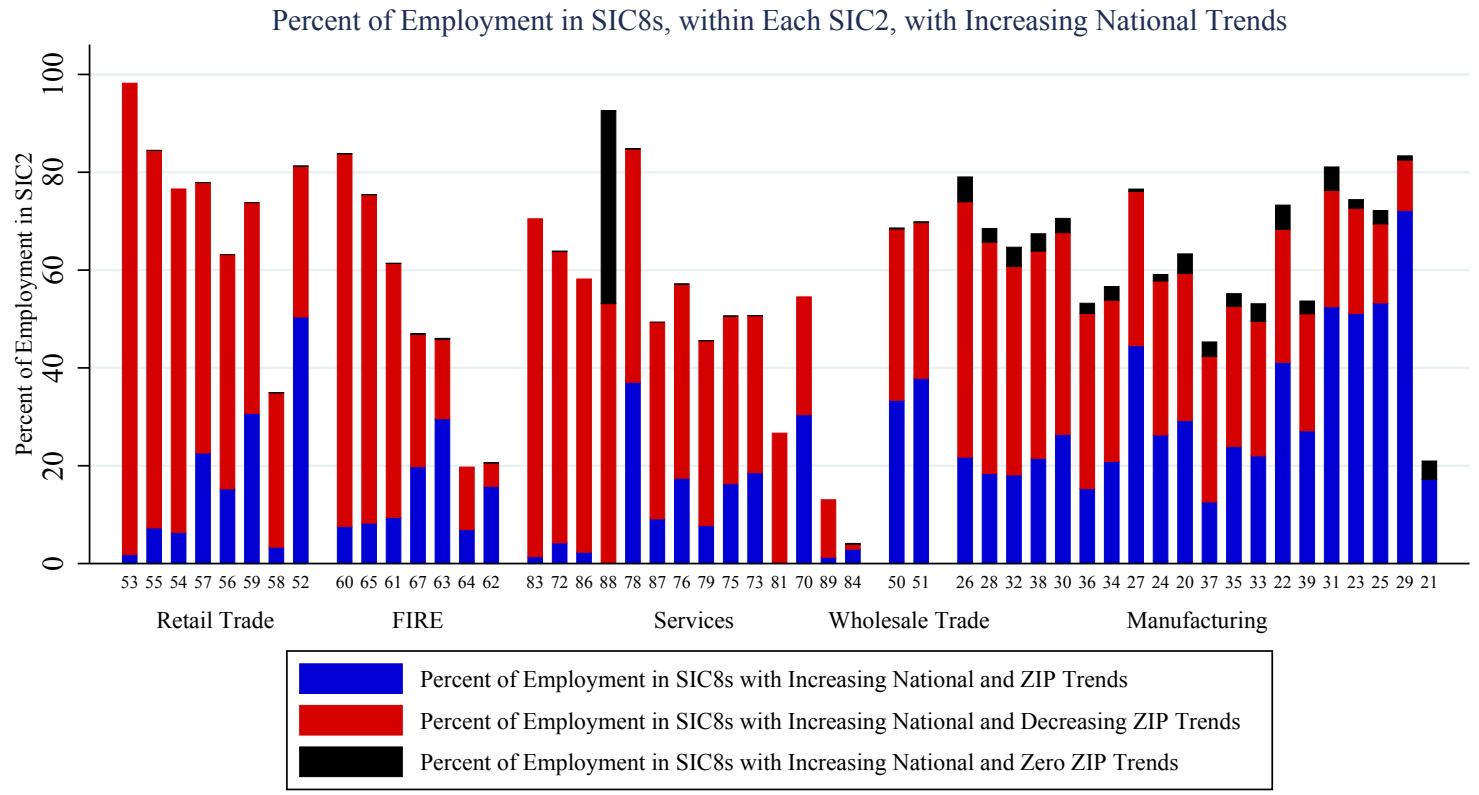

\section{B.2.1 Removing Enterprises with Only 1 Employee}

The figures below present results excluding, in each year, the sales and employment of enterprises with only 1 employee ${ }^{29}$ There are no substantial changes from the corresponding results in the main text.

\footnotetext{
${ }^{29}$ That is, we exclude the sales of each establishment when calculating the HHI and exclude the employment when calculating geographyindustry-year employment for taking weighted averages.
} 
Figure 15: Share of Top Enterprise: The role of top firms in national and local concentration trends

a) Average Change in Top 1 Share from First Year Across SIC8s with Positive National and Negative ZIP Trends

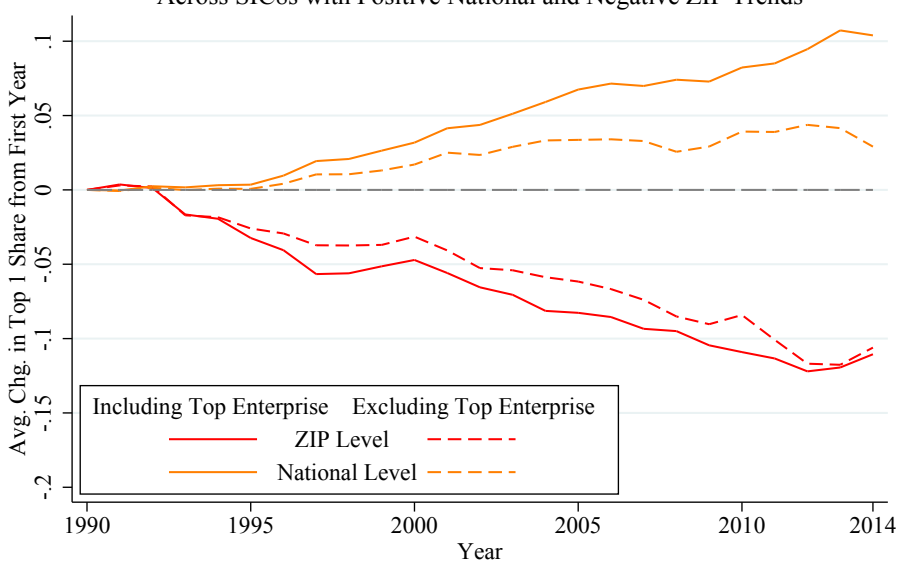

b) Average Change in Top 1 Share from First Year Across SIC8s with Positive National and Positive ZIP Trends

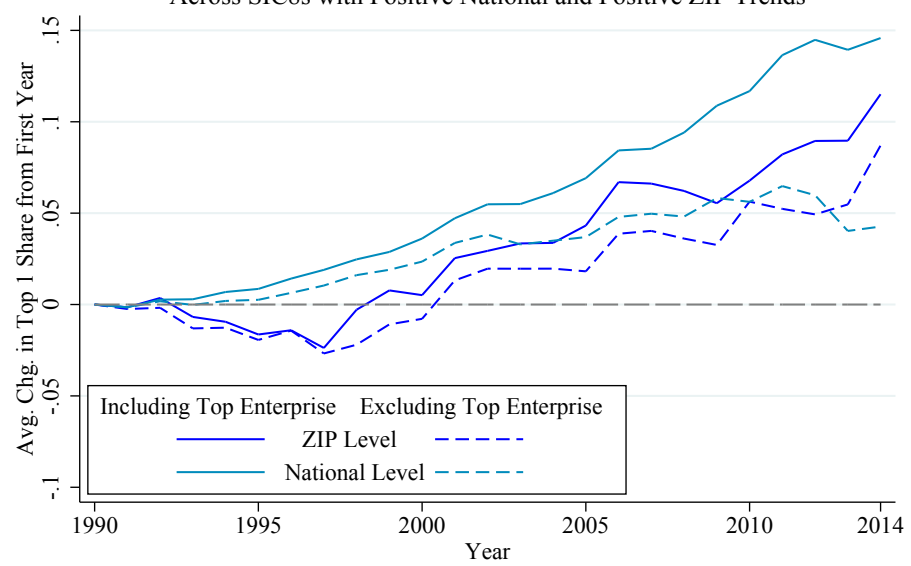

Figure 16: Share of Top Enterprise: Effect on concentration when a top firm enters a local market

a) Avg. Chg. in Top 1 Share after Top Enterprise Opening Across SIC8s with Positive National and Negative ZIP Trends

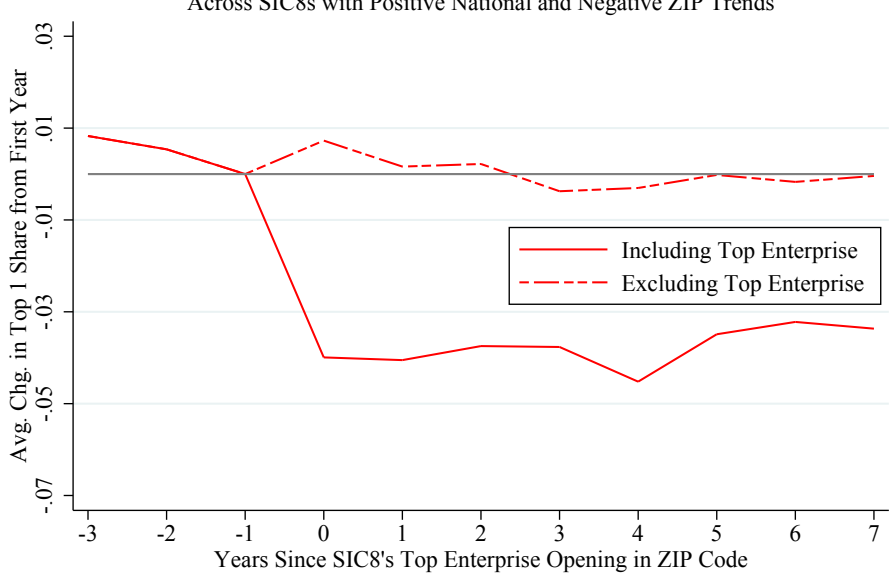

b) Avg. Chg. in Top 1 Share after Top Enterprise Opening Across SIC8s with Positive National and Positive ZIP Trends

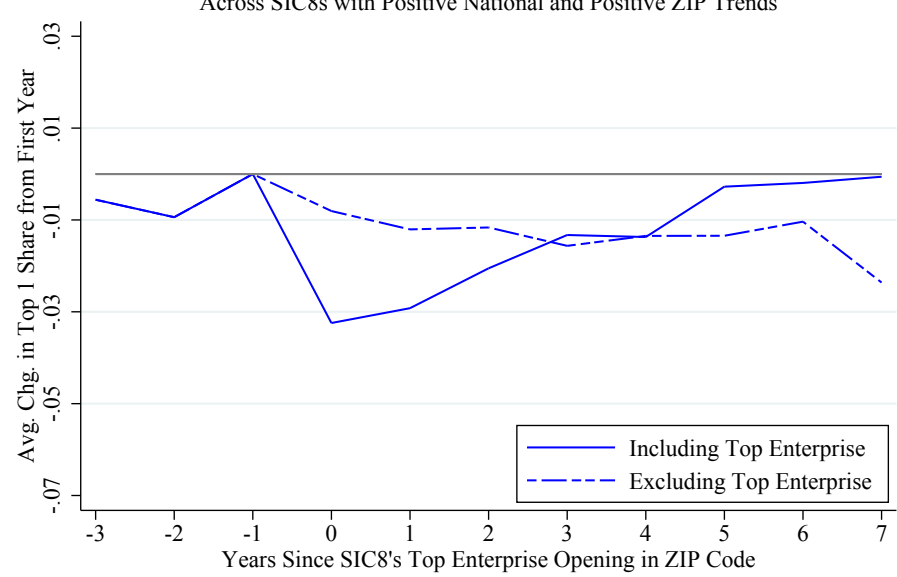

Figure 17: Share of Top Enterprise: Effect on concentration when Walmart enters a local market

a) Avg. Chg. in Top 1 Share Before and After Walmart Openings

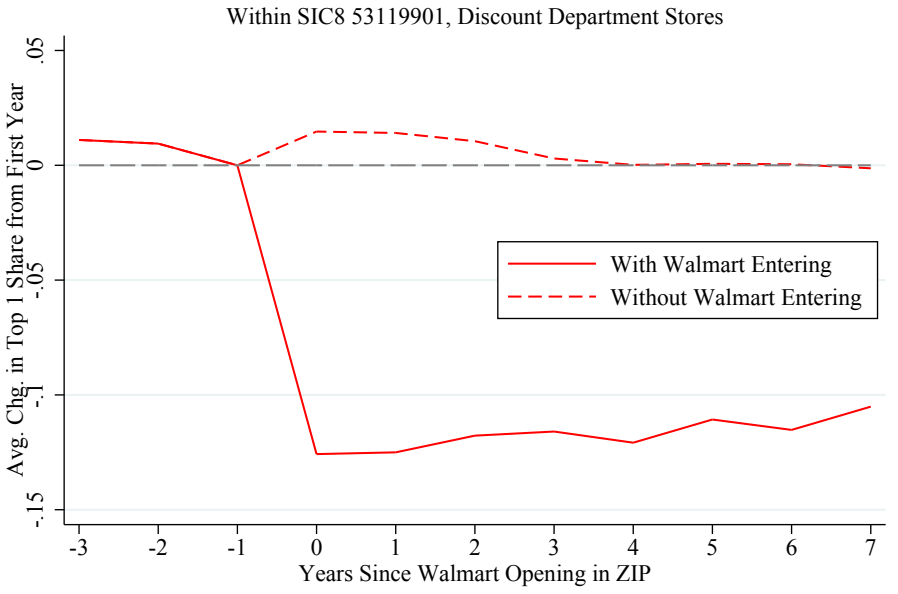


Figure 18: Removing Enterprises with One Employee: Diverging national and local concentration trends

a) Average Change in HHI from First Year Across All Divisions

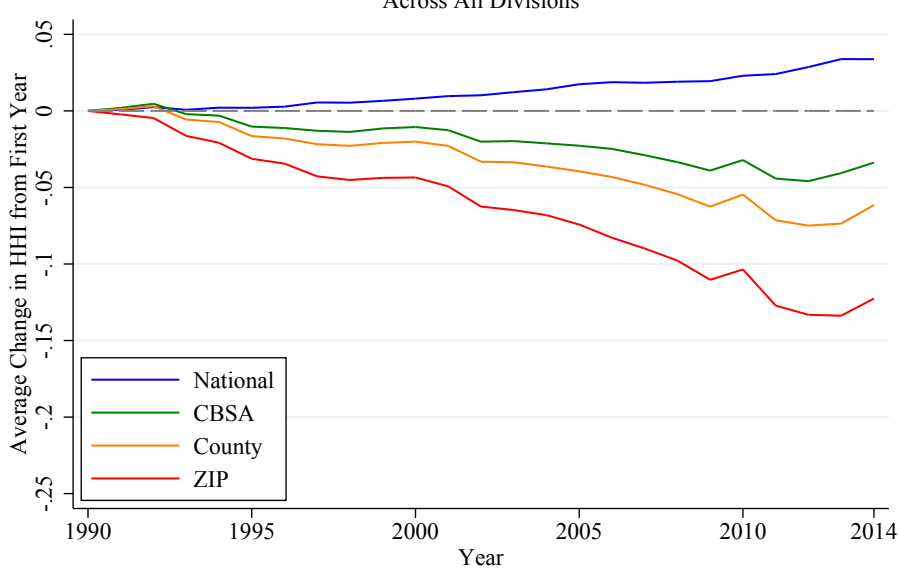

b) Average Change in HHI from First Year National and ZIP Levels, for Each Division

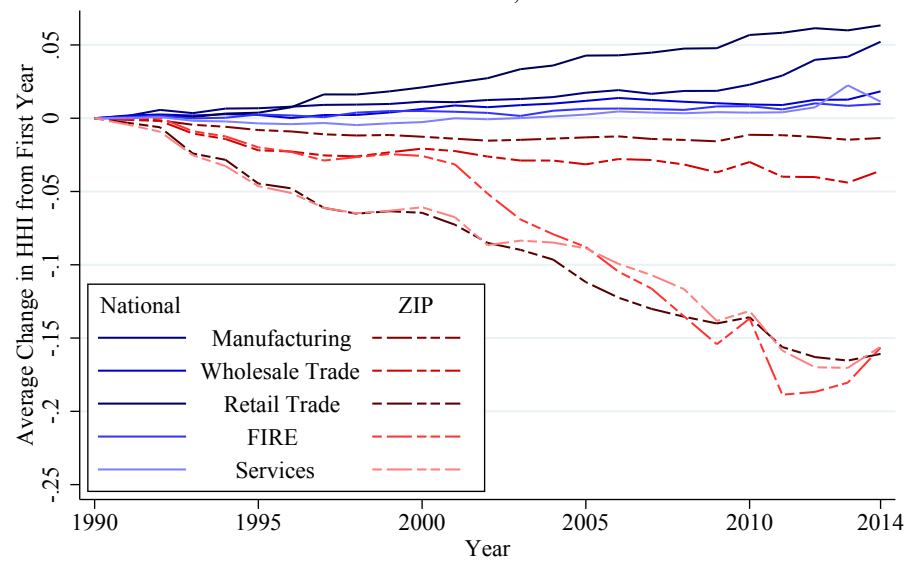

Figure 19: Removing Enterprises with One Employee: Pervasive diverging trends across 2-digit sectors

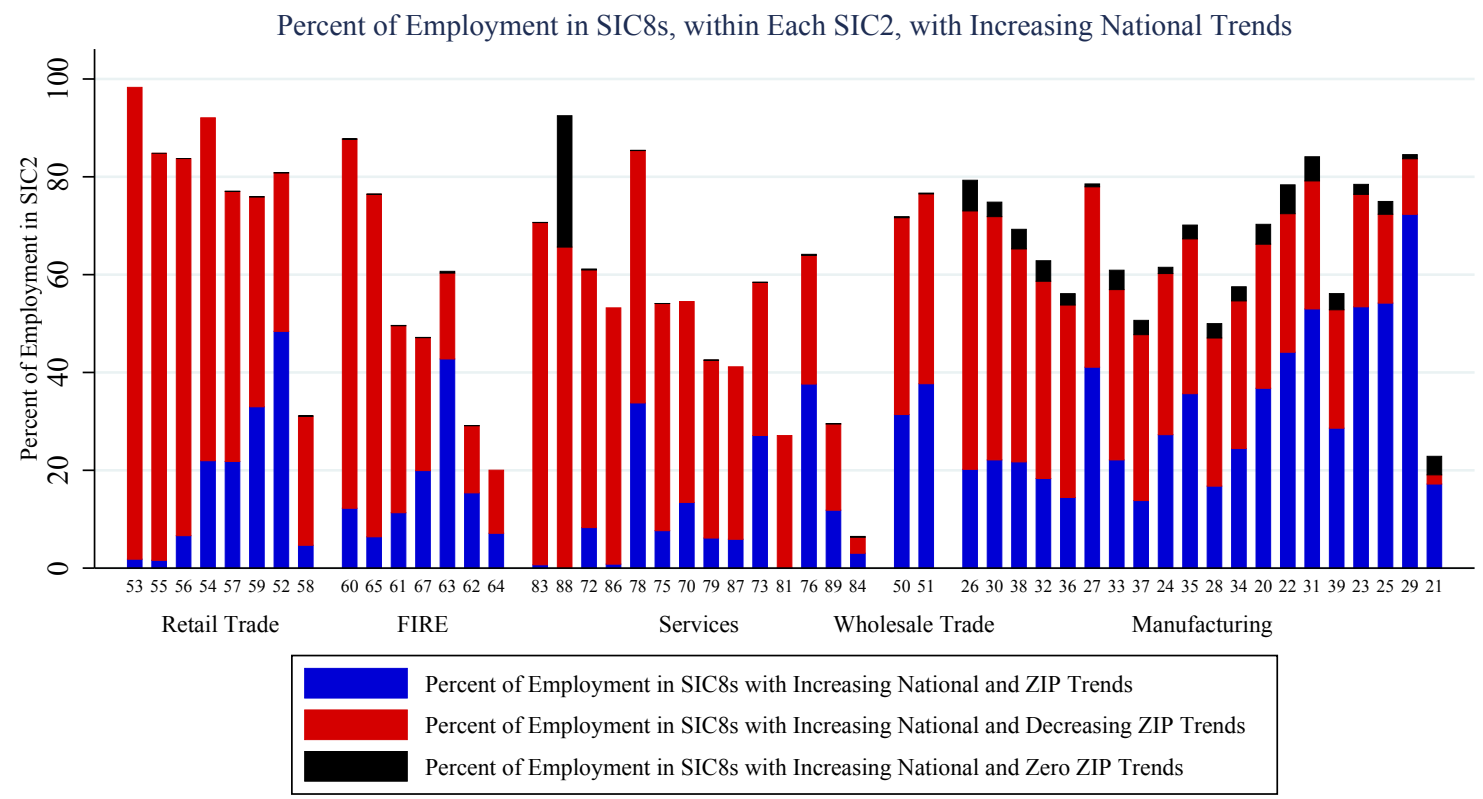


Figure 20: Removing Enterprises with One Employee: The role of top firms in national and local concentration trends

a) Average Change in HHI from First Year Across SIC8s with Positive National and Negative ZIP Trends

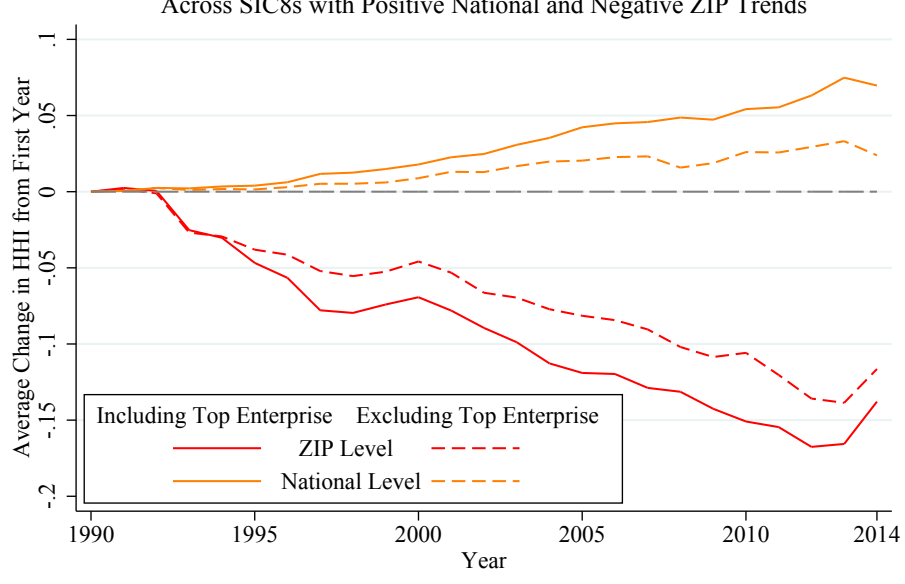

b) Average Change in HHI from First Year Across SIC8s with Positive National and Positive ZIP Trends

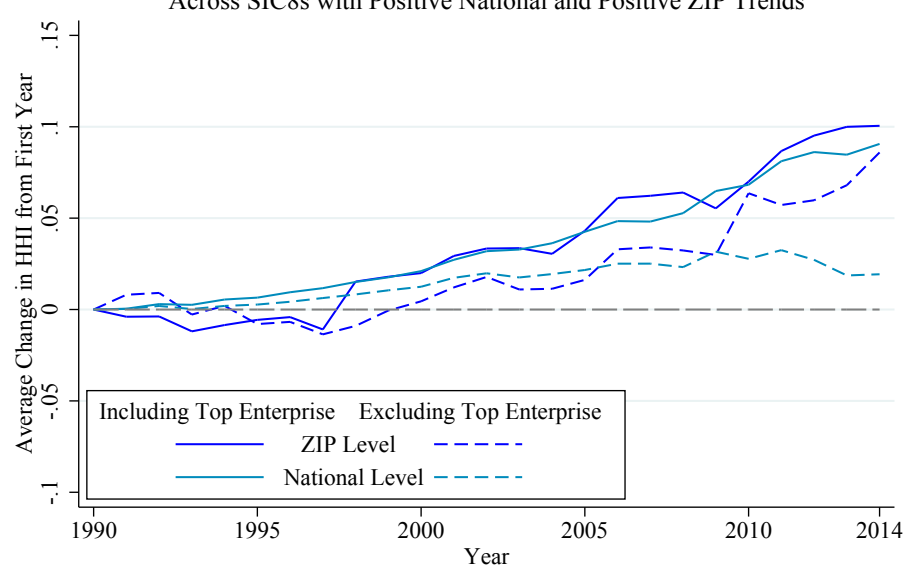

Figure 21: Removing Enterprises with One Employee: Effect on concentration when a top firm enters a local market

a) Average Change in $\mathrm{HHI}$ after Top Enterprise Opening Across SIC8s with Positive National and Negative ZIP Trends

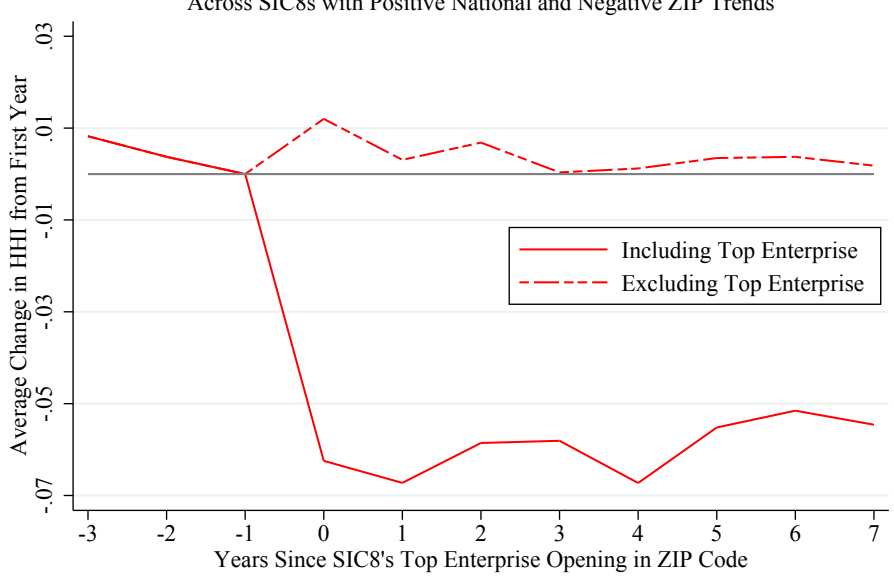

b) Average Change in HHI after Top Enterprise Opening Across SIC8s with Positive National and Positive ZIP Trends

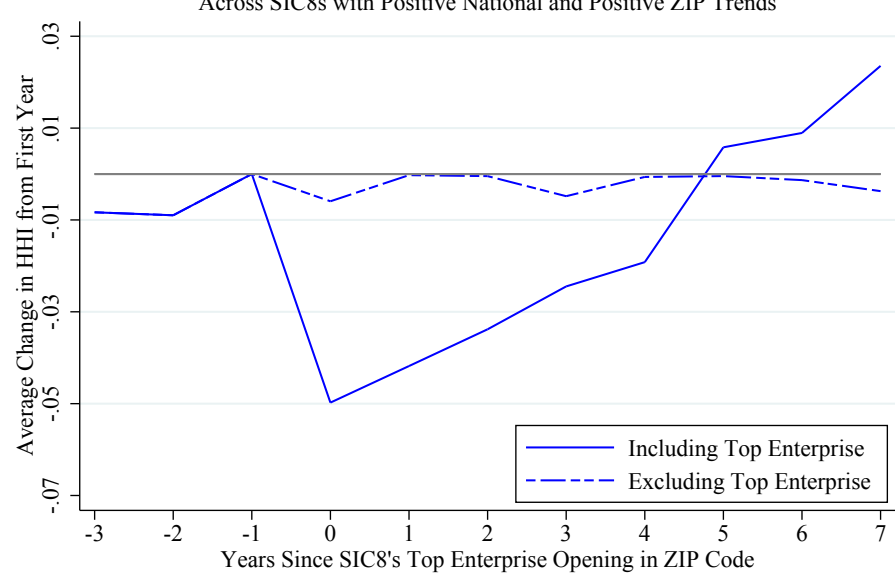

Figure 22: Removing Enterprises with One Employee: Effect on concentration when Walmart enters a local market

a) Average Change in HHI Before and After Walmart Openings Within SIC8 53119901, Discount Department Stores

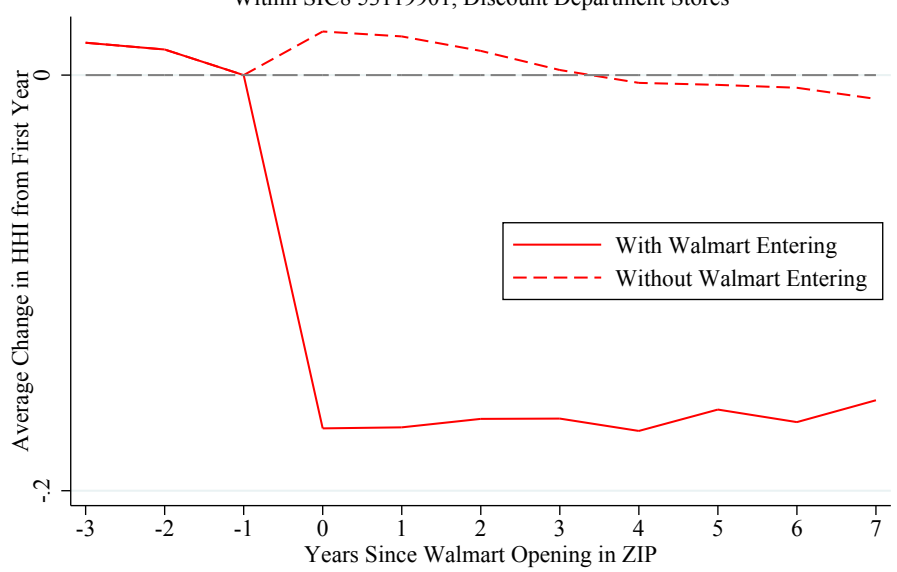

b) Avg. Number of Estab. Before and After Walmart Openings Within SIC8 53119901, Discount Department Stores

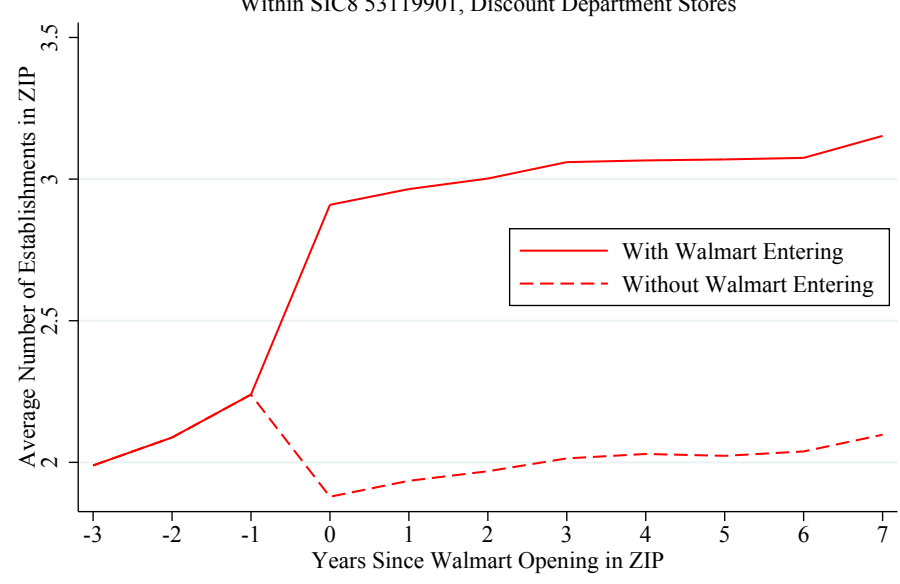


Figure 23: Removing Enterprises with Fewer than 5 Employees: Diverging national and local concentration trends

a) Average Change in HHI from First Year Across All Divisions

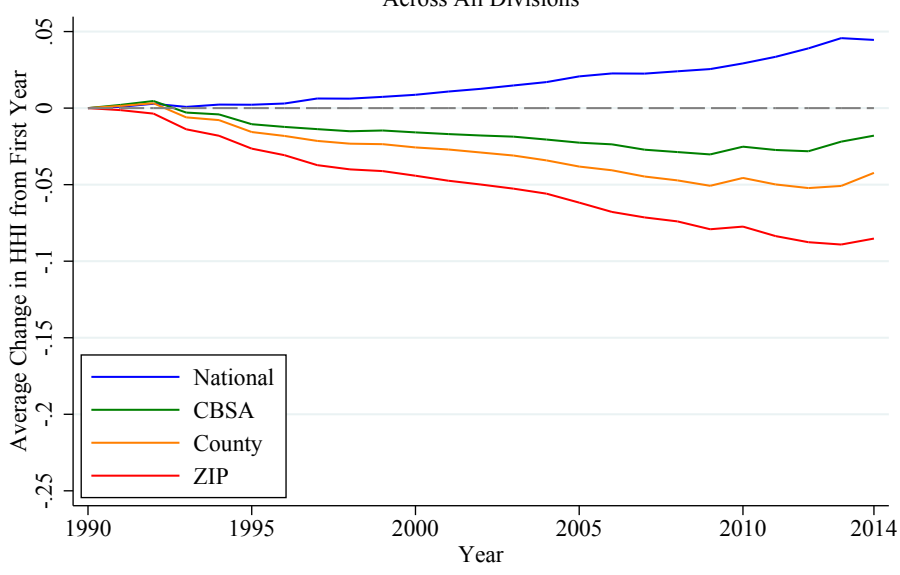

b) Average Change in HHI from First Year National and ZIP Levels, for Each Division

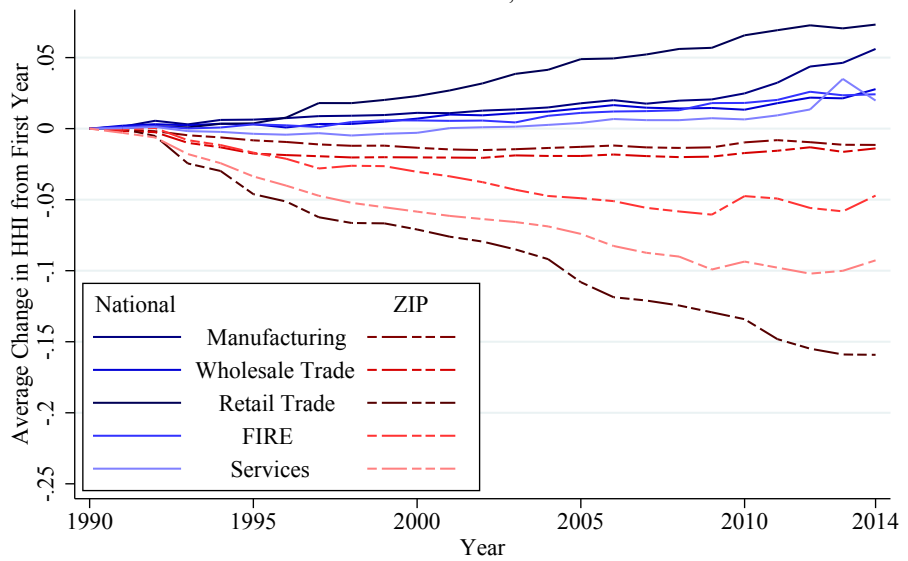

Figure 24: Removing Enterprises with Fewer than 5 Employees: Pervasive diverging trends across 2-digit sectors

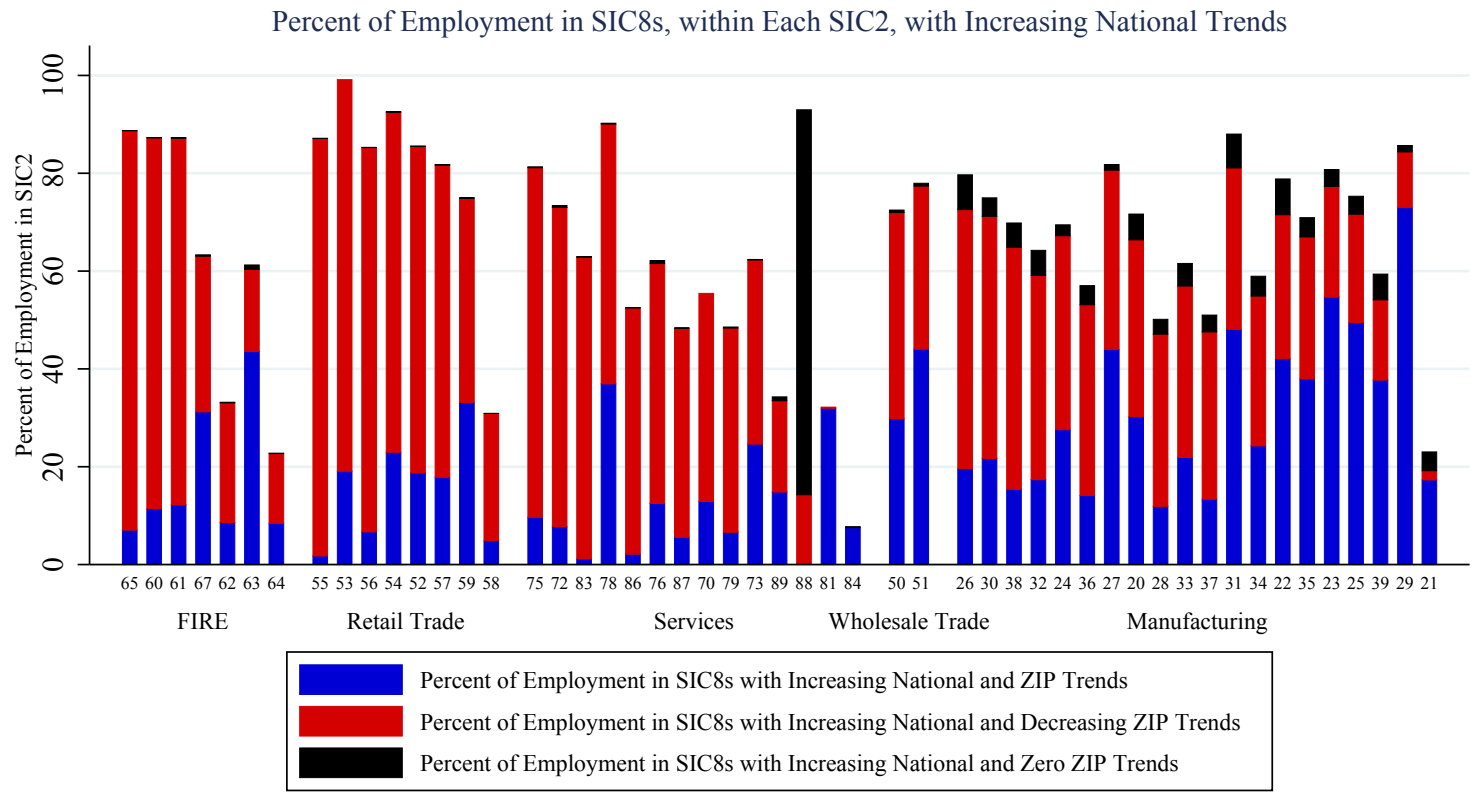

\section{B.2.2 Removing Enterprises with Fewer than 5 Employees}

Here we reproduce the main text figures excluding, in each year, enterprises with fewer than five employees. Figure (23) shows that the decrease in concentration at more local levels is somewhat less pronounced here than in Figure (1) in the main text, while Figure (24) reveals some sectors, including General Merchandise Stores (SIC 2 53), have a modestly lower share of employment in industries with diverging trends. On the other hand, in Figures (25) and (26), the downward effect of top enterprises on local concentration in industries with diverging trends is actually more pronounced. 
Figure 25: Removing Enterprises with Fewer than 5 Employees: The role of top firms in national and local concentration trends
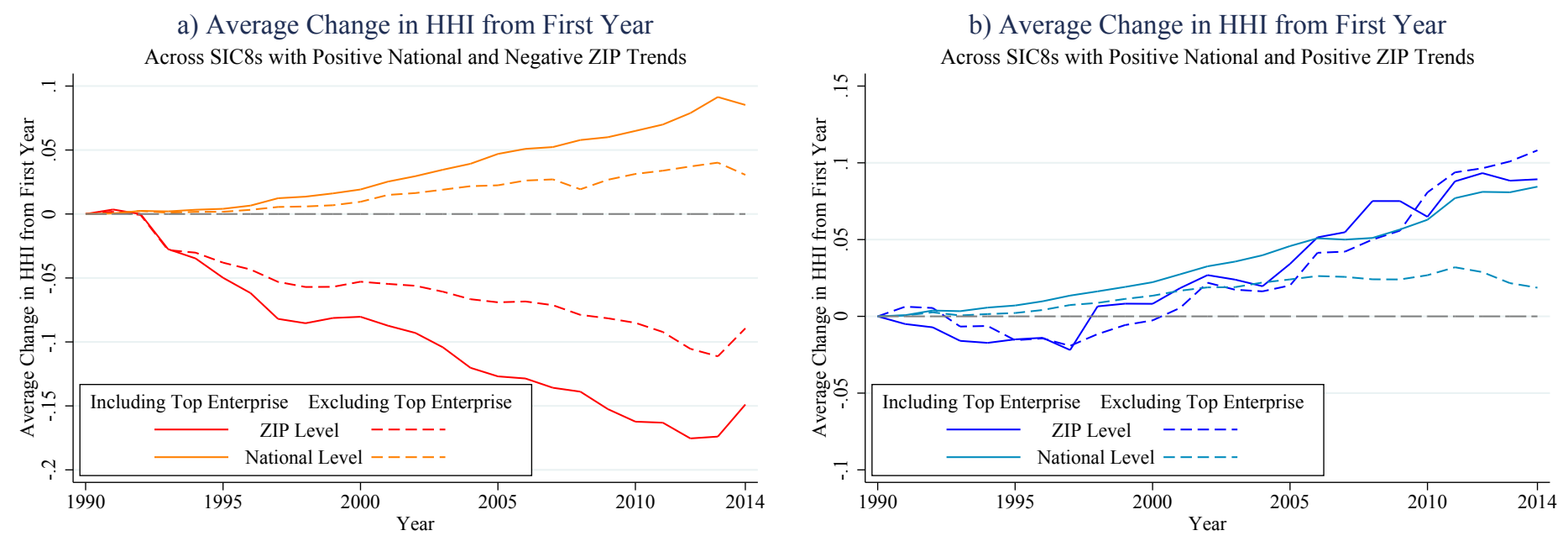

Figure 26: Removing Enterprises with Fewer than 5 Employees: Effect on concentration when a top firm enters a local market
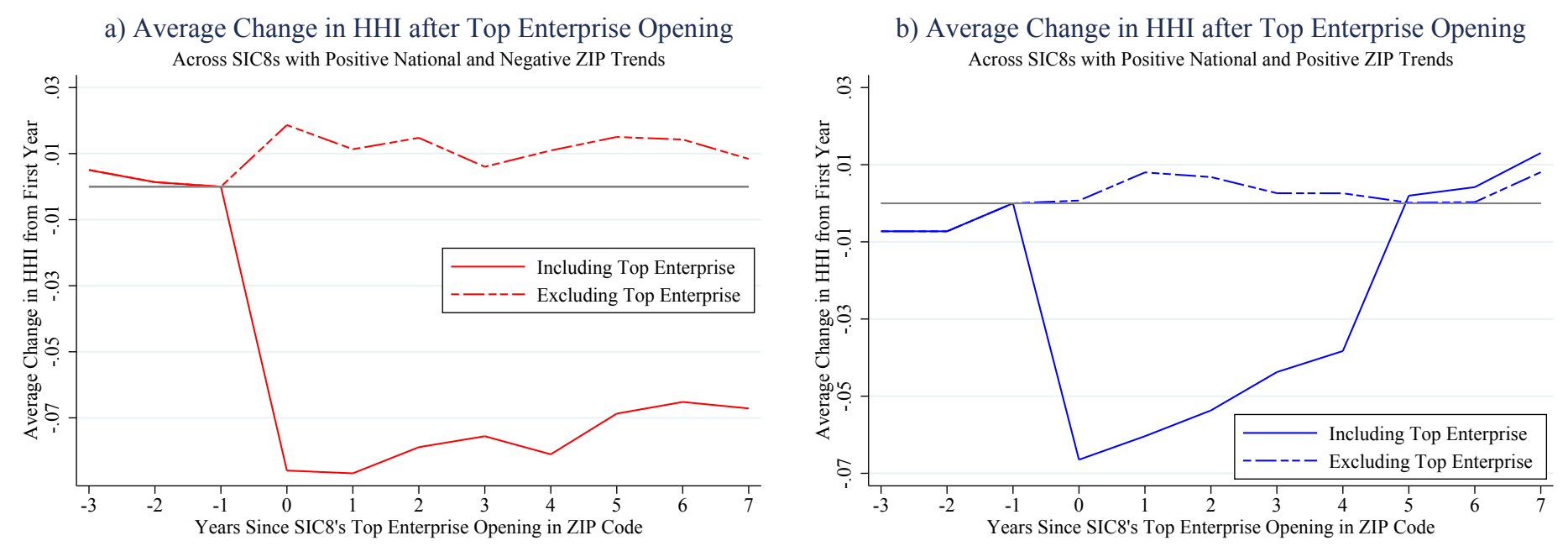

\section{B.3 Including Health Services}

All the figures in the main text exclude the health care sector, corresponding to SIC 280 (Health Services), because there is some evidence that institutional and policy changes specific to this sector, including the Affordable Care Act, have strongly affected concentration trends (Fulton (2017), for instance, finds an overall increase in concentration in hospital and health insurance markets between 2010 and 2016). In this section, we repeat Figures (1)-(4) in the main text including establishments whose primary SIC 2 code is $80{ }^{30}$ In Figure 29 , we can see that slightly over $40 \%$ of employment in this sector resides in industries with increasing national trends, most of which is contained in industries that also have decreasing local trends. Furthermore, Figure $(28 \mathrm{p})$ shows that including this sector, which is contained in the Services division, makes the national and local trends for this division very slightly more and less pronounced, respectively. The remaining figures illustrate that including this sector has almost no discernible

\footnotetext{
${ }^{30}$ We do not repeat Figure (5) because including this sector has no effect on Walmart's primary industry.
} 
Figure 27: Removing Enterprises with Fewer than 5 Employees: Effect on concentration when Walmart enters a local market
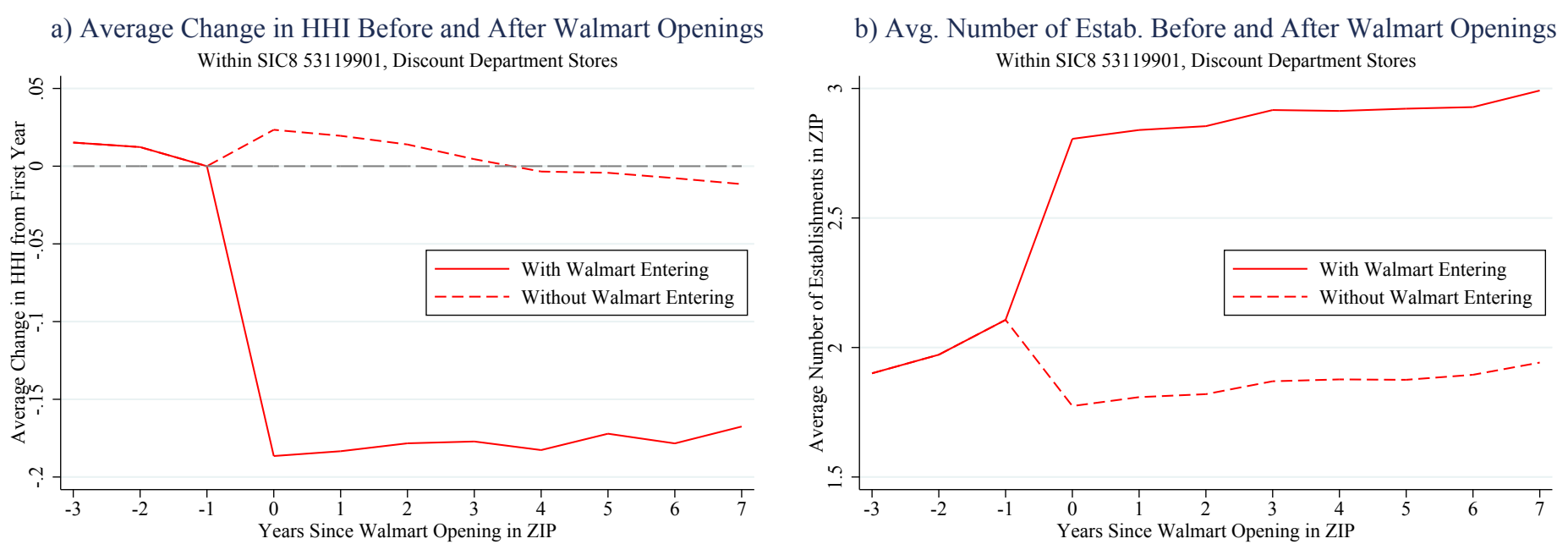

Figure 28: Including Health Services: Diverging national and local concentration trends

a) Average Change in HHI from First Year Across All Divisions

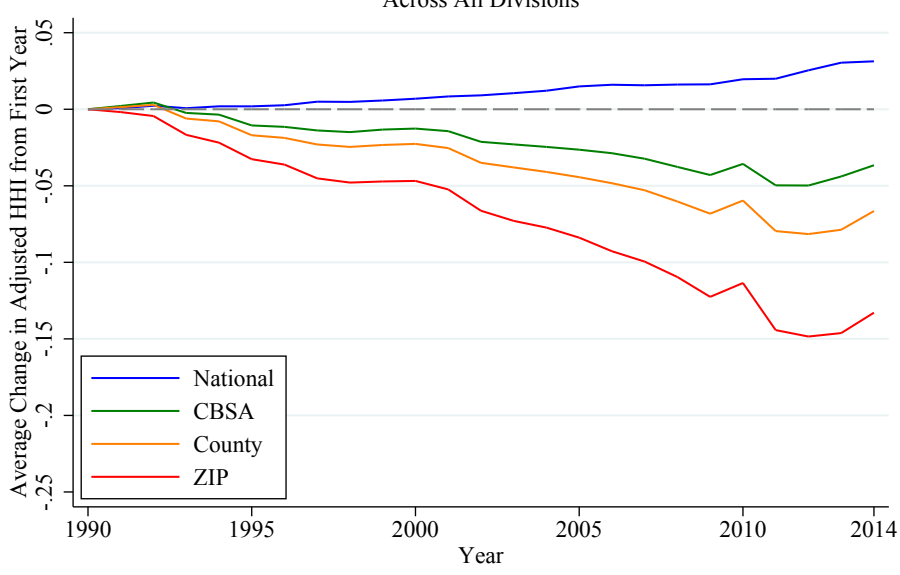

b) Average Change in HHI from First Year National and ZIP Levels, for Each Division

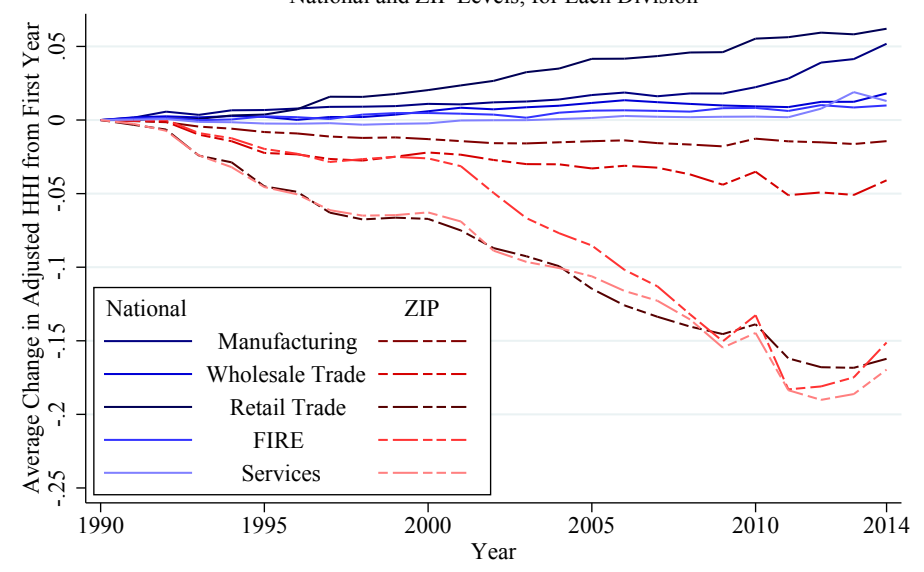

effect on the aggregate trends observed in the main text.

\section{B.4 Results for Other Geographic Measures}

As shown in Figure (1a) in the main text, while the decline in concentration is most pronounced at the ZIP code level, concentration is also declining over time at the county and Core-Based Statistical Area (CBSA) levels ${ }^{31}$ This section reproduces Figures (1b) and (2) for these two geographic levels. At the county level, it is still the case that concentration in all divisions is declining over time, while concentration is declining at the CBSA level in all divisions except Manufacturing, which has a roughly flat trend. Figure (33) indicates that industries with diverging trends are still prevalent in both cases, comprising approximately 29 and $23 \%$ of employment at the county and

\footnotetext{
${ }^{31}$ A CBSA is defined as either a Metropolitan or Micropolitan Statistical Area and is a collection of counties. Although CBSA boundaries can expand over time as new counties are added to them, for all years here we classify counties into CBSAs based on 2014 CBSA definitions. We also drop any observations not located in CBSAs.
} 
Figure 29: Including Health Services: Pervasive diverging trends across 2-digit sectors

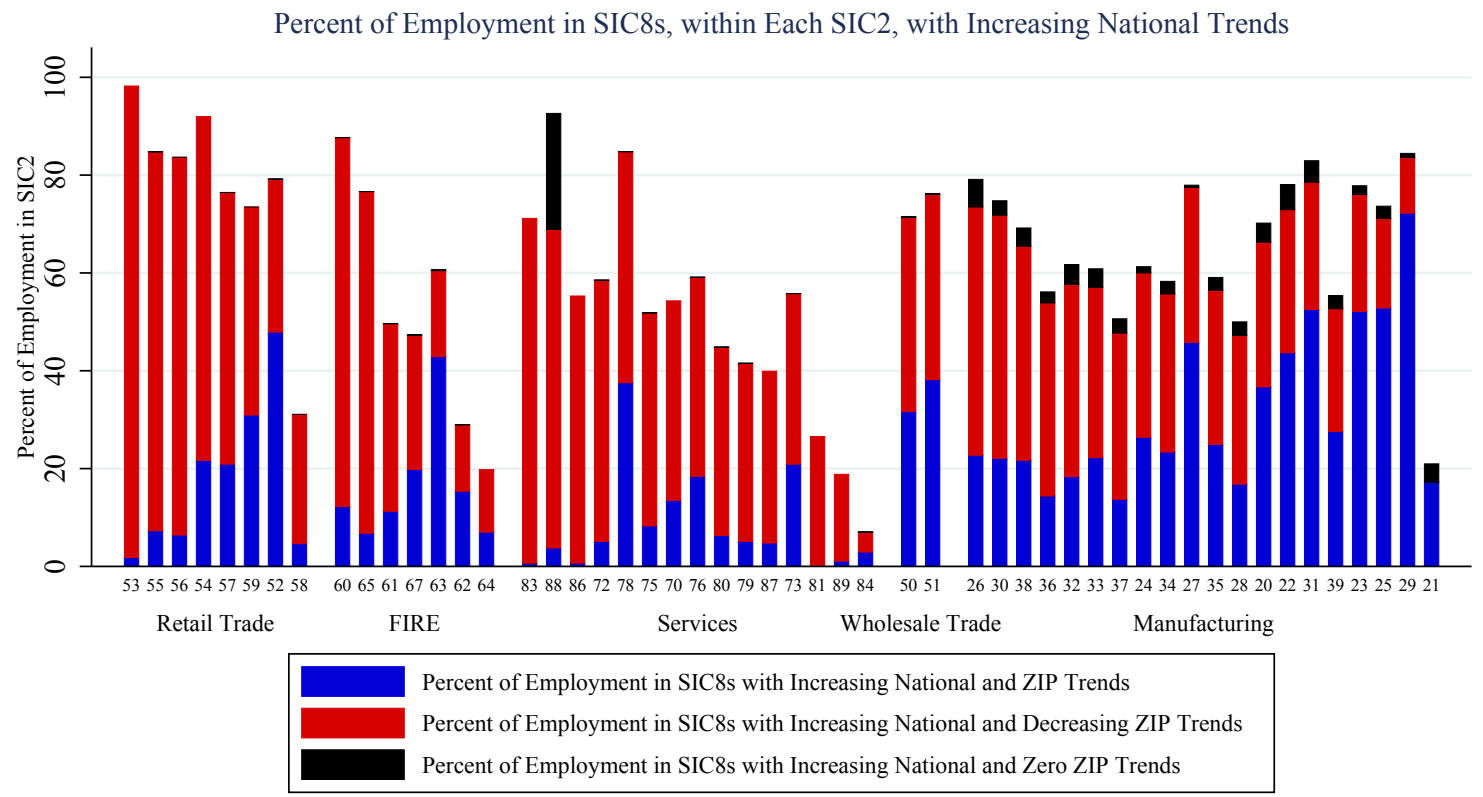

Figure 30: Including Health Services: The role of top firms in national and local concentration trends

a) Average Change in HHI from First Year Across SIC8s with Positive National and Negative ZIP Trends

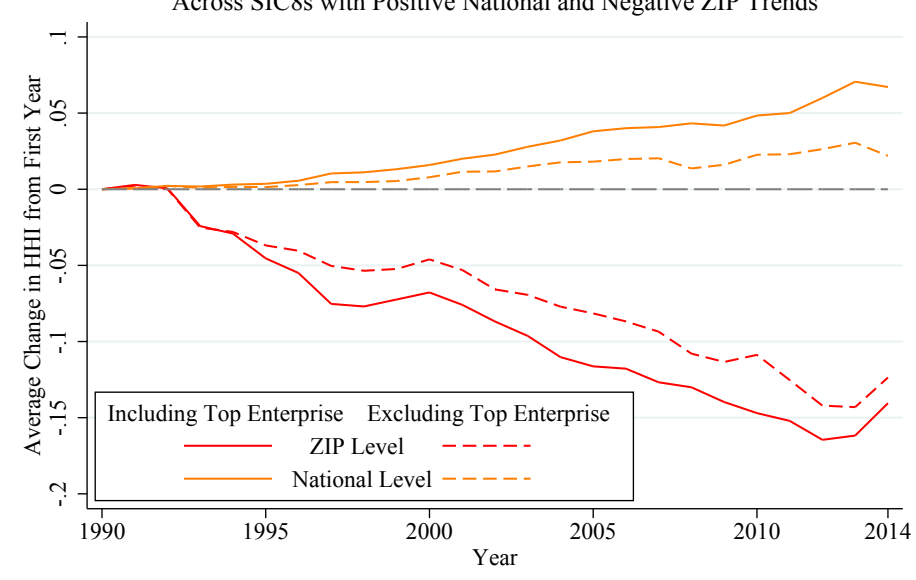

b) Average Change in HHI from First Year Across SIC8s with Positive National and Positive ZIP Trends

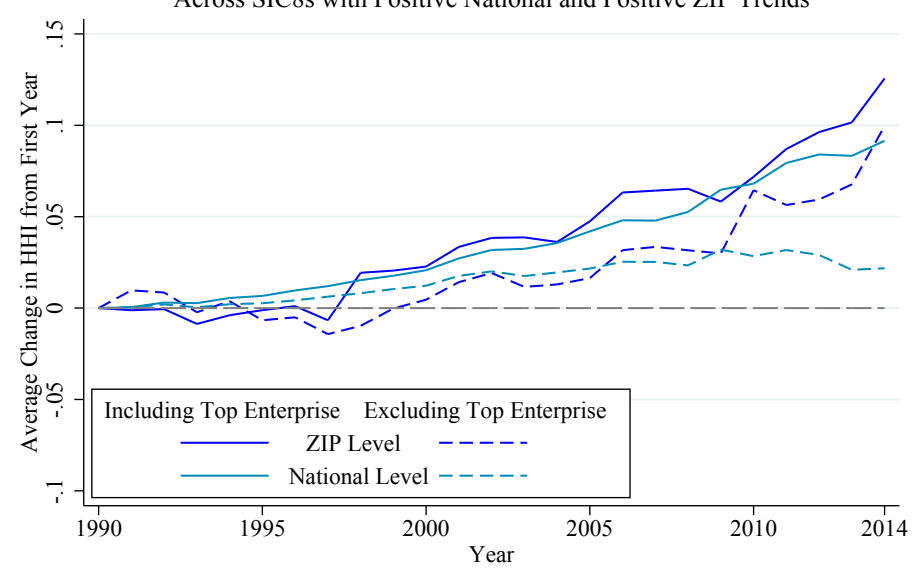

CBSA levels, respectively. Among industries that have increasing national trends, $48 \%$ of employment is located in industries that have declining employment at the county level and $38 \%$ at the CBSA level.

\section{B.5 Using Sales Instead of Employment Weights}

In the main text, we weight geography-industry-year groupings by their employment when taking averages of changes in concentration across groupings. The below figures show that weighting instead by sales of each grouping is relatively immaterial for our main findings ${ }^{32}$

\footnotetext{
${ }^{32}$ In this set of figures, the HHI and the change in the HHI is exactly the same for every geography-industry pair as in the main text, with concentration defined in terms of sales. Only the weights used when averaging across groupings change.
} 
Figure 31: Including Health Services: Effect on concentration when a top firm enters a local market
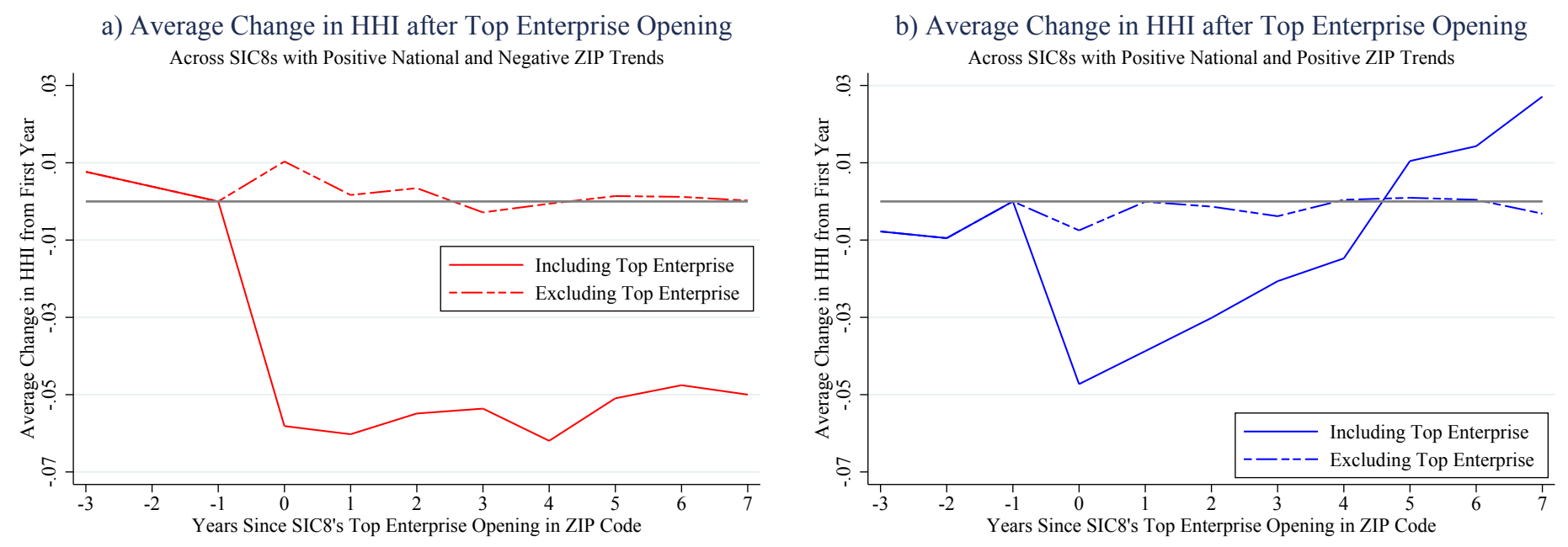

Figure 32: County and CBSA Levels: Diverging national and local concentration trends

(a) County Level

b) Average Change in HHI from First Year National and County Levels, for Each Division

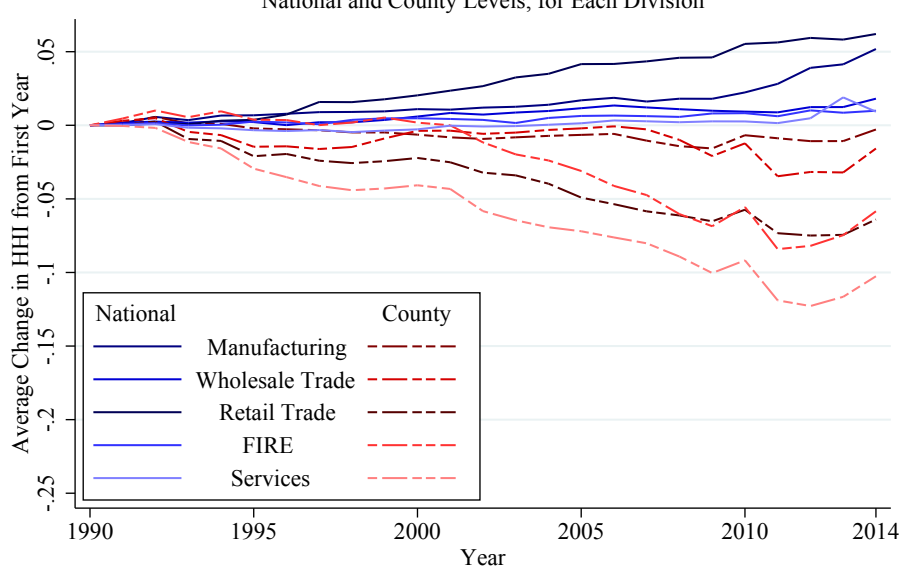

(b) CBSA Level

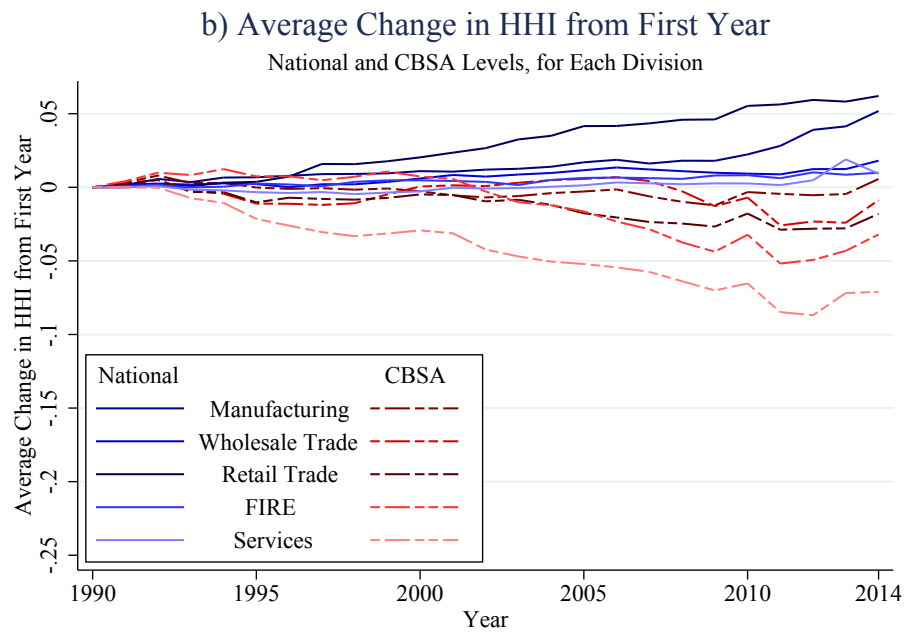

\section{B.6 Other Results}

The results in this section expand on the figures in the main text.

\section{B.6.1 Effect of Top Enterprises on Number of Establishments}

Figure (39) expands on Figure (5b) in the main text by looking at the number of number of establishments in industry-ZIP code pairs over time in response to the arrival of an industry's top enterprise into that ZIP code. The red line displays the weighted average number of establishments in the years before and after an opening of an industry's top enterprise across industries with diverging trends; the blue lines display the same number average across industries with positive trends at the national and local levels. When a top enterprise opens in an industry with positive local trends, there is on average no exit of existing establishments, while there is close to one-to-one 
Figure 33: County and CBSA Level: Pervasive diverging trends across 2-digit sectors

(a) County Level

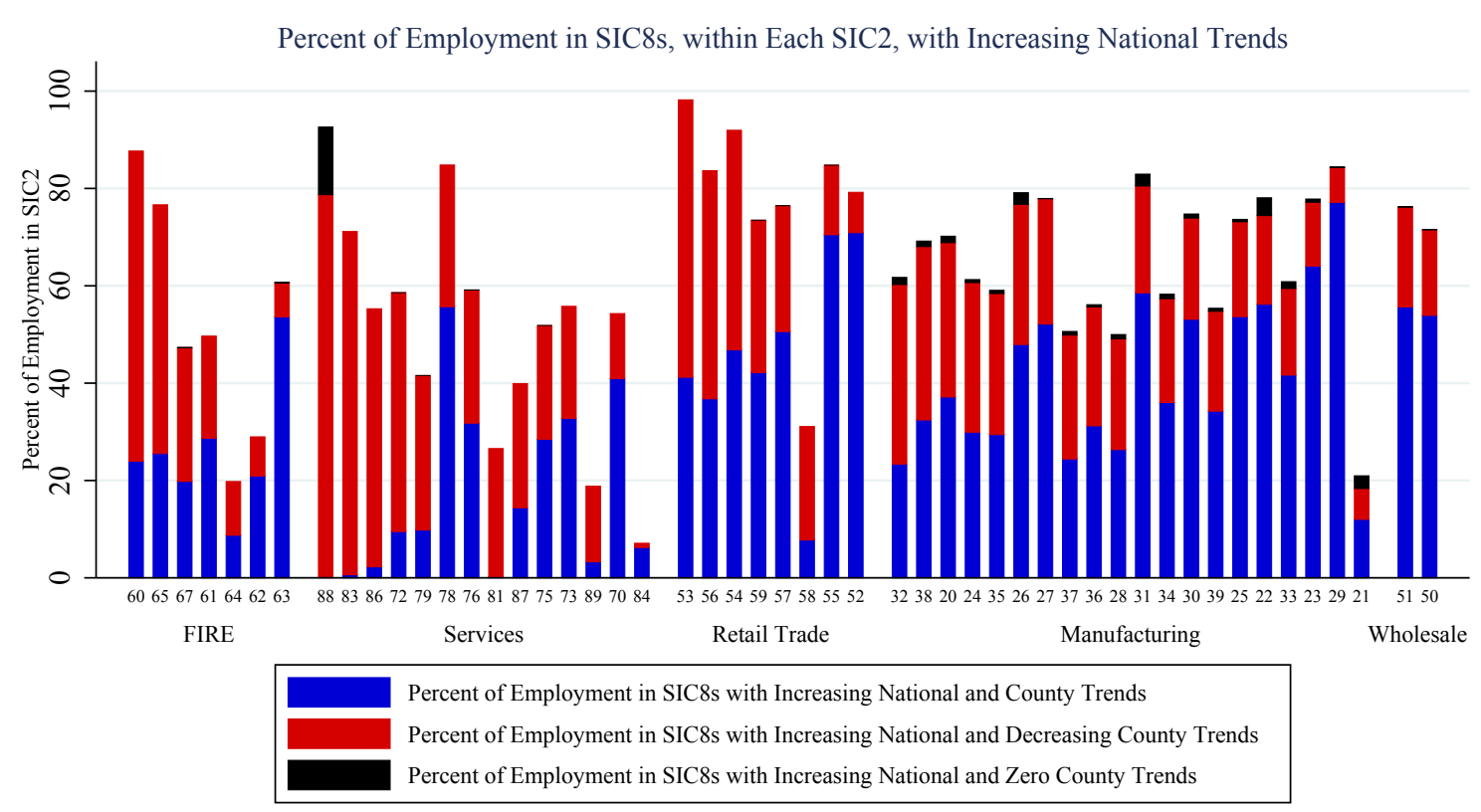

(b) CBSA Level

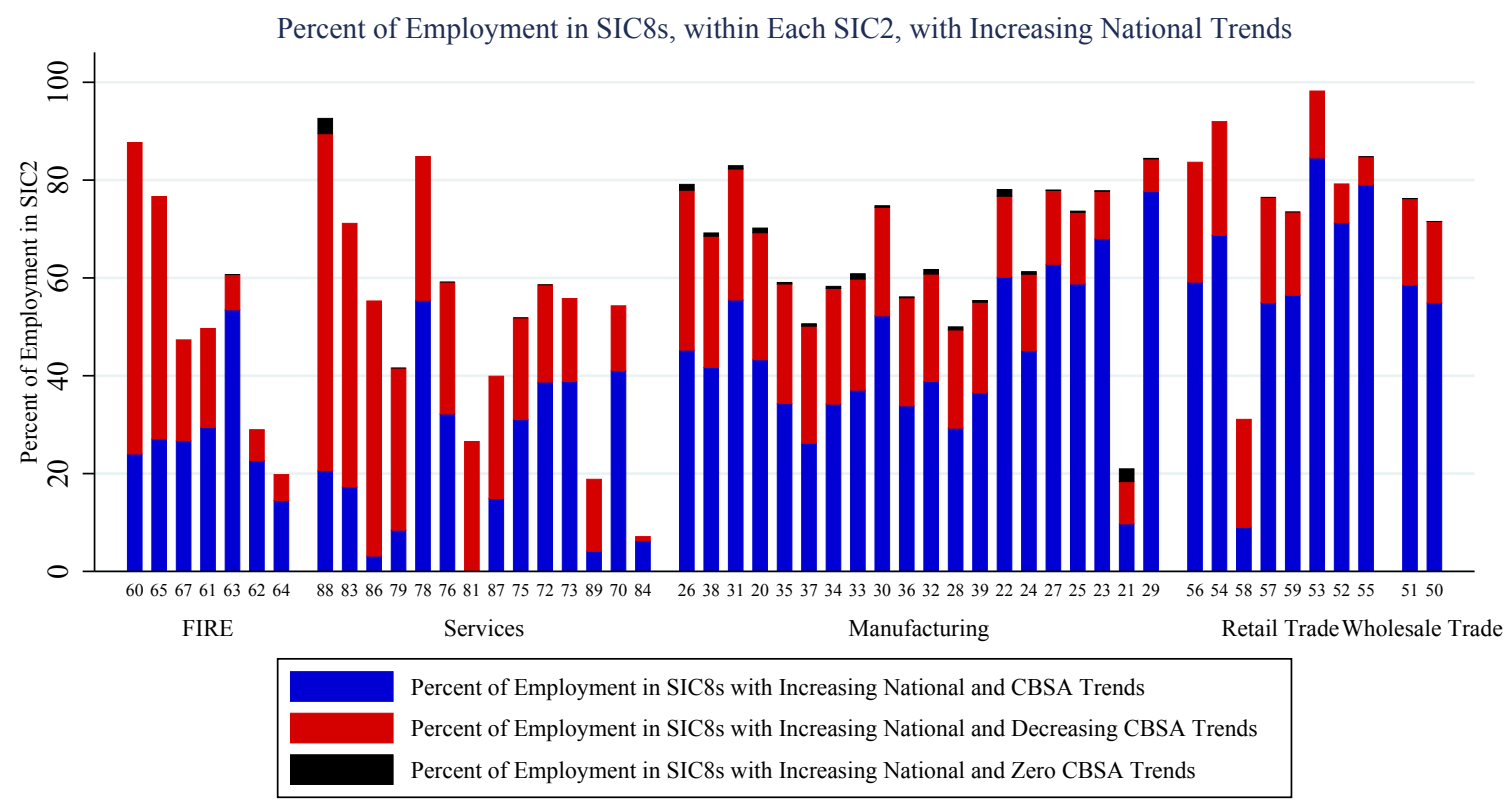

exit of existing establishments in industries with diverging trends. Over time, however, for both sets of industries the number of establishments both including and excluding establishments belonging to the top enterprise increases following an opening. Because these lines are weighted by employment in a geography-industry-year grouping, which is highly correlated with the number of establishments, the results of this figure should be interpreted with caution. 
Figure 34: Sales Weights: Diverging national and local concentration trends

a) Average Change in HHI from First Year

Across All Divisions

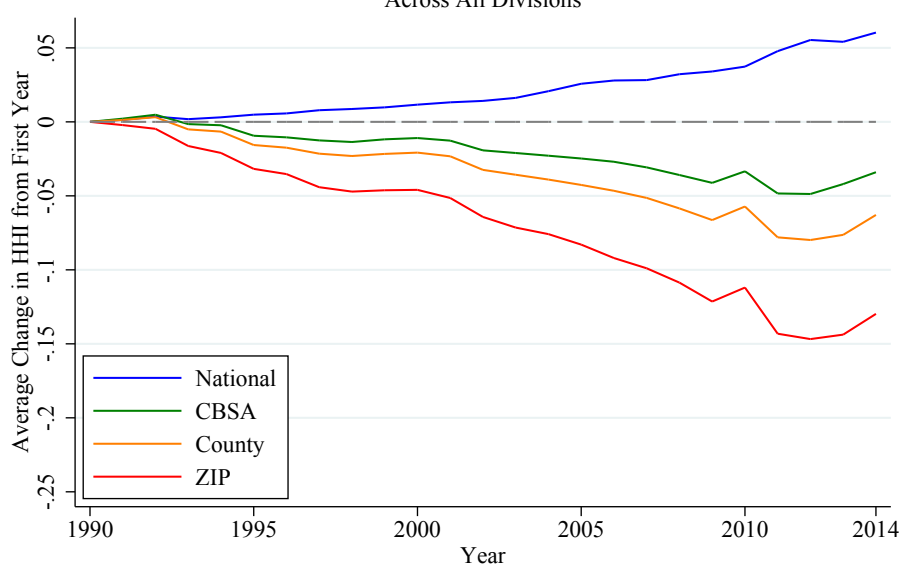

b) Average Change in HHI from First Year National and ZIP Levels, for Each Division

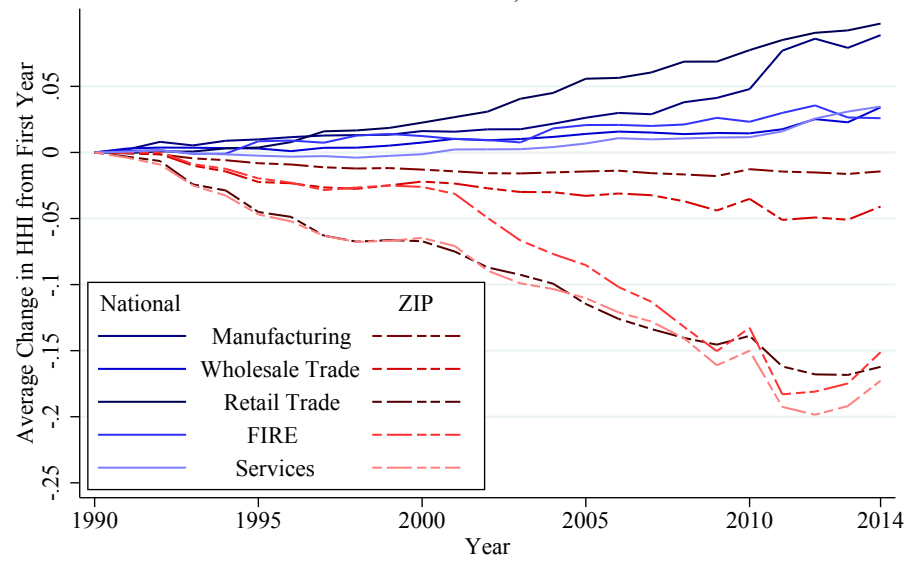

Figure 35: Sales Weights: Pervasive diverging trends across 2-digit sectors

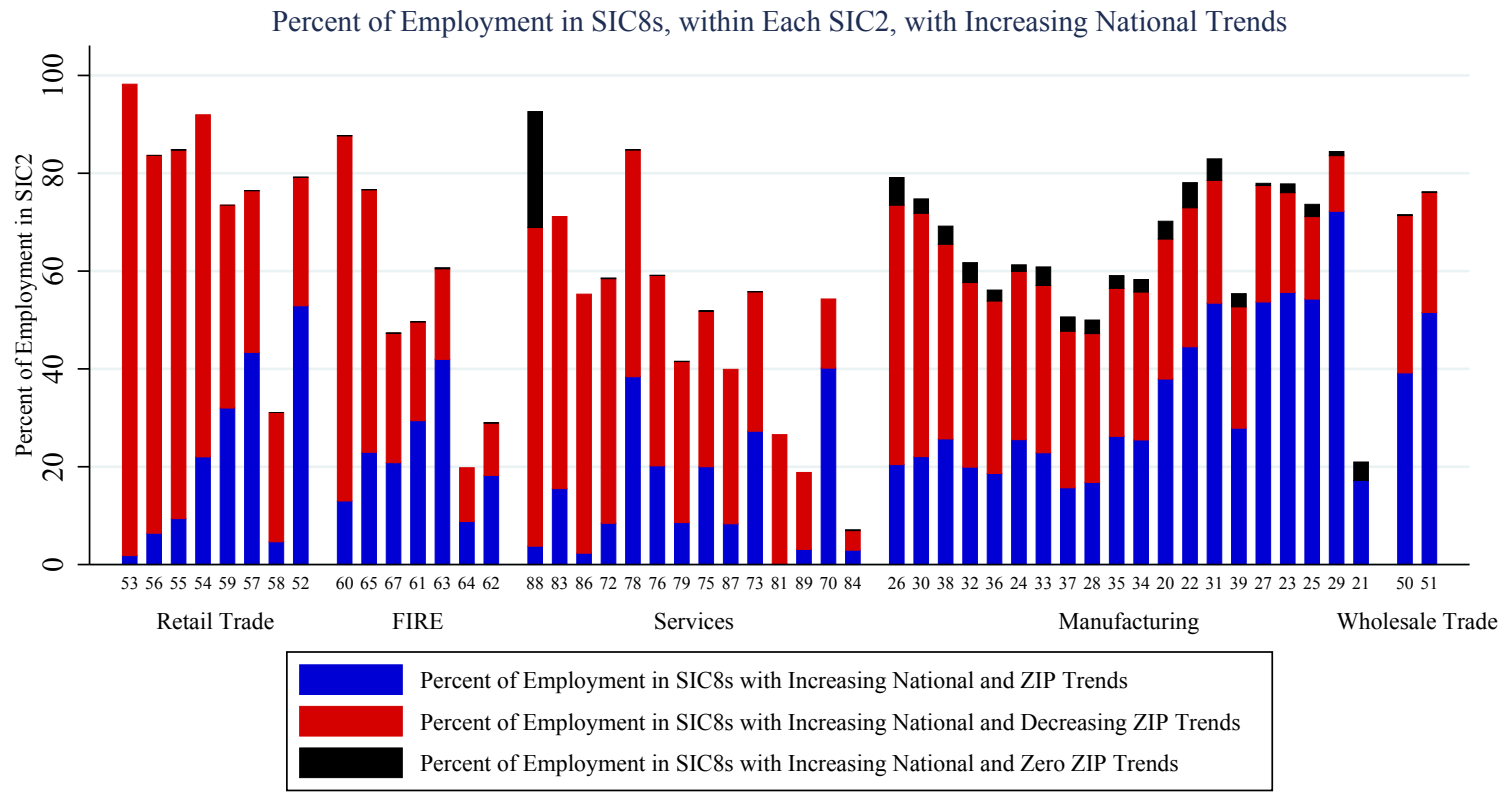

\section{B.6.2 Replicating Figure (3) with Top 3 Enterprises}

Here, we replicate Figure (3) in the main text using the top 3 enterprises (as measured by sales in 2014) in each industry as opposed to just the top enterprise. That is, we look at geography-industry pairs where at least one of these enterprises is present in at least one year. Within this subset of pairs, we drop geography-industry-year groupings where there are no enterprises in that group remaining after dropping the top three enterprises in that industry. We then calculate, for each grouping, the HHI both including and excluding the top 3 enterprises. Figure (40) shows that when averaged across SIC 8 industries with diverging trends, removing the top 3 enterprises makes the increase in the national trend much less pronounced, but increases concentration at the local level. In contrast, Figure (40p) shows that across industries with increasing trends at the national and local levels, excluding the top 
Figure 36: Sales Weights: The role of top firms in national and local concentration trends

a) Average Change in HHI from First Year Across SIC8s with Positive National and Negative ZIP Trends

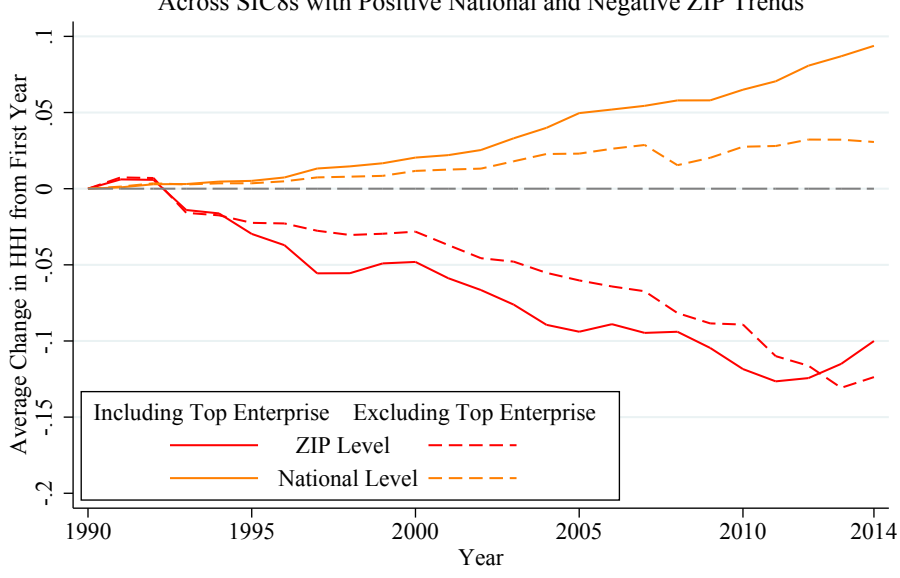

b) Average Change in HHI from First Year Across SIC8s with Positive National and Positive ZIP Trends

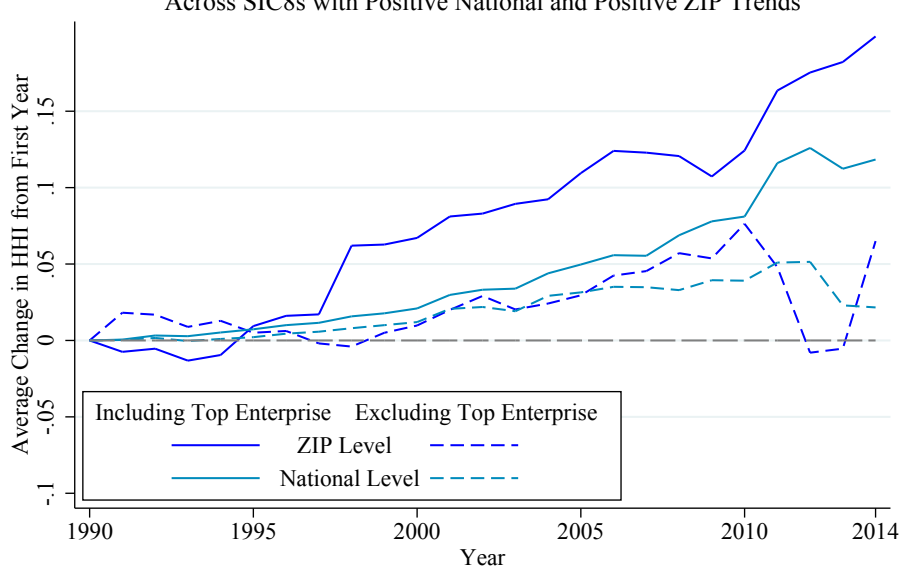

Figure 37: Sales Weights: Effect on concentration when a top firm enters a local market

a) Average Change in $\mathrm{HHI}$ after Top Enterprise Opening Across SIC8s with Positive National and Negative ZIP Trends

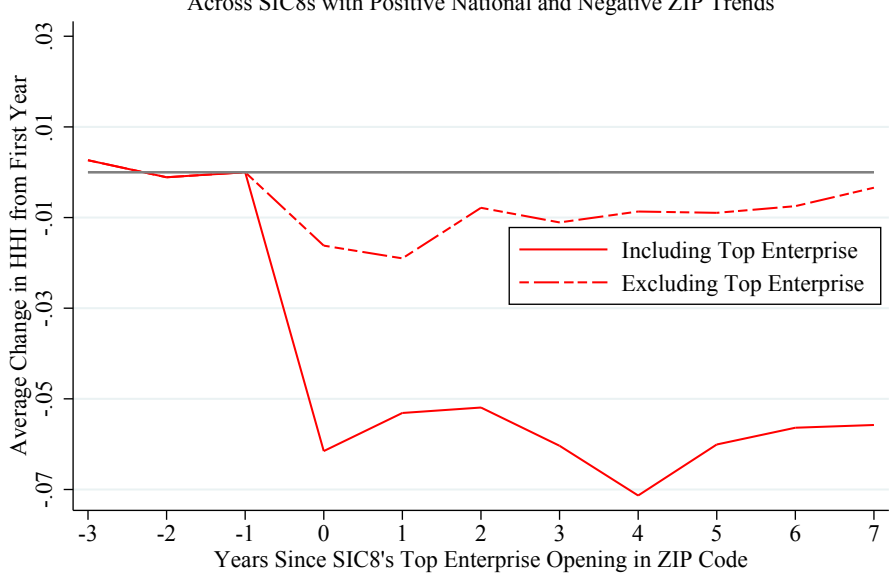

b) Average Change in HHI after Top Enterprise Opening Across SIC8s with Positive National and Positive ZIP Trends

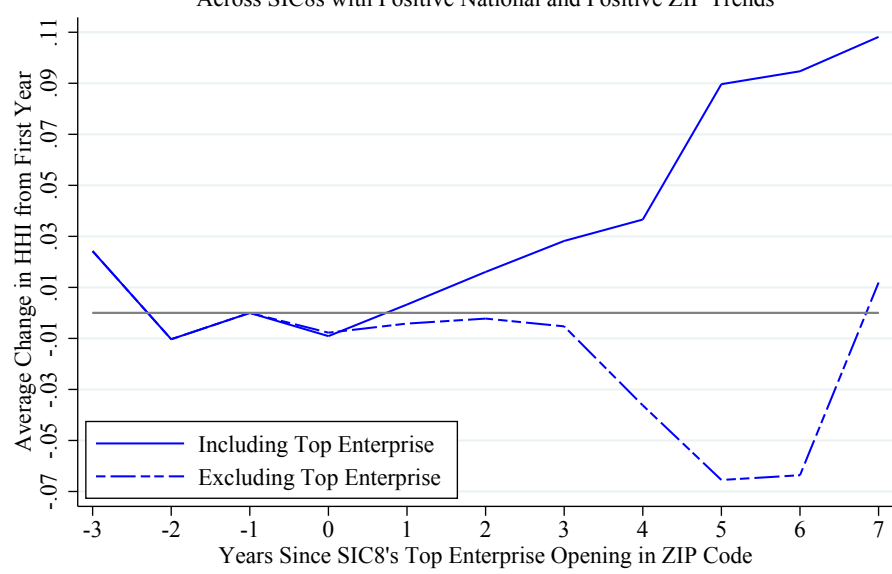

Figure 38: Sales Weights: Effect on concentration when Walmart enters a local market

a) Average Change in HHI Before and After Walmart Openings Within SIC8 53119901, Discount Department Stores

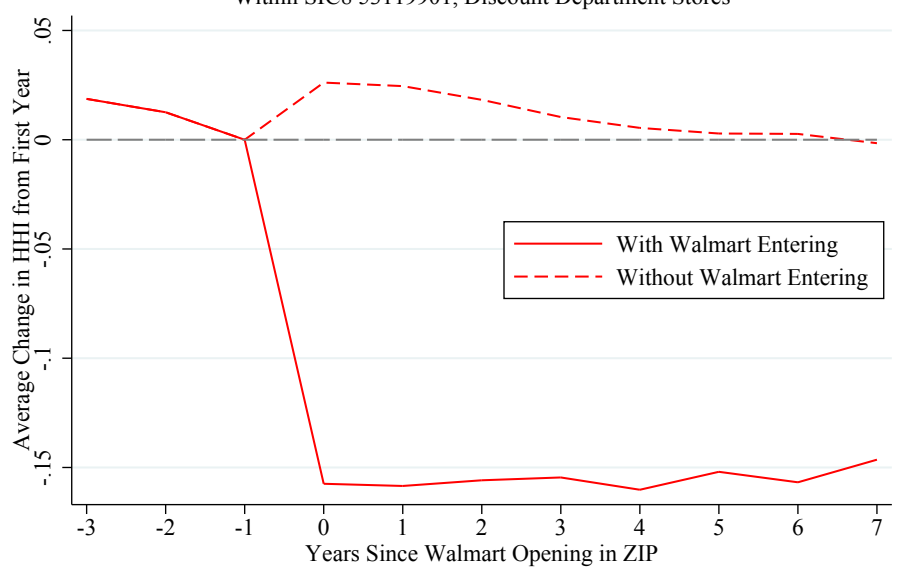

b) Avg. Number of Estab. Before and After Walmart Openings Within SIC8 53119901, Discount Department Stores

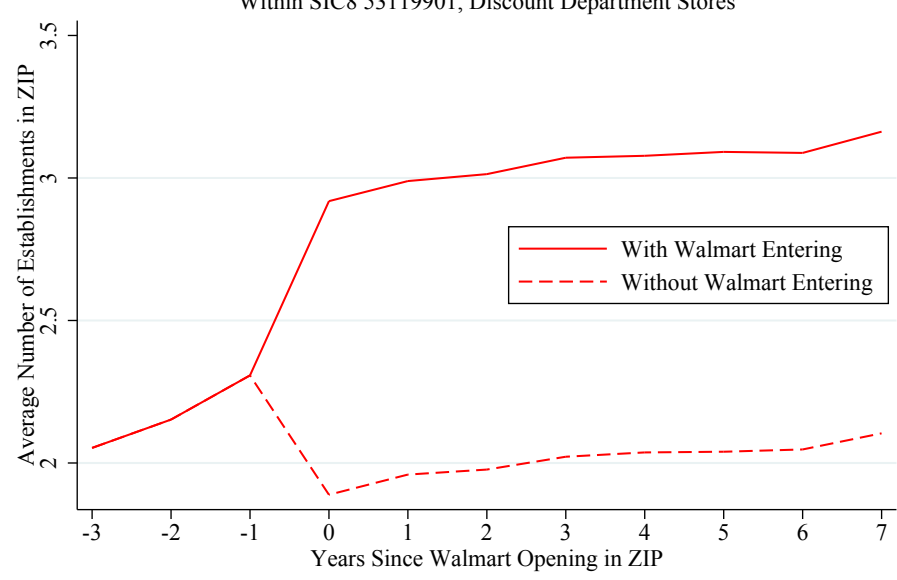


Figure 39: Number of Establishments When Top Enterprise Enters

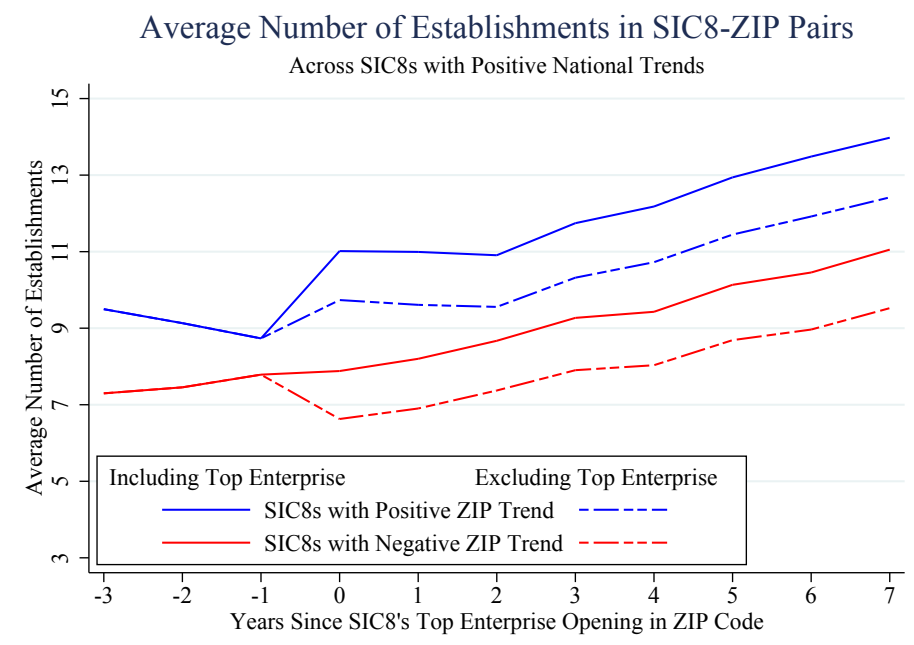

Figure 40: The role of the top 3 firms in national and local concentration trends
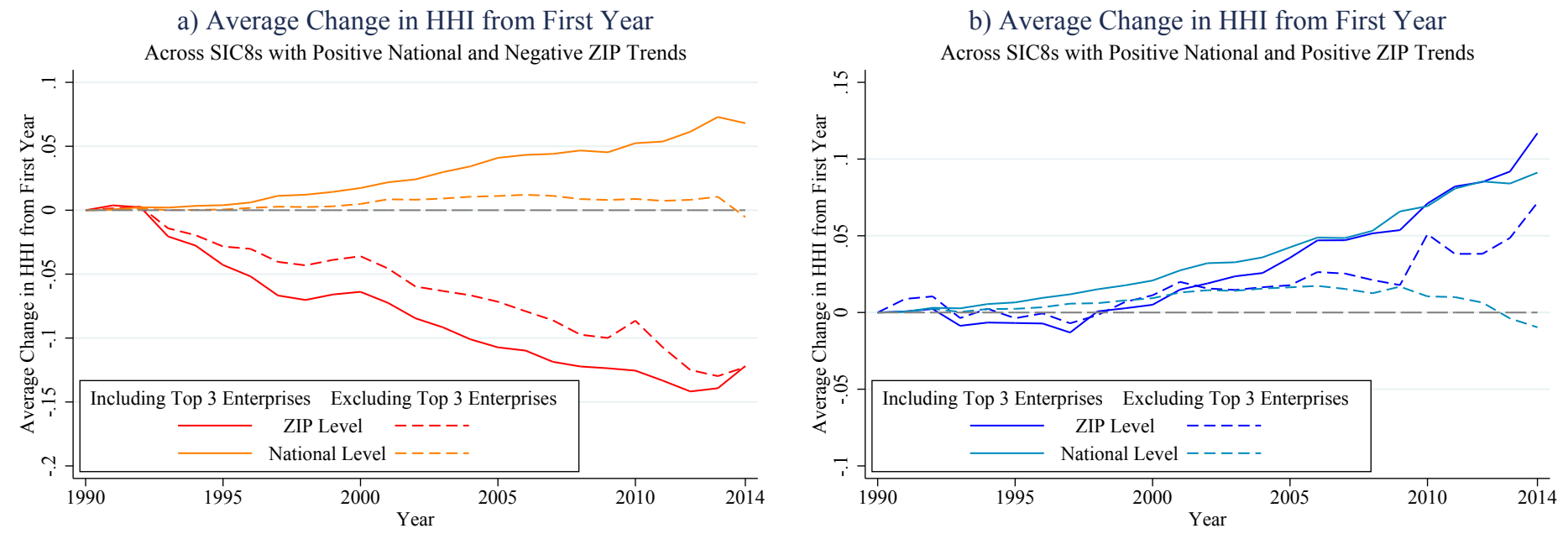

3 enterprises brings down concentration at both levels. These observations are consistent with Figure (3) in the main text.

\section{B.6.3 Effect on Concentration when Walmart Enters a County}

While most industries within the retail sector have local markets, in some instances a ZIP code may be too narrow a definition of a market. In the case of Walmart, for instance, it is likely that many Walmart stores draw shoppers from beyond the immediate ZIP code and instead serve entire counties. Along these lines, Figure (41) reproduces Figure (5) in the main text at the county level. That is, within SIC 8 53119901, we look only at counties where Walmart is present in at least one year, and only look at county-year pairs in which concentration can be measured after removing Walmart. We then calculate both the HHI and the number of establishments including and excluding Walmart in the years before and after a Walmart opening, and take a weighted average across counties for each year relative to Walmart openings. Figure (41) shows that county-level concentration within this industry declines after 
Figure 41: County Level: Effect on concentration when Walmart enters a local market

a) Average Change in HHI Before and After Walmart Openings Within SIC8 53119901, Discount Department Stores

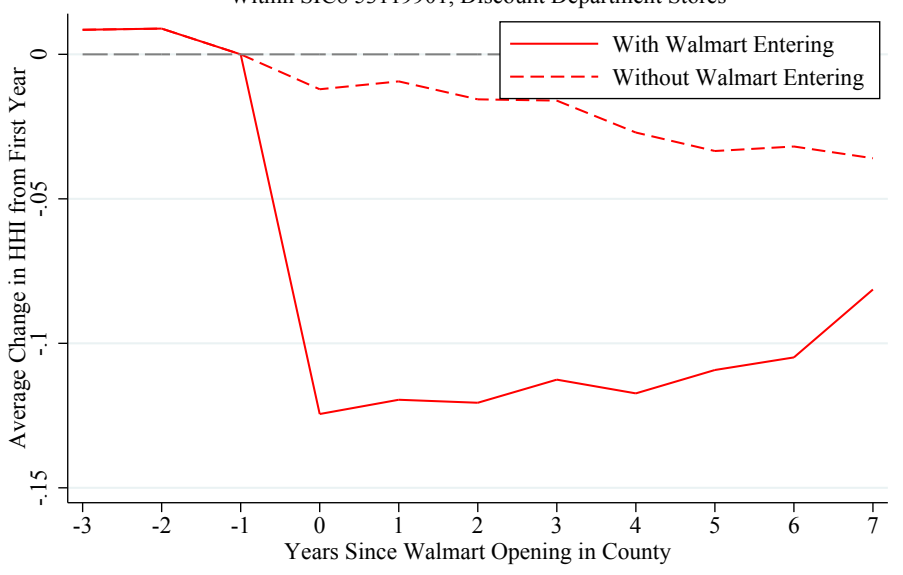

b) Avg. Number of Estab. Before and After Walmart Openings Within SIC8 53119901, Discount Department Stores

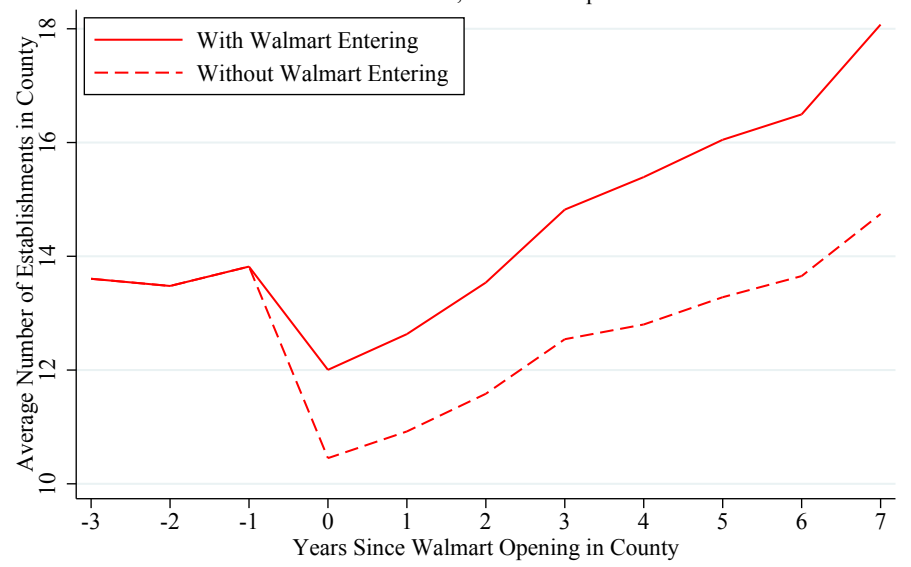

Walmart enters a county, and this effect still persists for at least 7 years. In Figure (41b), we see that the arrival of Walmart into a county is associated with with exit of about three non-Walmart establishments, on average. This result indicates substantially higher exit at the county than at the ZIP code level and is consistent with Jia (2008).

\section{B.6.4 When a Top Enterprise Comes to Town: An Example in Manufacturing}

Figure (2) in the main text indicates that a very high share of employment in Retail Trade resides in industries with diverging national and local trends, while this phenomenon is much less prevalent in Manufacturing and Wholesale Trade. However, the sector-level of aggregation presented in Figure (2) obscures considerable heterogeneity within industries in a given sector. It is still the case that many Manufacturing industries have diverging trends and see declining local concentration following the arrival of their top enterprise in a ZIP code. To use one example, Figure (42) highlights the SIC 8 code 32730000, Ready-Mixed Concrete, whose top enterprise by sales in 2014 is Cemex, a building materials company. Panel (42 ) shows that the arrival of Cemex into a ZIP code decreases its HHI by about 0.1. Although this effect dissipates after 7 years, the HHI measured excluding Cemex remains higher than it would be including them, so that this company is still bringing local concentration down. Panel (42b) shows that, as with the case of Walmart, there is some exit of existing establishments when Cemex opens a plant but the overall number of establishments in the ZIP-industry pair rises, on average. Although Syverson (2008) documents increasing national concentration within this industry, consistent with our findings, Syverson (2008) and Syverson (2004) argue that high transport costs make local measures of concentration, which we show exhibit a downward trend, more relevant. 
Figure 42: Effect on concentration when Cemex enters a local market

a) Average Change in HHI Before and After Cemex Openings

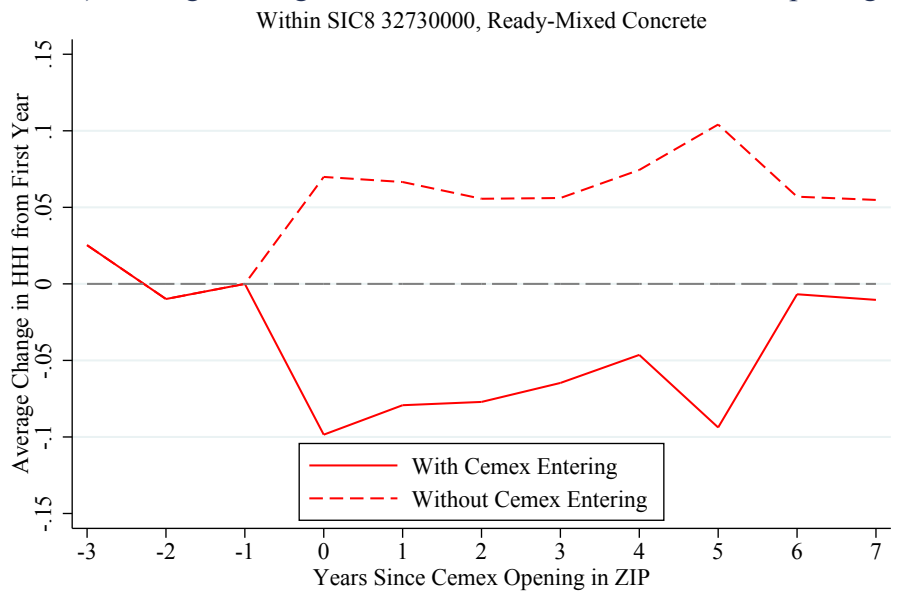

b) Avg. Number of Estab. Before and After Cemex Openings Within SIC8 32730000, Ready-Mixed Concrete

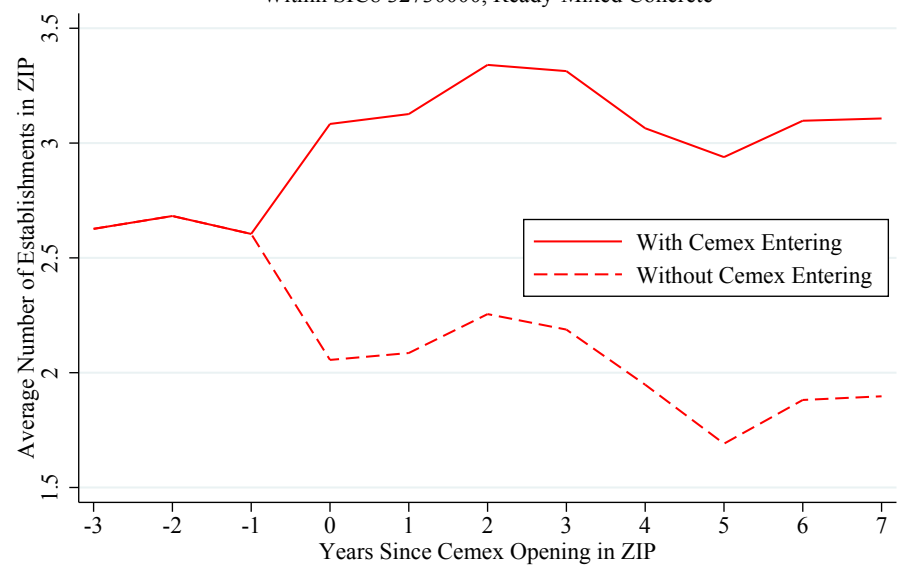

